\author{
PROGRAMA DE DOCTORADO EN \\ INVESTIGACIÓN EN CIENCIAS DE LA SALUD
}

TESIS DOCTORAL:

\title{
MODELO PREDICTIVO DE MORTALIDAD HOSPITALARIA EN ENDOCARDITIS INFECCIOSA IZQUIERDA. DESARROLLO DE UNA APLICACIÓN INFORMÁTICA
}

\section{Presentada por Pablo Elpidio García Granja}

para optar al grado de Doctor por la Universidad de Valladolid

\section{Dirigida por:}

\section{Dr. J. Alberto San Román Calvar}

Jefe de Servicio de Cardiología del Hospital Clínico Universitario de Valladolid

Profesor asociado de Cardiología de la Universidad de Valladolid.

\section{Dr. Javier López Díaz}

Jefe de Sección de docencia e investigación del Servicio de Cardiología del Hospital Clínico Universitario de Valladolid

Profesor asociado de Cardiología de la Universidad de Valladolid. 
Universidad deValladolid

\section{NOTA DEL EQUIPO DE INVESTIGACIÓN}

El presente trabajo forma parte de una línea de investigación sobre Endocarditis Infecciosa realizada por el grupo multicéntrico ENDOVAL que incluye al Servicio de Cardiología del Hospital Clínico Universitario de Valladolid, al Servicio de Cardiología del Hospital Clínico San Carlos de Madrid y al Servicio de Medicina Interna - Unidad de Enfermedades Infecciosas del Hospital Universitario La Princesa de Madrid.

Los miembros del equipo de investigación han verificado toda la información presente en este documento y aseguran que es veraz, singular y que se encuentra libre de plagios.

\section{Conflictos de interés:}

No existen conflictos de interés respecto a la información presentada en la tesis doctoral.

\section{Fuentes de financiación:}

Esta tesis ha recibido una beca de colaboración de la Gerencia Regional de Salud de la Junta de Castilla y León durante el año 2018. GRS 1523/A/17 "Desarrollo de una aplicación para el cálculo de la mortalidad hospitalaria en pacientes con endocarditis infecciosa izquierda”. Cuantía: 8.124 euros. Investigador principal: José Alberto San Román Calvar. 
"No greater opportunity, responsibility, or obligation can fall to the lot of a human being than to become a physician. In the care of the suffering he needs technical skill, scientific knowledge, and human understanding. He who uses these with courage, with humility, and with wisdom will provide a unique service for his fellow man, and will build an enduring edifice of character within himself. The physician should ask of his destiny no more than this; he should be content with no less."

Tinsley R. Harrison 
ÍNDICE 
1. RESUMEN 11-17

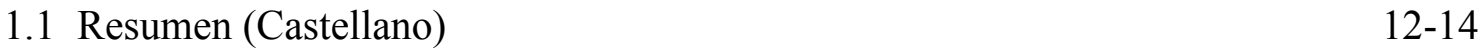

$\begin{array}{lr}1.2 \text { Abstract (inglés) } & 15-17\end{array}$

2. INTRODUCCIÓN 18-50

$\begin{array}{lr}2.1 \text { Introducción } & 19-20\end{array}$

2.2 Pronóstico de la endocarditis infecciosa izquierda 21-47

2.3 Impacto de la cirugía cardiaca en la evolución de la endocarditis 48-50 infecciosa izquierda

3. HIPÓTESIS 51-52

3.1 Justificación del trabajo $\quad 52$

3.2 Hipótesis $\quad 52$

4. OBJETIVOS 53-54

4.1 Objetivos principales $\quad 54$

4.2 Objetivos secundarios $\quad 54$

5. MATERIAL Y MÉTODOS 55-66

5.1 Ámbito del estudio 56

5.2 Poblaciones del estudio 56

5.3 Diseño del estudio 57

5.4 Variables analizadas $\quad 58-60$

5.5 Definición de variables 61-64

5.6 Análisis estadístico 64-65

5.7 Diseño de la aplicación informática 66

6. RESULTADOS 67-97

6.1 Características principales de la población de endocarditis infecciosa $\quad$ 68-69 izquierda del grupo ENDOVAL

6.2 Características principales de la población de endocarditis infecciosa $\quad 70-75$ izquierda del Hospital Universitario Puerta de Hierro 
6.3 Aleatorización y análisis comparativo de las muestras de ajuste y derivación del modelo pronóstico

6.4 Derivación del modelo pronóstico de mortalidad hospitalaria en endocarditis infecciosa izquierda

6.5 Validación del modelo pronóstico de mortalidad hospitalaria en endocarditis infecciosa izquierda

6.6 Desarrollo de la aplicación informática

6.7 Valoración del impacto pronóstico de la cirugía cardiaca en la mortalidad hospitalaria de la endocarditis infecciosa izquierda

\section{DISCUSIÓN}

7.1 Principales hallazgos del trabajo

7.2 Comparación de los resultados con la literatura

7.3 Implicaciones prácticas del trabajo

7.4 Líneas futuras de investigación

9.1 Anexo I. Criterios diagnósticos de endocarditis infecciosa

9.2 Anexo II. Criterios de Duke para el diagnóstico de endocarditis infecciosa

9.3 Anexo III. Criterios de Duke modificados para el diagnóstico de endocarditis infecciosa

9.4 Anexo IV. Definición de las variables del grupo ENDOVAL

9.5 Anexo V. Tabla descriptiva de la población de endocarditis infecciosa izquierda del grupo ENDOVAL 


\section{ÍNDICE DE TABLAS}

Tabla 1. Factores pronósticos en endocarditis infecciosa propuestos por la guía europea de manejo de la enfermedad.

Tabla 2. Indicaciones de cirugía cardiaca en endocarditis infecciosa según la guía europea.

Tabla 3. Definición de cada factor pronóstico utilizado en el modelo de predicción de muerte hospitalaria en endocarditis infecciosa izquierda.

Tabla 4. Análisis comparativo de los datos epidemiológicos entre las poblaciones de endocarditis infecciosa izquierda del grupo ENDOVAL y del Hospital Universitario Puerta de Hierro.

Tabla 5. Análisis comparativo de la evolución clínica entre las poblaciones de endocarditis infecciosa izquierda del grupo ENDOVAL y del Hospital Universitario Puerta de Hierro.

Tabla 6. Análisis comparativo de la microbiología entre las poblaciones de endocarditis infecciosa izquierda del grupo ENDOVAL y del Hospital Universitario Puerta de Hierro.

Tabla 7. Análisis comparativo de los hallazgos de las pruebas de imagen entre las 74 poblaciones de endocarditis infecciosa izquierda del grupo ENDOVAL y del Hospital Universitario Puerta de Hierro.

Tabla 8. Análisis comparativo del tratamiento entre las poblaciones de endocarditis infecciosa izquierda del grupo ENDOVAL y del Hospital Universitario Puerta de Hierro.

Tabla 9. Análisis comparativo de los datos epidemiológicos entre la muestra de ajuste y la muestra de validación interna. 
Tabla 10. Análisis comparativo de la evolución clínica entre la muestra de ajuste y la muestra de validación interna.

Tabla 11. Análisis comparativo de la microbiología entre la muestra de ajuste y la muestra de validación interna.

Tabla 12. Análisis comparativo de los hallazgos en pruebas de imagen entre la 80 muestra de ajuste y la muestra de validación interna.

Tabla 13. Análisis comparativo del tratamiento entre la muestra de ajuste y la muestra de validación interna.

Tabla 14. Análisis comparativo de las variables pronósticas propuestas por la guía europea entre la muestra de ajuste y la muestra de validación interna.

Tabla 15. Asociación de las variables pronósticas propuestas por la guía europea de 84 manejo de la endocarditis infecciosa con la mortalidad hospitalaria.

Tabla 16. Análisis multivariado de mortalidad hospitalaria en endocarditis infecciosa izquierda utilizando las variables pronósticas propuestas por la guía Europea de manejo de la Endocarditis Infecciosa.

Tabla 17. Tabla de contingencia para la prueba de Hosmer y Lemeshow.

Tabla 18. Asociación de la cirugía cardiaca y su momento de realización con la mortalidad hospitalaria de la endocarditis infecciosa izquierda

Tabla 19. Análisis multivariado de mortalidad hospitalaria en endocarditis 96 infecciosa izquierda incluyendo la variable cirugía cardiaca. 


\section{ÍNDICE DE FIGURAS}

Figura 1. Distribución por decádas de edad en la endocarditis infecciosa izquierda de la serie del grupo ENDOVAL.

Figura 2. Tipo de microorganismo según el cuartil de edad de los pacientes con endocarditis infecciosa.

Figura 3. Complicación perianular visualizada en TC cardiaco.

Figura 4. Estratificación pronóstica de acuerdo al acúmulo de factores pronósticos en endocarditis infecciosa izquierda.

Figura 5. Infartos embólicos en TC craneal.

Figura 6. Relación eco-histológica en endocarditis por Candida albicans.

Figura 7. Captación perivalvular homogénea de 18 fluorodesoxiglucosa $\left({ }^{18} \mathrm{~F}\right.$ FDG) en un paciente con infección del tubo valvulado aórtico.

Figura 8. Vegetación endocárdica sobre válvula mitral nativa.

Figura 9. Diseño del estudio.

Figura 10. Mortalidad de cada subpoblación de endocarditis infecciosa atendiendo a las variables pronósticas de la guía europea de endocarditis infecciosa.

Figura 11. Curva ROC del modelo pronóstico en la muestra de ajuste.

Figura 12. Validación interna del modelo de predicción pronóstica.

Figura 13. Validación externa del modelo de predicción pronóstica.

Figura 14. Diseño de la aplicación móvil. 
Figura 15. Presentación de la predicción en la aplicación.

Figura 16. Mortalidad de la endocarditis infecciosa atendiendo a la cirugía cardiaca y su momento de realización.

Figura 17. Curva ROC en la muestra de ajuste del modelo de predicción de mortalidad hospitalaria en endocarditis infecciosa izquierda utilizando las variables pronósticas de la guía europea y la cirugía cardiaca.

Figura 18. Curva de predicción de mortalidad hospitalaria en endocarditis infecciosa izquierda según el modelo que incluye cirugía cardiaca. 
1. RESUMEN 


\subsection{RESUMEN}

\section{INTODUCCIÓN}

La endocarditis infecciosa es una enfermedad compleja con una alta mortalidad hospitalaria. La valoración pronóstica es esencial para tomar una actitud terapéutica adecuada. La guía de la Sociedad Europea de Cardiología sobre endocarditis infecciosa propone unos factores pronósticos basados en las características del paciente, las complicaciones clínicas de la enfermedad, el microorganismo causal y los hallazgos en las pruebas de imagen. Estos factores deben ayudar en la evaluación integral y multidisciplinar de los pacientes, y permitir la identificación precoz de aquellos con alto riesgo. Sin embargo, la guía europea no aporta una evaluación objetiva de los mismos ni recomendaciones específicas según los factores presentes en cada caso.

Por otro lado, la cirugía cardiaca se presenta como la intervención terapéutica capaz de modificar el curso clínico de la enfermedad. Se precisa en aproximadamente el $50 \%$ de los casos de endocarditis infecciosa, y aunque parece ser un factor protector de mortalidad hospitalaria existen muchas lagunas sobre su indicación, el momento óptimo para realizarla y las expectativa que debe generar.

\section{OBJETIVO}

Desarrollar un modelo predictivo de mortalidad hospitalaria en endocarditis infecciosa izquierda con las variables pronósticas propuestas por la guía europea.

\section{MATERIAL Y MÉTODOS}

Estudio de cohortes prospectivo que utiliza 2 poblaciones de endocarditis infecciosa izquierda: población del grupo ENDOVAL $(\mathrm{n}=1002)$ y población del Hospital Universitario Puerta de Hierro ( $n=133)$. La población del grupo ENDOVAL se aleatoriza en una proporción 2:1 para obtener dos muestras: una muestra de ajuste $(n=688)$, y una muestra de validación $(\mathrm{n}=314)$. Se realiza un análisis descriptivo y comparativo de las poblaciones de endocarditis infecciosa izquierda. La muestra de ajuste se utiliza para construir un modelo de predicción de muerte hospitalaria por medio de una regresión logística incluyendo los odds ratio ajustados para cada variable propuestas por la guía 
europea de manejo de la endocarditis infecciosa. La muestra de validación y la población del Hospital Puerta de Hierro se utilizan para la validación interna y externa de los resultados. El modelo predictivo se presenta en formato aplicación móvil.

Además, para valorar el impacto de la cirugía cardiaca en la mortalidad hospitalaria de la endocarditis infecciosa izquierda repetimos el análisis multivariado de mortalidad con las variables pronósticas propuestas por la guía europea incluyendo la variable cirugía cardiaca y su momento de realización.

\section{RESULTADOS}

El análisis multivariado de mortalidad hospitalaria en endocarditis infecciosa izquierda realizado sobre la muestra de ajuste muestra la asociación de cada variable pronóstica propuesta por la guía de manejo de la endocarditis infecciosa de la Sociedad Europea de Cardiología con la mortalidad hospitalaria. Las variables que muestran una asociación independiente con la mortalidad hospitalaria son la edad (OR 1.033, IC 95\% 1.016 - 1.051), la endocarditis protésica (OR 1.841, IC 95\% 1.187 - 2.856), la comorbilidad (OR 1.652, IC 95\% 1.039 - 2.626), la insuficiencia cardiaca (OR 3.292, IC $95 \% 2.063$ - 5.255), la insuficiencia renal (OR 2.173, IC 95\% 1.407 - 3.357), el shock séptico (OR 5.367, IC 95\% 3.063 - 9.405), el Estafilococo aureus (OR 3.653, IC 95\% 2.193 - 6.084), los hongos (OR 7.532, IC 95\% 1.665 - 34.082), las complicaciones perianulares (OR 2.046, IC 95\% 1.307 - 3.203), la disfunción ventricular (OR 2.179, IC $95 \% 1.094-4.338$ ) y las vegetaciones (OR 2.449, IC 95\% 1.221 - 4.914).

En el modelo predictivo se incluyen todas las variables independientemente de su p-valor, utilizando el odds ratio y la constante derivada para construir la fórmula de predicción de mortalidad hospitalaria. El modelo presenta buena capacidad discriminativa con un área bajo la curva ROC de 0.859 (Intervalo de confianza al 95\%: 0.830 - 0.889), y un p-valor en el Test de Hosmer-Lemeshow de 0.350, que se ratifica en los análisis de validación interna (área bajo la curva ROC 0.834, intervalo de confianza al 95\% 0.786 - 0.881) y externa (área bajo la curva ROC 0.759, IC 95\% 0.665-0.853). Para la muestra de validación interna (mortalidad observada 29.9\%) el modelo predice una mortalidad hospitalaria de 30.8\% (IC 95\% 27.8 - 33.9\%), y para la población del 
Hospital Puerta de Hierro (mortalidad observada 27.1\%) predice una mortalidad de 25.4\% (IC 95\% 21.2-29.5\%)

La cirugía cardiaca muestra una asociación significativa con la mortalidad hospitalaria $(\mathrm{p}=0.025)$. La inclusión de la variable en el modelo predictivo mantiene la capacidad predictiva del mismo (área bajo la curva ROC 0.861, IC 95\% 0.830 - 0.891). La cirugía es un factor protector de mortalidad que muestra su mayor beneficio en pacientes de riesgo intermedio con una reducción del riesgo de muerte de $10.7 \% \pm 0.3 \%$. La reducción del riesgo de muerte es menor en pacientes de bajo riesgo (mortalidad estimada $0-20 \%$, reducción media del riesgo de muerte de $3.2 \pm 1.6 \%$ ) y de muy alto riesgo (mortalidad estimada mayor al 80\%, reducción media del riesgo de $4.6 \pm 2.1 \%$ ).

\section{CONCLUSIONES}

Las variables pronósticas propuestas por la guía de manejo de la endocarditis infecciosa de la Sociedad Europea de Cardiología conforman un modelo predictivo de mortalidad hospitalaria en endocarditis infecciosa izquierda con buena capacidad discriminativa.

La cirugía cardiaca se muestra como un factor protector de mortalidad hospitalaria en endocarditis infecciosa izquierda, y aporta su mayor beneficio en los pacientes con riesgo intermedio. 


\subsection{ABSTRACT}

\section{INTODUCTION}

Infective endocarditis is a complex disease with high in-hospital mortality. Prognostic assesment is essential to take a therapeutic approach. European guideline on the management of infective endocarditis proposes some prognostic factors based on the characteristics of the patient, the clinical complications of the disease, the type of microorganism and the findings in the imaging tests. These factors should help in the comprehensive and multidisciplinary evaluation of patients, and allow early identification of those at high risk. However, the guideline does not provide an objective evaluation of them neither specific recommendations according to the factors in each case.

On another hand, cardiac surgery is presented as the therapeutic intervention capable of modifying the clinical course of the disease. It is required in approximately $50 \%$ of cases of infective endocarditis, and although it seems to be a protective factor of in-hospital mortality, there are many gaps in its indication, in its optimal time, and in what to expect from it.

\section{OBJECTIVE}

To develop a predictive model of in-hospital mortality in left-sided infective endocarditis with the prognostic variables proposed by the European guideline.

\section{MATERIAL AND METHODS}

We conduct a prospective cohort study using 2 populations of left-sided infective endocarditis: the population of ENDOVAL group $(n=1002)$ and the population of Puerta de Hierro University Hospital $(n=133)$. The population of ENDOVAL group is randomized in a 2: 1 ratio to obtain two samples: an adjustment sample $(\mathrm{n}=688)$, and a validation sample $(n=314)$. Firstly we perform a descriptive and a comparative analysis of the populations of left-sided infective endocarditis. Then, the adjustment sample is used to derive an in-hospital mortality prediction model using a logistic regression which includes the adjusted odds ratios of each variable proposed by the European guideline on the management of infective endocarditis. The validation sample and the population of 
Puerta de Hierro Hospital are used for the internal and external validations of the results. Finally, the predictive model is presented in a mobile application format.

In addition, to assess the impact of cardiac surgery on in-hospital mortality of leftsided infective endocarditis, we repeat the multivariate analysis of mortality with the prognostic variables proposed by the European guideline but also including the variable cardiac surgery and its time of completion.

\section{RESULTS}

The multivariate analysis of in-hospital mortality in left-sided infective endocarditis performed on the adjustment sample shows the association of each prognostic variable proposed by European guidelien on the management of infective endocarditis with in-hospital mortality. Variables that show an independent association with in-hospital mortality are age (OR 1.033, 95\% CI: 1.016 - 1.051), prosthetic endocarditis (OR 1.841, CI 95\% 1.187 - 2.856), comorbidity (OR 1,652, 95\% CI: 1,039 - 2,626), heart failure (OR 3,292, 95\% CI: 2,063 - 5,255), renal failure (OR 2,173, 95\% CI: 1,407 - 3,357), septic shock (OR 5.367, 95\% CI: 3.063 - 9.405), Staphylococcus aureus (OR 3.653, 95\% CI: 2.193 - 6.084), fungi (OR 7.532, 95\% CI: 1.665 - 34.082), perianular complications (OR 2,046, 95\% CI: 1,307 - 3,203), ventricular dysfunction (OR 2,179, 95\% CI: 1,094 - 4,338) and vegetations (OR 2,449, 95\% CI: 1,221 - 4,914). In the predictive model we include all prognostic variables regardless of their $p$-value, using the odds ratio and the derived constant to construct the prediction formula for in-hospital mortality. The model shows good discriminative capacity with an area under the ROC curve of 0.859 (95\% CI: 0.830 - 0.889), and a p-value in the Hosmer-Lemeshow test of 0.350 , which is ratified in the internal (area under the ROC curve 0.834, 95\% CI: 0.786 0.881 ) and external validations (area under the ROC curve $0.759,95 \%$ CI: $0.665-0.853$ ). For the internal validation sample (observed mortality 29.9\%) the model predicts an inhospital mortality of $30.8 \%$ (95\% CI: $27.8-33.9 \%)$, and for the population of the Puerta de Hierro Hospital (observed mortality $27.1 \%$ ) it predicts a mortality of $25.4 \%$ (95\% CI: $21.2-29.5 \%)$.

Cardiac surgery shows a significant association with in-hospital mortality ( $\mathrm{p}$ value of 0.025$)$. The inclusion of this variable in the predictive model maintains its predictive 
performance (area under the ROC curve $0.861,95 \%$ CI: $0.830-0.891$ ). Surgery is a protective factor of mortality that shows its greatest benefit in patients at intermediate risk with a reduction in the risk of death of $10.7 \% \pm 0.3 \%$. The mean reduction in the risk of death is lower for low risk (estimated mortality $0-20 \%$, mean risk reduction of death of $3.2 \pm 1.6 \%$ ) and very high risk patients (estimated mortality greater than $80 \%$, mean risk reduction of $4.6 \pm 2.1 \%)$.

\section{CONCLUSIONS}

The prognostic variables proposed by the European guideline on the management of infective endocarditis make up a predictive model of in-hospital mortality in left-sided infective endocarditis with high discriminative capacity.

Cardiac surgery is shown as a protective factor of in-hospital mortality in leftsided infective endocarditis, and provides its greatest benefit in patients with intermediate risk. 
2. INTRODUCCIÓN 


\subsection{INTRODUCCIÓN}

La endocarditis infecciosa es una enfermedad caracterizada por la invasión del endocardio por microorganismos, principalmente bacterias, pero también hongos y ocasionalmente virus. Esta invasión da lugar a la formación de vegetaciones, lesión característica de la enfermedad, que consiste en una masa amorfa de tamaño variable formada por plaquetas y fibrina con abundantes microorganismos entrelazados y una cantidad moderada de células inflamatorias. La infección afecta la mayoría de las veces a las válvulas cardíacas, aunque puede aparecer en otras estructuras como comunicaciones interauriculares o interventriculares, sobre las cuerdas tendinosas o sobre el endocardio mural. (1)(2)

Fácilmente evidenciable mediante el estudio anatomopatológico del tejido afectado, lo cierto es que el proceso diagnóstico de endocarditis infecciosa es difícil, y se trata básicamente de asociar un síndrome infeccioso con una lesión endocárdica de aparición reciente. (3) Se han sucedido diferentes criterios diagnósticos a lo largo de los años en consonancia con las mejoras de las técnicas de imagen. Actualmente el diagnóstico se basa en los criterios modificados de Duke, con la inclusión de los nuevos criterios de la Sociedad Europea de Cardiología 2015, que incluyen fundamentalmente el uso de la tomografía axial computerizada cardiaca y las técnicas diagnósticas de medicina nuclear. (3) (4)

La enfermedad era prácticamente letal hasta mediados del siglo XX, momento desde el cual se han sucedido varios hitos que han modificado drásticamente el pronóstico de la misma. Primero, la llegada de los antibióticos ayudó a mejorar el control del estado infeccioso, y posteriormente el desarrollo de la cirugía cardiaca permitió el desbridamiento de los tejidos infectados y la reparación de las lesiones valvulares causantes de la insuficiencia cardiaca. Desde principios del siglo XXI la mortalidad se ha mantenido estable, con cifras que varían según las series entre el 20\% de mortalidad hospitalaria y el 30-40\% de mortalidad durante el primer año. El incremento de la complejidad de los pacientes parece hacer estéril la mejora continua de las diferentes técnicas diagnósticas (ecocardiograma transesofágico, ecocardiograma 3D, PET-TC, 
gammagrafía leucocitos marcados, PCR digital, técnicas serológicas...) y terapéuticas (antibióticos más potentes, técnicas quirúrgicas, extracción de dispositivos...) e impide una reducción significativa de la mortalidad global. (5)

El aumento de la complejidad de los pacientes y la heterogeneidad de la enfermedad hacen que la endocarditis infecciosa precise para su manejo un enfoque multidisciplinar. Un solo médico no puede abarcar todo el espectro de la misma. Al tratarse de una enfermedad con múltiples formas de presentación precisa para su manejo correcto de diversos especialistas con alto nivel de experiencia en sus respectivos campos. Hasta tal punto es preciso un enfoque multidisciplinar que la guía europea de endocarditis infecciosa del año 2015 propone la necesidad de crear "Equipos de Endocarditis" (“Endocarditis Team”) en centros de referencia en la atención de la patología, y establece unos criterios para la referencia de pacientes, unos requisitos que debe disponer el centro de referencia y las labores específicas del "Equipo de Endocarditis". (3)

Este enfoque multidisciplinar, que ya se ha mostrado tremendamente útil en el manejo de las valvulopatías en general, y particularmente en la selección de candidatos para el implante de prótesis aórticas percutáneas, es una novedad en el campo de la endocarditis infecciosa dónde incluso ha llegado a mostrar una reducción de la mortalidad. (6) (7)

Probablemente, el diagnóstico precoz y el conocimiento de los factores que ensombrecen el pronóstico de los pacientes con endocarditis son los factores clave en la mejoría de resultados, ya que permitirían la aplicación precoz de métodos agresivos de tratamiento. 


\subsection{PRONÓSTICO DE LA ENDOCARDITIS INFECCIOSA IZQUIERDA}

La endocarditis infecciosa izquierda es el subtipo más frecuente de endocarditis infecciosa, suponiendo un 90-95\% de los casos atendidos. (8)(9)(10) A diferencia de la endocarditis infecciosa derecha, en la que la mortalidad hospitalaria se sitúa en torno al $5-10 \%$ (10) (11-14), la endocarditis izquierda presenta una mortalidad mayor, entre el $15 \%$ y el $30 \%$ según las series. (15-20)

Como ya hemos señalado, la identificación precoz de los pacientes de alto riesgo es crucial en el manejo de la endocarditis para poder modificar el curso natural de la enfermedad y mejorar el pronóstico. (21) Clásicamente, las diferentes guías europeas en el manejo de la endocarditis infecciosa han clasificado los factores pronósticos atendiendo a 4 particularidades: las características del paciente, las complicaciones clínicas de la enfermedad, el microorganismo causal y los hallazgos ecocardiográficos. (3)

La tabla 1 recoge los predictores de mal pronóstico propuesto en la última guía de la Sociedad Europea de Cardiología para el manejo de la endocarditis infecciosa. 
Tabla 1. Factores pronósticos en endocarditis infecciosa propuestos por la guía europea de manejo de la enfermedad.

\section{Características del paciente}

- Edad avanzada

- Endocarditis protésica

- Diabetes mellitus

- Comorbilidades: fragilidad, inmunosupresión, enfermedad renal o pulmonar.

\section{Complicaciones clínicas}

- Insuficiencia cardiaca

- Insuficiencia renal

- Ictus isquémico

- Hemorragia cerebral

- Shock séptico

\section{Microorganismo causal}

- Estafilococo aureus

- Bacilos Gram negativos no-HACEK

- Hongos

\section{Hallazgos ecocardiográficos}

- Complicación perianular

- Disfunción valvular izquierda severa

- Disfunción protésica severa

- Baja fracción de eyección del ventrículo izquierdo

- Hipertensión pulmonar

- Vegetaciones de gran tamaño

- Cierre mitral prematuro y otros signos de elevación de la presión diastólica

*HACEK: H. Influenzae, Haemophilus parainfluenzae, H. Aphrophilus, H. Paraphrophilus, Actinobacillus actinomycetemcomitans, Cardiobacterium hominis, Eikenella corrodens, Kingella kingae y $K$. denitrificans. 


\subsubsection{Características del paciente}

Las características basales del paciente marcan la evolución clínica para cualquier patología y existen numerosos trabajos científicos que avalan el impacto pronóstico de las comorbilidades en el curso clínico de diferentes enfermedades. Es difícil, no obstante, agrupar el término comorbilidad para que sea una medida tangible y reproducible, por lo que han surgido diversas escalas de riesgo para su evaluación. El índice de comorbilidad de Charlson es una de las escalas más conocidas. Se trata de un sistema de evaluación de la esperanza de vida a 10 años, de acuerdo a la edad y las comorbilidades del paciente. Inicialmente validado como predictor pronóstico en población oncológica, ha sido posteriormente validado como factor pronóstico en la evaluación de enfermedades cardiovasculares con buenos resultados tanto en cardiopatía isquémica, insuficiencia cardiaca y estenosis aórtica, como también en endocarditis infecciosa. (22-27)

Dentro del presente trabajo nos ceñiremos a las características del paciente propuestas por la guía europea de manejo de la endocarditis infecciosa y que incluyen la edad, la diabetes mellitus y las comorbilidades.

\subsubsection{Edad avanzada}

La mortalidad de la endocarditis infecciosa se incrementa progresivamente con la edad de los pacientes, lo que se ha relacionado fundamentalmente con una mayor mortalidad quirúrgica, ya que la edad es un factor independiente de mortalidad en cirugía cardiaca bien conocido. (28-30)

En los últimos años se han producido cambios profundos en las características demográficas de los pacientes con endocarditis infecciosa, con un progresivo incremento de la edad de los mismos. $(5,27,31)$ En torno a mediados del siglo XX, la mayoría de pacientes afectados por endocarditis infecciosa presentaban edades comprendidas entre los 20 y los 30 años y sólo un 5\% alcanzaba los 60 años. (32) Actualmente la proporción de pacientes mayores de 60 años se ha incrementado dramáticamente y el progresivo 
envejecimiento de la población en los países occidentales sugiere que esta tendencia continuará, de tal forma que el grueso de pacientes con endocarditis infecciosa se sitúa entre los 70 y los 80 años. (Figura 1) $(28,33,34)$

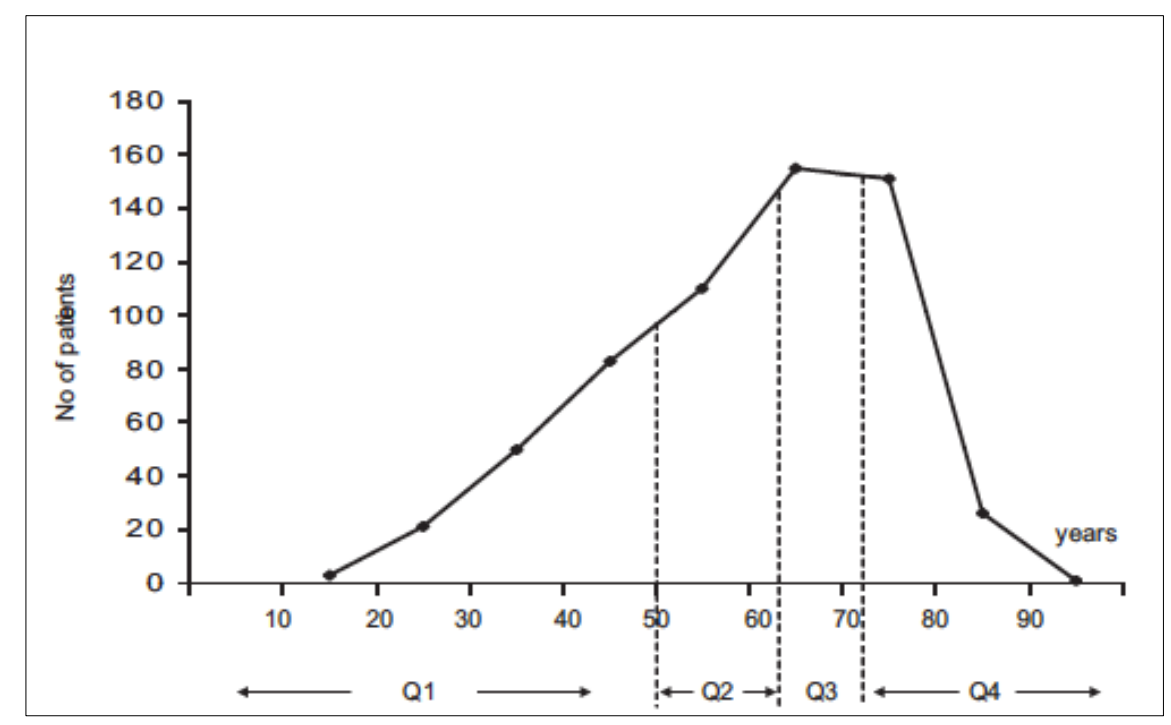

Figura 1. Distribución por decádas de edad en la endocarditis infecciosa izquierda de la serie del grupo ENDOVAL. Tomada de López et al. (35)

Diversos estudios han analizado la influencia de la edad en la endocarditis infecciosa; sin embargo, existen marcadas diferencias en sus resultados, debido principalmente a la elección de diferentes puntos de corte en la edad, pero también a cambios en las características basales de los pacientes y al uso de diferentes protocolos de actuación entre los estudios. (28,36-47)

De forma general, podemos decir que los pacientes con endocarditis infecciosa y edad más avanzada presentan con más frecuencia cardiopatía de base, fundamentalmente de tipo protésico y enfermedad valvular degenerativa, así como mayores tasas de origen nosocomial y más enfermedades predisponentes como la diabetes mellitus. (28) Curiosamente también se ha reportado un incremento de la afectación en mujeres ligado a la edad, que parece estar relacionado con su mayor esperanza de vida. El perfil microbiológico de la enfermedad también es diferente de acuerdo con la edad, y como 
norma general se puede establecer que el Estafilococo aureus y los bacilos Gram negativos aparecen más frecuentemente en gente joven mientras que el Estreptococo bovis y los Enterococcos son más frecuentes en pacientes de mayor edad. (Figura 2) (3648) Esta asociación entre Estreptococo bovis y edad parece estar relacionada con una mayor frecuencia de lesiones gastrointestinales en pacientes de edad avanzada, siendo bien conocida la relación entre éstas y el Estreptococo bovis. (49) Por otro lado, las infecciones por Enterococos también se asocian frecuentemente a intervenciones gastrointestinales y genitourinarias, y presentan origen hospitalario hasta en un $50 \%$ de los casos, lo que justificaría su mayor incidencia en pacientes de edad avanzada. $(28,50)$

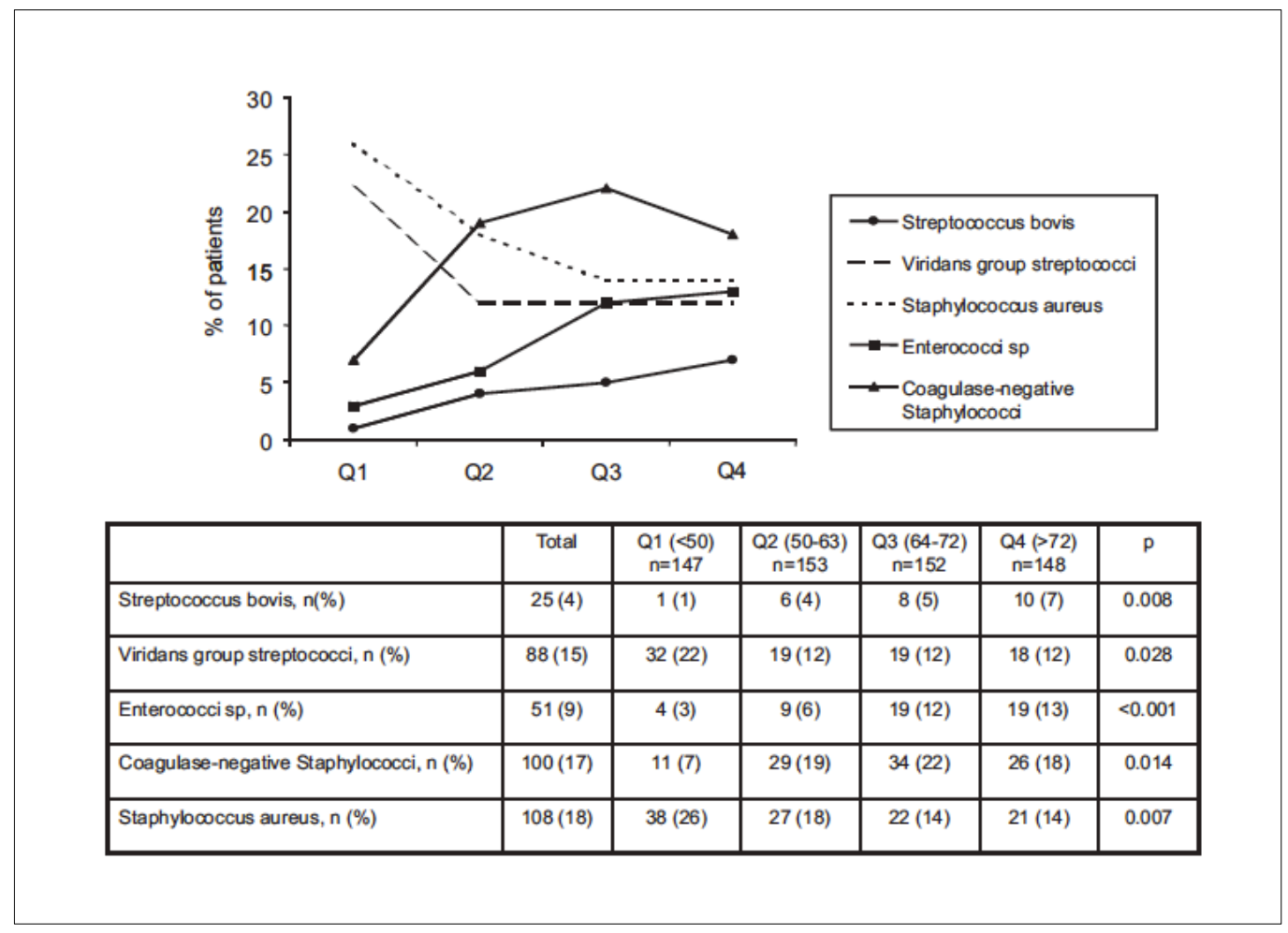

Figura 2. Tipo de microorganismo según el cuartil de edad de los pacientes con endocarditis infecciosa. Q1 menores de 50 años, Q2 entre 50 y 63 años, Q3 entre 64 y 72 años y Q4 mayores de 72 años. Tomada de López et al. (35) 
El manejo terapéutico de los pacientes también varía con la edad, de tal forma que el porcentaje de pacientes sometidos a cirugía cardiaca tanto de forma urgente como electiva disminuye progresivamente con la edad. Diversas razones pueden justificar este hallazgo, como pueden ser una más leve afectación valvular y una tasa menor de endocarditis por Estafilococo aureus, pero el factor determinante parece ser la mayor comorbilidad asociada y el mayor riesgo quirúrgico que conducen al rechazo de la cirugía por alto riesgo. De hecho, el porcentaje de pacientes con indicación quirúrgica rechazados para cirugía por alto riesgo se incrementa con la edad y alcanza el $50 \%$ en mayores de 70 años. (28)

\subsubsection{Endocarditis protésica}

La endocarditis protésica es la forma de endocarditis más severa y afecta entre el 1 y el $6 \%$ de los pacientes con prótesis valvulares, con una incidencia entre el 0.3 y el $1.2 \%$ por paciente-año. (51-55) Representa el 10-30\% de todos los casos de endocarditis. $(33,55-57)$ Se diferencia una endocarditis protésica precoz y una endocarditis protésica tardía, según aparezca antes o después de un año desde la cirugía cardiaca, y ambas entidades presentan un perfil clínico, microbiológico y pronóstico diferente. $(58,59)$

Esta entidad todavía se asocia con dificultades en el diagnóstico y en la elección de la estrategia terapéutica más adecuada y conlleva por tanto un peor pronóstico. (3,48,60-62) Aunque el ecocardiograma transesofágico es primordial en el estudio de la endocarditis, su valor diagnóstico es algo menor en caso de endocarditis protésica. (63) Por tanto, en este contexto, son de gran ayuda las nuevas técnicas de imagen como la tomografía axial computerizada cardiaca y las pruebas de medicina nuclear (PET/TC y SPECT/TC) como se propone en el nuevo algoritmo diagnóstico de endocarditis infecciosa de 2015 de la Sociedad Europea de Cardiología. (Figura 3) $(3,64)$ 


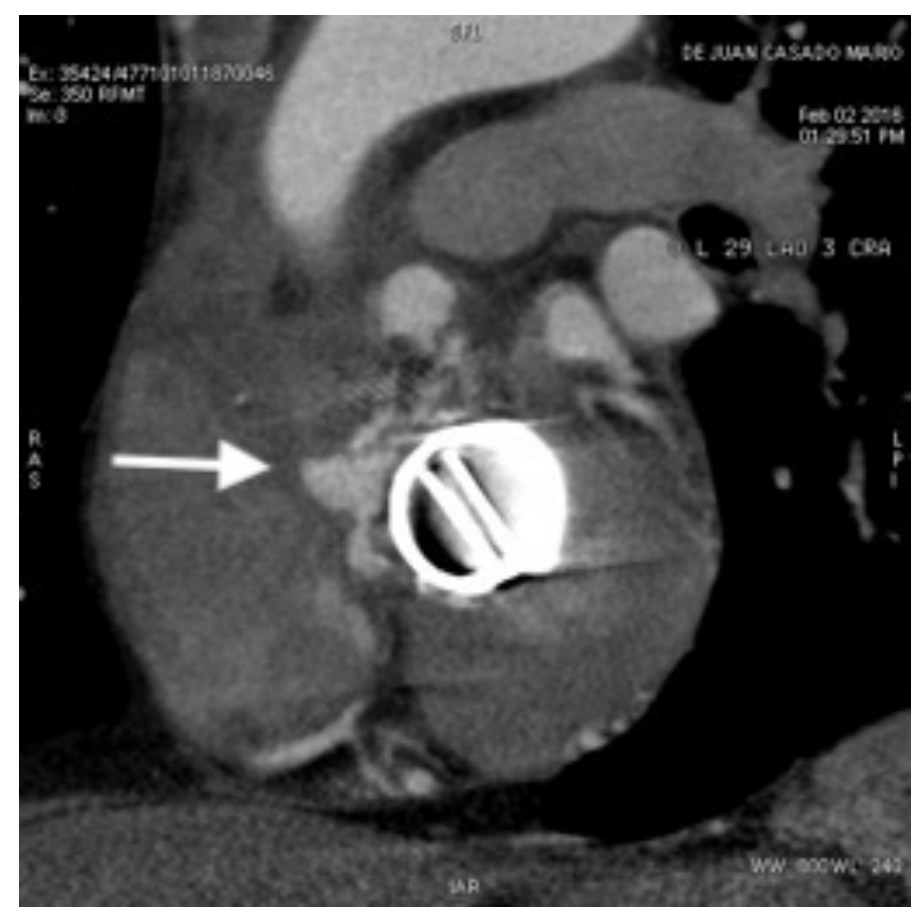

Figura 3. Complicación perianular visualizada en TC cardiaco. La flecha señala una cavidad en la continuidad mitroaórtica con comunicación con la luz cardiaca que se rellena con contraste (pseudoaneurisma).

La mortalidad asociada a la endocarditis protésica se sitúa entre el 20 y el $40 \%$. $(53,56)$ La evaluación pronóstica es crucial en estos pacientes, si bien la mejor opción terapéutica es todavía causa de debate. (65-71) Aunque la cirugía se considera generalmente la mejor opción en casos de disfunción protésica severa o insuficiencia cardiaca, sólo se realiza en aproximadamente un 50\% de los pacientes con endocarditis protésica. $(55,57,65,72)$ Existe información contradictoria, pero la guía europea de práctica clínica recomienda la estrategia quirúrgica en casos de endocarditis protésica y alto riesgo, pudiéndose optar por el manejo conservador con una vigilancia activa en casos de endocarditis protésica tardía no complicada sin afectación por Estafilococos $\mathrm{u}$ hongos. $(69,70,73)$ 


\subsubsection{Diabetes mellitus}

La frecuencia de la diabetes mellitus en pacientes con endocarditis infecciosa se sitúa en torno al 20\%, si bien esta cifra se espera que aumente de forma paralela al incremento en la prevalencia de diabetes mellitus en la población general. Se espera que para el año 2030 se doble el número actual de pacientes con la enfermedad. (74-77)

Es bien conocido que la diabetes mellitus predispone a la infección grave debido fundamentalmente a anomalías en la inmunidad celular y las funciones de fagocitosis asociadas a la hiperglucemia, así como una alteración secundaria de la vascularización. $(74,78,79)$ Además, en estos pacientes se ven favorecidos los procesos de colonización, fundamentalmente por Estafilococo aureus a nivel cutáneo y nasal, lo que predispone a la bacteriemia inicialmente y finalmente a la sepsis y la endocarditis infecciosa. (80-83) De hecho, aparte de la enfermedad cardiovascular, la infección es una de las principales causas de muerte en pacientes con diabetes mellitus hospitalizados, y es un factor de riesgo de mal pronóstico en diferentes infecciones bacterianas. (84)

Típicamente los pacientes con diabetes mellitus y endocarditis infecciosa son más mayores, frecuentemente mujeres y asocian otras comorbilidades como insuficiencia renal crónica o enfermedad pulmonar obstructiva crónica. $(74,76,85)$ Los Estafilococos son los microorganismos más frecuentemente involucrados, pero su frecuencia es similar a la de pacientes sin diabetes mellitus, al contrario que ocurre con los Enterococcos y el Estreptococo bovis que sí parecen ser más frecuentes en pacientes con diabetes mellitus, aunque esta información no es consistente en los diversos estudios. $(28,74,80)$

Respecto a la influencia de la diabetes mellitus en el pronóstico de la endocarditis infecciosa, la información también es contradictoria; sin embargo, existe un consenso general en que la mortalidad en estos pacientes está aumentada. $(15,74-76,80,84,85)$ Lo que no está tan claro es si la diabetes mellitus es un factor pronóstico independiente de mortalidad como sugieren algunos grupos. $(75,80,84)$ En nuestra serie no hemos encontrado esta asociación independiente en un gran estudio multicéntrico, aunque sí es un factor independiente de desarrollo de shock séptico y éste un factor independiente de mortalidad. (74) 


\subsubsection{Comorbilidades}

Recientemente diversos trabajos han mostrado cómo la mortalidad hospitalaria bruta de la endocarditis infecciosa se ha mantenido estable en los últimos años, si bien la mortalidad ajustada al riesgo muestra una discreta reducción. $(5,16,31,86)$ Son bien conocidos los cambios en el perfil epidemiológico de los pacientes con endocarditis infecciosa, que tienden a mostrar edad más avanzada y mayores comorbilidades como diabetes mellitus, historia de cáncer, insuficiencia renal crónica, etc. Actualmente el paciente tipo con endocarditis infecciosa muestra una edad superior a 60 años, con cardiopatía protésica o enfermedad valvular degenerativa concomitante, y con presencia de comorbilidades asociadas; hasta un 70\% presentan un índice de Charlson superior a 2 puntos. (16,27,87-89) Este perfil epidemiológico más agresivo podría justificar la ausencia de mejoría en el pronóstico de la enfermedad a pesar del mayor uso de la cirugía cardiaca y la mejora de las técnicas de imagen, como hemos observado en nuestro grupo por medio de un análisis de emparejamiento por puntuaje de propensión. (5) En este análisis se valida un modelo predictivo de mortalidad hospitalaria en endocarditis infecciosa izquierda con los pacientes atendidos en 3 hospitales nacionales entre $1997 \mathrm{y}$ 2002 y se aplica dicho modelo a los pacientes atendidos entre 2003-2008 y entre 20092014; la mortalidad observada de la población del último sexenio fue significativamente menor que la esperada si consideramos su peor perfil pronóstico. (5)

Existen otras evidencias del impacto de las comorbilidades en el pronóstico de la endocarditis infecciosa; por ejemplo la relación entre endocarditis infecciosa y cáncer, que surgió de forma casual en 1951, en contexto de infección por Estreptococo gallolyticus y cáncer de colon, pero que no fue reconocida hasta finales de la década de los 70. (90-94) Un estudio danés mostró que la endocarditis era un fuerte marcador para prevalencia oculta de cáncer y un predictor de un aumento discreto del riesgo de cáncer a largo plazo. (95) Por otro lado, un estudio en Taiwan demostró que los pacientes con endocarditis tienen 2 veces más riesgo de padecer cáncer colorrectal. (90) La endocarditis y el cáncer comparten algunos factores de riesgo como la infección y la inmunosupresión, pero estos resultados deben ser siempre interpretados con cautela. (96-98)

\section{INTRODUCCIÓN}




\subsubsection{Complicaciones clínicas}

Antes de la inclusión de los antibióticos en el armamento terapéutico, la endocarditis infecciosa izquierda era una enfermedad prácticamente letal. Con los antibióticos se redujo la tasa de infección no controlada de forma significativa y la insuficiencia cardiaca paso a ser la principal causa de muerte. Dos décadas después, la cirugía en fase activa de la enfermedad logró de nuevo mejorar el pronóstico de la enfermedad. $(99,100)$ La infección no controlada y la insuficiencia cardiaca han sido y son los grandes determinantes del pronóstico de la endocarditis infecciosa. El objetivo del tratamiento antibiótico y fundamentalmente de la cirugía cardiaca es eliminar el tejido infectado facilitando el control de la infección, y restaurar la funcionalidad de las estructuras cardiacas, mejorando una situación hemodinámica que de otra forma puede conducir irremediablemente a la muerte. $(3,57,101,102)$

De acuerdo con un trabajo clásico sobre el pronóstico de la endocarditis infecciosa izquierda llevado a cabo por nuestro grupo, el pronóstico de la endocarditis infecciosa izquierda se basa en los 3 ejes esenciales en el diagnóstico de la misma: la evaluación clínica, la microbiología y el ecocardiograma, de tal forma que el riesgo puede evaluarse de forma precisa, sencilla y rápida. En este trabajo se propone un algoritmo de estratificación pronóstica basado en la presencia de insuficiencia cardiaca, complicación perianular e infección por Estafilococo aureus, con un aumento exponencial del riesgo cuando se combinaban estas variables. (Figura 4) (103) 


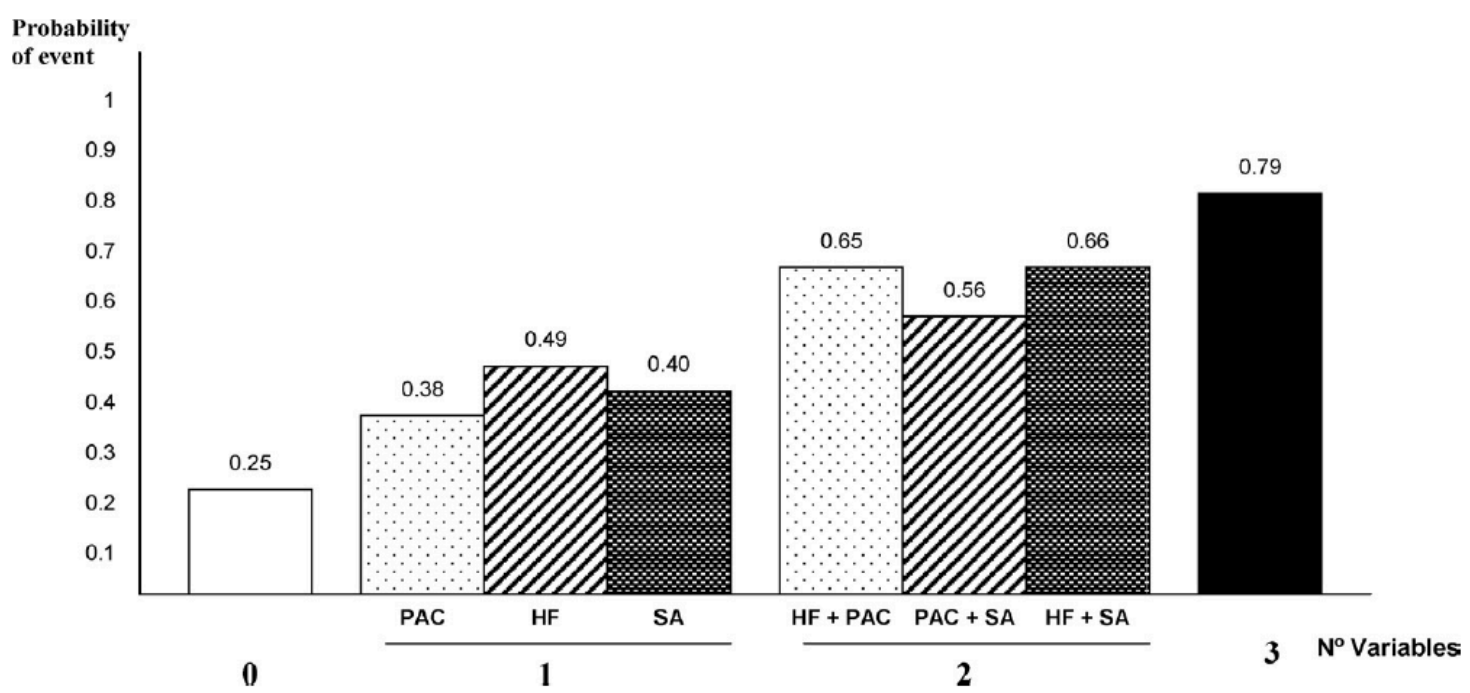

Figura 4. Estratificación pronóstica de acuerdo al acúmulo de factores pronósticos en endocarditis infecciosa izquierda. Se observa un incremento exponencial del riesgo de evento a medida que se combinan la presencia de factores pronósticos. PAC: complicación perianular. HF: insuficiencia cardiaca. SA: Estafilococo aureus. Tomada de Alberto San Román et al. (103)

\subsubsection{Insuficiencia cardiaca}

La insuficiencia cardiaca es la complicación más frecuente de la endocarditis infecciosa y representa también la indicación quirúrgica más frecuente. (57) Se observa entre un 40-60\% de los pacientes de endocarditis infecciosa nativa y es más frecuente en caso de afectación aórtica que mitral. $(17,104,105)$

Puede presentarse de forma aguda por una dehiscencia protésica, o una obstrucción valvular súbita o secundaria a la perforación o rotura de un velo valvular o el aparato subvalvular mitral, o al desarrollo de una fístula. También es frecuente la presentación subaguda, generalmente por la nueva aparición o el empeoramiento de una insuficiencia valvular previa. (106-108) Se han descrito otras causas menos frecuentes como el infarto embólico, la compresión coronaria por una complicación perianular o la miocarditis. (3) 
El espectro clínico de la insuficiencia cardiaca es amplio pero no es infrecuente que los pacientes se presenten en fases avanzadas o incluso en shock cardiogénico. $(17,51,109)$ En un trabajo de nuestro grupo hemos determinado un riesgo 2 veces mayor de mortalidad hospitalaria o necesidad de cirugía en caso de insuficiencia cardiaca en el momento del ingreso hospitalario. (110) Los pacientes con insuficiencia cardiaca más avanzada (clase funcional III y IV de la NYHA) acumulaban más eventos y presentan peor pronóstico. $(15,17,89,101,103,104,111,112)$

Respecto al tratamiento, la sola presencia de insuficiencia cardiaca supone una indicación de cirugía cardiaca precoz, incluso en casos de shock cardiogénico, salvo alto riesgo quirúrgico por comorbilidades del paciente. (3) Como ya hemos señalado, previo a la introducción y generalización de la cirugía cardiaca para la reparación o sustitución valvular en el contexto de endocarditis infecciosa, la insuficiencia cardiaca era responsable de aproximadamente el $90 \%$ de la mortalidad por endocarditis infecciosa en fase aguda. Desde entonces, la insuficiencia cardiaca supone el $65-75 \%$ de las indicaciones quirúrgicas y se ha reducido la mortalidad de este subgrupo de pacientes al 25\% aproximadamente. (113) En este sentido, la insuficiencia cardiaca actuaría como un factor protector de mortalidad al compararla con la infección persistente en el contexto de endocarditis infecciosa intervenida de forma urgente. (103) Esto es lógico, la insuficiencia cardiaca secundaria a un problema local por disfunción valvular, se resuelve con una actuación local como es la cirugía cardiaca, mientras que la infección persistente refleja una situación sistémica, con probable fracaso de los fármacos antibióticos, y que por tanto, la cirugía no puede resolver. De hecho, en un trabajo reciente de nuestro grupo también hemos demostrado que el cultivo valvular positivo es un factor independiente de mortalidad hospitalaria al reflejar una situación de infección no controlada que no puede ser resuelta con el mero acto quirúrgico. (114) 


\subsubsection{Insuficiencia renal}

No existen trabajos que evalúen de forma directa las características de la población con endocarditis infecciosa e insuficiencia renal aguda durante el curso clínico de la enfermedad, pero sabemos que la insuficiencia renal es una complicación frecuente y un factor predictor de mal pronóstico, especialmente si aparece en el periodo post-operatorio. (101,102,115-123) Evidentemente la insuficiencia renal leve es a menudo reversible, mientras que los casos más graves en los que se requieren técnicas de reemplazo renal se asocian a mayor mortalidad. (124)

La insuficiencia renal aparece aproximadamente entre el $6 \%$ y el $30 \%$ de los pacientes con endocarditis infecciosa, $(115,121,124-126)$ y puede ser debida a diversos mecanismos. La toxicidad farmacológica es la causa más frecuente de insuficiencia renal en este contexto, $(3,127)$ pero también puede ser parte de la fisiopatología del shock séptico y la insuficiencia cardiaca. En estos casos es marcador de una situación clínica avanzada con mal estado hemodinámico. (128-130) Mientras que la insuficiencia cardiaca simple podría resolverse con la cirugía cardiaca al restaurarse la funcionalidad de las estructuras cardiacas, la insuficiencia cardiaca avanzada con daño renal asociado reflejaría una situación clínica más grave y por tanto con peor pronóstico. $(3,101)$ Otros mecanismos fisiopatológicos incluyen los fenómenos inmunológicos, los infartos renales embólicos, la deshidratación o la nefrotoxicidad por los contrastes de las pruebas de imagen. (3) 


\subsubsection{Complicaciones neurológicas: ictus isquémico y hemorragia cerebral}

Las complicaciones neurológicas sintomáticas aparecen entre un 15\% y un 30\% de los pacientes con endocarditis infecciosa y son principalmente consecuencia de fenómenos embólicos. (Figura 5) $(16,19,131)$ En la mayoría de los casos estas manifestaciones aparecen antes del diagnóstico de endocarditis, aunque no son infrecuentes las recurrencias durante el curso clínico de la enfermedad.

Las formas de presentación incluyen el accidente isquémico transitorio, el ictus isquémico, la hemorragia cerebral o el absceso cerebral, si bien existe evidencia firme de la presencia de eventos embólicos cerebrales silentes entre el 35\% y el $60 \%$ de los pacientes con endocarditis infecciosa. (132-134) Entre los factores asociados al desarrollo de complicaciones embólicas deben tenerse en cuenta fundamentalmente el microorganismo (Estafilococo aureus) y el tamaño, movilidad y localización de la vegetación. Existen escalas específicamente validadas para la predicción de fenómenos embólicos. $(135,136)$

Es importante destacar el impacto pronóstico de las complicaciones neurológicas, no sólo en términos de mortalidad, sino también de secuelas funcionales, particularmente en el caso del ictus. $(19,131)$ En este sentido un diagnóstico precoz permite el inicio del tratamiento antibiótico que es de suma importancia para prevenir el primer evento o la recurrencia de complicaciones neurológicas. (137) Aunque la cirugía cardiaca es el segundo paso en la prevención de embolias, tras un evento neurológico el riesgo perioperatorio debe ser cuidadosamente evaluado antes de tomar decisiones quirúrgicas. Los estudios randomizados no parecen posibles en este contexto, y los estudios de cohortes tienen sesgos inherentes. El riesgo quirúrgico es aparentemente bajo en casos de embolias silentes o accidentes isquémicos transitorios, sin embargo, tras una hemorragia cerebral el pronóstico neurológico es malo y se recomienda post-poner la cirugía al menos un mes en caso de riesgo de deterioro durante la intervención. (138-141) 


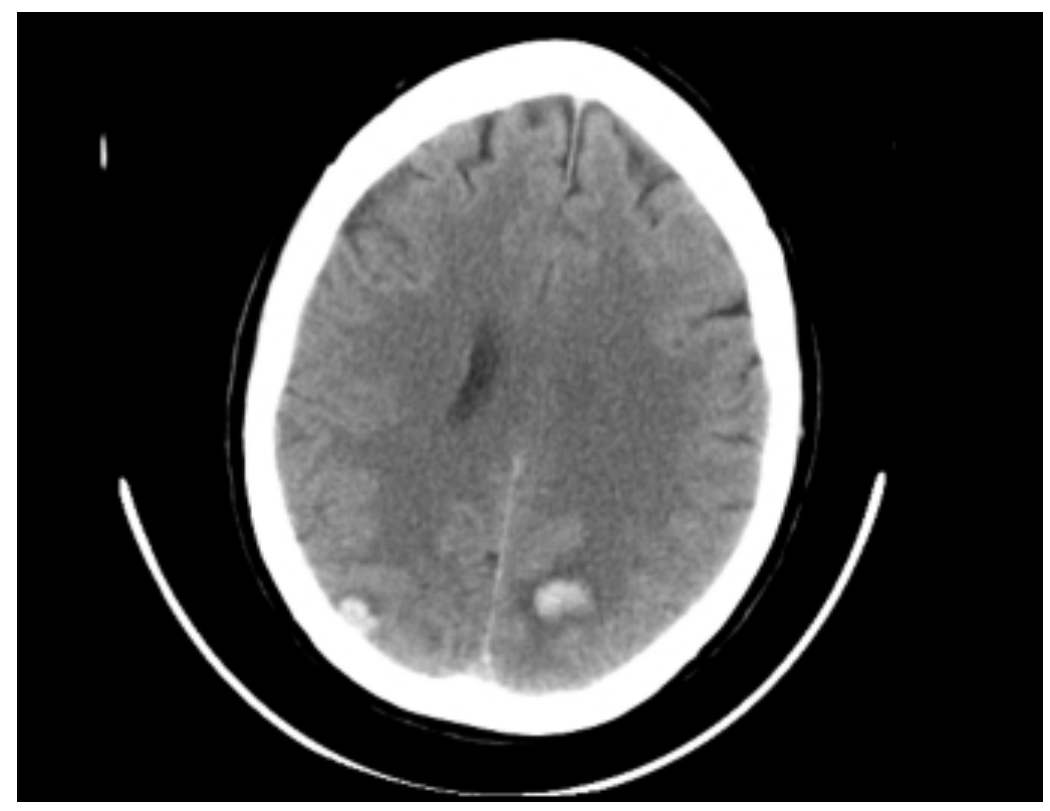

Figura 5. Infartos embólicos en TC craneal. Se observan 2 infartos con transformación hemorrágica en región parietal posterior con transformación hemorrágica.

\subsubsection{Shock séptico}

El shock séptico es la complicación clínica más grave de la endocarditis infecciosa y refleja una situación de infección persistente con una mortalidad que alcanza hasta el $50 \%$ según las series. $(16,18,20,76,109,117,118,142-144)$ La nueva aparición o la persistencia de shock séptico en el período post-operatorio reflejan una situación de infección no controlada que es difícil de manejar de forma exitosa. $(3,101)$ Más del $50 \%$ de los pacientes con shock séptico después de la cirugía cardiaca mueren durante el ingreso según un estudio de nuestro grupo destinado a evaluar el impacto pronóstico de las complicaciones clínicas post-cirugía. (101) El shock séptico después de la cirugía multiplica casi por 10 veces el riesgo de muerte durante el ingreso, y es, junto la insuficiencia renal post-operatoria, el principal factor determinante de mortalidad en pacientes con endocarditis infecciosa izquierda intervenidos durante la fase activa de la enfermedad. (101) 
Respecto a la epidemiología del shock séptico existen diversos estudios que muestran resultados interesantes. Entre las comorbilidades asociadas al desarrollo de esta complicación clínica encontramos afecciones caracterizadas por una disminución de la inmunidad como la diabetes mellitus y los procesos oncológicos. $(18,119,145-147)$ La bacteriemia por Estafilococo aureus es un factor predictor independiente de desarrollo de shock séptico para cualquier tipo de infección sistémica y conlleva un peor pronóstico vital intrahospitalario. $(18,148)$ Muchos investigadores han demostrado la asociación de Estafilococo aureus con evolución clínica desfavorable, mayor riesgo de infección persistente y mayor mortalidad en la endocarditis infecciosa. $(16,84,103,104,117,118,120,149-151)$ Como ya hemos señalado, la insuficiencia renal también es un factor predictor de shock séptico, $(18,152)$ probablemente debido a la hipovolemia, la hipotensión y la vasoconstricción renal asociada a este proceso. Se discute la implicación pronóstica del tamaño de la vegetación en el desarrollo de shock séptico. Algunos trabajos apoyan la hipótesis de que el mayor número y el mayor tamaño de las vegetaciones se asocian a infección descontrolada y mayor desarrollo de shock séptico. $(18,153)$

El manejo clínico del shock séptico es complicado y algunos autores sugieren que a pesar de que la eliminación del foco infeccioso es un factor clave en el control de la infección, la cirugía cardiaca entraña un alto riesgo en este contexto que podría justificar un manejo conservador en algunos casos. (154) Sin embargo, si consideramos el shock séptico como una manifestación de la infección persistente, la cirugía cardiaca urgente debe recomendarse ampliamente en este escenario, debido a que refleja un fallo del tratamiento conservador y asocia una alta mortalidad. (3,155-158) La evaluación multidisciplinar siempre es importante en este contexto, ya que podría decidirse no operar al paciente en caso de alto riesgo derivado de la situación clínica o de sus comorbilidades. (3) 


\subsubsection{Tipo de microorganismo}

El éxito del tratamiento de la endocarditis infecciosa depende de la erradicación del microorganismo; fundamentalmente mediante el uso de antibióticos y también por medio del desbridamiento quirúrgico. El sistema inmunitario propio del paciente es de poca ayuda en este contexto, razón por la cual los regímenes antibióticos bactericidas son claramente más efectivos que los bacteriostáticos en la erradicación de la infección. $(159,160)$

El perfil microbiológico de la enfermedad ha variado progresivamente con el paso del tiempo. Se describe un incremento progresivo de las tasas de infección por Estafilococo aureus y Enterococos, particularmente las formas con multiresistencia a antibióticos. Por otro lado, los Estreptococos están disminuyendo su importancia relativa. $(5,16,31,86)$

\subsubsection{Estafilococo aureus}

El Estafilococo aureus generalmente es responsable de episodios de endocarditis infecciosa aguda y destructiva y asocia una alta mortalidad especialmente en casos de afectación protésica. (161)

Epidemiológicamente destaca un incremento progresivo de la endocarditis por Estafilococo aureus en los últimos años, asociado a un incremento en su resistencia a la meticilina, fundamentalmente por el ambiente nosocomial y los procedimientos invasivos sanitarios. (54,162-164) Su frecuencia relativa se sitúa entre el 25\% y el 35\% según las series y llega a ser la causa más frecuente en algunas de ellas. $(163,165)$

Clínicamente la endocarditis por Estafilococo aureus suele originarse a partir de focos cutáneos (heridas, abscesos, catéteres intravasculares, etc) de ahí la gran importancia que ha cobrado recientemente el tratamiento profiláctico de portadores nasales de Estafilococo aureus en el preoperatorio de una cirugía cardiaca de carácter valvular. $(166,167)$ Existen numerosos trabajos que repasan las características de la

\section{INTRODUCCIÓN}


endocarditis infecciosa asociada al Estafilococo aureus, si bien las características de las poblaciones son heterogéneas debido a diferentes criterios de inclusión. $(87,163,168-$ 172) Típicamente los pacientes con endocarditis infecciosa por Estafilococo aureus son más frecuentemente diabéticos y tienen como factor desencadenante un procedimiento invasivo sanitario. Como ya hemos señalado, el curso clínico suele ser más agresivo y rápido, con mayor tasa de infección persistente y accidentes cerebrovasculares, secundario a su gran poder destructivo y capacidad de embolización. Tradicionalmente la adicción a drogas por vía parenteral era también un factor de riesgo importante, sobre todo para la endocarditis infecciosa derecha, pero su importancia relativa se ha reducido en los últimos años.

La mortalidad asociada también varía según las series, desde el $22.1 \%$ de un estudio clásico que incluía todo tipo de endocarditis hasta el $46 \%$ de un estudio danés con 260 pacientes diagnosticados entre 1982 y 1991 en el que se excluyó la endocarditis derecha y los pacientes adictos a drogas por vía parenteral. $(163,173)$ Todos los autores coinciden en que la endocarditis por Estafilococo aureus es un factor determinante de mortalidad y la guía europea así lo recoge. (3) Nuestro grupo identificó la infección de Estafilococo aureus como el principal factor de riesgo de mortalidad hospitalaria o cirugía urgente. El riesgo de tener uno de estos dos eventos era 2.9 veces superior en la endocarditis provocada por Estafilococo aureus. (110)

Otros autores han tratado de identificar los factores pronósticos asociados a la mortalidad de la endocarditis infecciosa por Estafilococo aureus. Entre ellos destacan la insuficiencia renal, la cardiopatía previa, la diabetes mellitus, la afectación valvular izquierda, la insuficiencia cardiaca, la sepsis severa, la afectación protésica, los eventos neurológicos mayores y el índice de comorbilidad de Charlson. (172) La cirugía cardiaca precoz se ha identificado como un factor protector. (174) 


\subsubsection{Hongos}

Los hongos son raros como causa de endocarditis infecciosa y tradicionalmente se observan con mayor frecuencia en endocarditis protésica y en pacientes adictos a drogas por vía parenteral o inmunocomprometidos. (175) Candida y Aspergillus spp son los géneros más frecuentes (figura 6), con una mortalidad muy alta, superior al $50 \%$ a pesar de tratamiento antifúngico y cirugía valvular. (175-178) Debido a la agresividad de estos microorganismos se recomiendan tratamientos por vía oral de larga duración tras el evento agudo e incluso en algunas ocasiones de forma indefinida. $(175,178,179)$
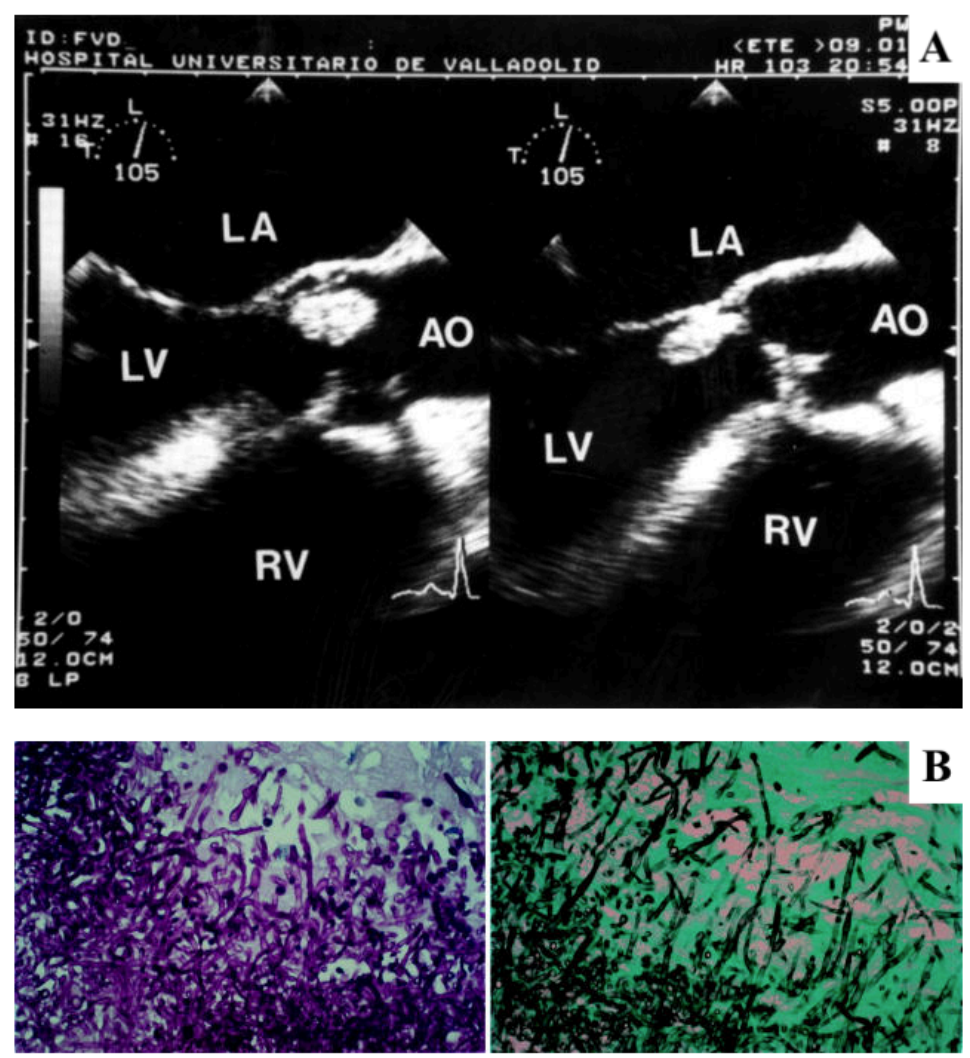

Figura 6. Relación eco-histológica en endocarditis por Candida albicans. A.

Ecocardiograma transesofágico muestra una vegetación grade en el velo aórtico no coronario (AO, aorta; LA, aurícula izquierda; LV, ventrículo izquierdo; RV, ventrículo derecho). B. Histología muestra levaduras y pseudo-hifas típicas de las especies de Candida tanto en la tinción con ácido periódico de Schiff (izquierda) como con metenamina de plata (derecha). Imagen tomada de Serrador et al. (180) 


\subsubsection{Bacilos Gram negativos no-HACEK}

Aunque existen diversos trabajos de características muy heterogéneas sobre la endocarditis infecciosa por bacilos Gram-negativos no-HACEK, sólo existe un estudio que realmente analiza de forma sistemática esta población. Se trata de un trabajo del grupo ICE ("International Collaboration on endocarditis") que realiza una revisión de sus 49 episodios de endocarditis infecciosa por estas bacterias, de un total de 2761 casos (1.8\%). (181) Escherichia coli y Pseudomonas aeureginosa son los microorganismos más frecuentes de este grupo. La mayoría de pacientes presenta infecciones asociadas a cuidados sanitarios $(57 \%)$ y es el implante de dispositivos endovasculares el factor predisponente más frecuente. La mortalidad hospitalaria es alta (24\%), especialmente si tenemos en cuenta la comparación con la mortalidad hospitalaria del resto de microorganismos en este estudio (17\%) aunque la diferencia no fuera estadísticamente significativa ( $\mathrm{p}=0.190$ ), y más aún si evaluamos otros trabajos de la literatura en los que las cifras varían entre el 30\% y el 85\% de mortalidad. (181-190)

En este contexto se recomienda una estrategia terapéutica que incluye la cirugía cardiaca precoz y un esquema de tratamiento antibiótico prolongado, como recoge la guía europea de manejo de la endocarditis infecciosa. (3) 


\subsubsection{Hallazgos por técnicas de imagen}

El ecocardiograma es la herramienta diagnóstica clave en el diagnóstico y manejo de la endocarditis infecciosa y es también útil en la evaluación pronóstica de los pacientes, así como para el seguimiento de los pacientes bajo tratamiento, antes y después de la cirugía. (101,191-193) La guía europea de manejo de la endocarditis infecciosa recomienda la realización de un ecocardiograma transtorácico tan pronto como la sospecha clínica aparezca, y la realización de un ecocardiograma transesofágico en caso de sospecha clínica alta y ecocardiograma transtorácico negativo (Recomendación de clase I, con nivel de evidencia B). (3,191,192,194-197)

Sin embargo, aunque se reporta una especificidad de entorno al 90\% para el diagnóstico de endocarditis infecciosa por ecocardiograma, su sensibilidad está limitada particularmente para el método transtorácico. $(191,192)$ En este escenario y con el fin de aumentar la sensibilidad diagnóstica, se han aplicado nuevas técnicas de imagen al proceso diagnóstico-terapéutico de la endocarditis infecciosa como la tomografía axial computerizada multicorte, la resonancia magnética y las técnicas de medicina nuclear como la gammagrafía de leucocitos marcados con radiotrazador SPECT/TC o el 18 fluoro-desoxiglucosa PET-TC. (4,64,132-134,136,198-205)

\subsubsection{Complicación perianular}

La extensión perivalvular de la endocarditis infecciosa es la causa más frecuente de infección no controlada, y asocia peor pronóstico y alta probabilidad de necesidad de cirugía. Entre las complicaciones perianulares encontramos el absceso, la fístula y el pseudoaneurisma, $(206,207)$ que constituyen un proceso dinámico cuyos principales factores de riesgo son la endocarditis protésica, los Estafilococos coagulasa-negativos y la afectación aórtica. $(208,209)$ 
Estas complicaciones tienden a asociar disfunción valvular o perivalvular severa y precisan altas tasas de cirugía cardiaca, incluso cercanas al 90\%, a pesar de lo cual la mortalidad hospitalaria se sitúa en torno al 40\%. $(52,106,210)$

La extensión perivalvular debería sospecharse en casos de datos de infección persistente y obliga a realizar técnicas de imagen más avanzadas como el ecocardiograma transesofágico, el TC cardiaco o el PET-TC por su gran utilidad en la evaluación de la complicación valvular. (Figura 7) (158,211-214)
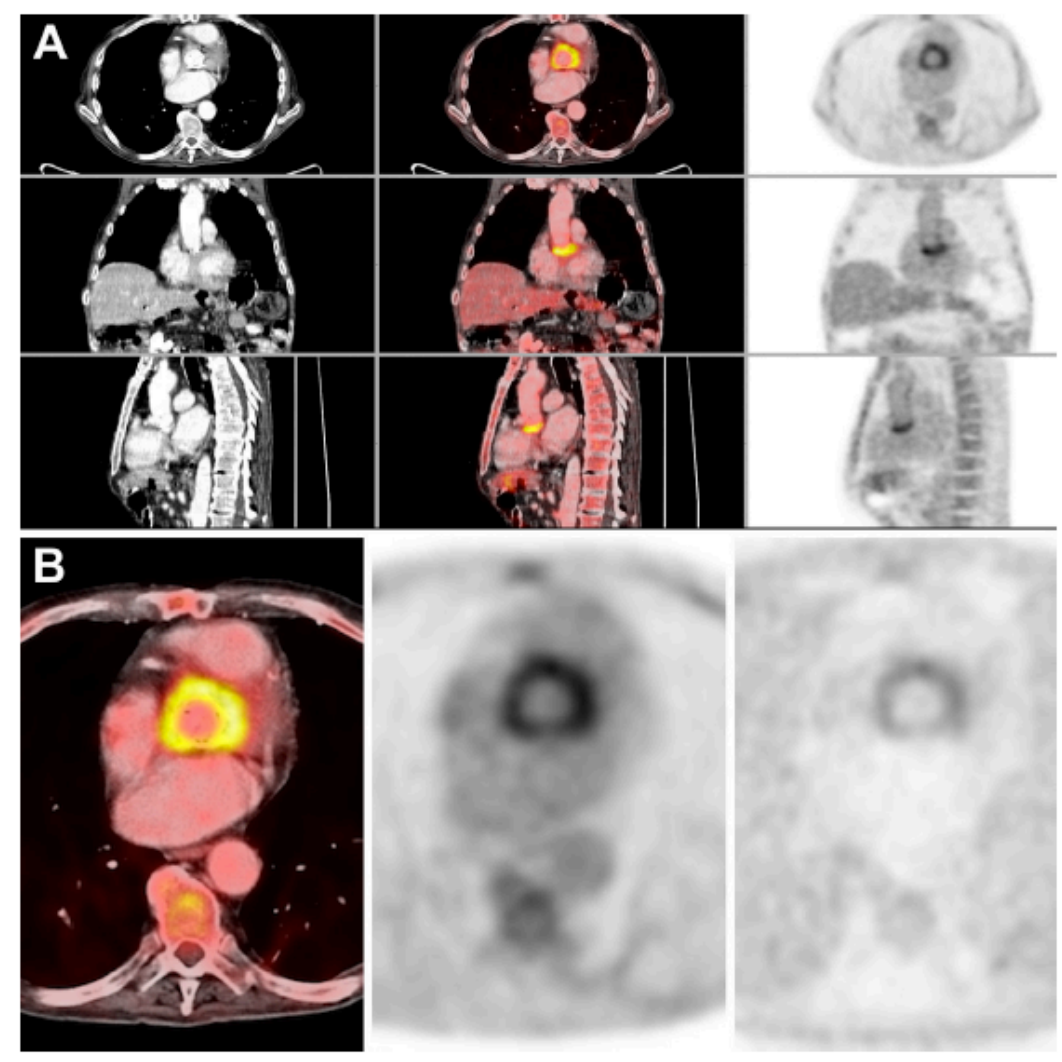

Figura 7. Captación perivalvular homogénea de 18 fluorodesoxiglucosa $\left({ }^{18}\right.$ F-FDG) en un paciente con infección del tubo valvulado aórtico. (A) Se visualiza captación perivalvular intensa y homogénea en paciente con un tubo valvulado en proyección axial (fila superior), coronal (fila medio) y sagital (fila inferior). (B) Proyección axial del mismo paciente en detalle: imagen de fusión (izquierda), imagen corregida (medio) e imagen no corregida (derecha). Persistencia de captación de ${ }^{18}$ F-FDG en la imagen no corregida. Figura tomada de García-Arribas et al. (213) 


\subsubsection{Disfunción valvular o protésica severa}

La disfunción valvular es la consecuencia de diversos mecanismos que incluyen rotura de cuerdas tendinosas, rotura o perforación de los velos valvulares o la interferencia de la vegetación con el cierre de los velos. La disfunción protésica suele ser debida a desinserción de la misma con aparición de dehiscencias paravalvulares que son los causantes de la insuficiencia valvular. (3)

Tanto la disfunción valvular como la protésica pueden cursar de forma asintomática aunque sean severas, de tal forma que el paciente tolere hemodinámicamente la situación y pueda ser intervenido de forma electiva tras finalizar el tratamiento antibiótico. Sería el caso ideal, y generalmente es la situación de pacientes con disfunción valvular preexistente a la cual el corazón ya se encuentra adaptado. Cuando la aparición de la insuficiencia valvular tiene un carácter agudo, la tolerancia clínica es mala, típicamente aparece insuficiencia cardiaca izquierda y no es infrecuente la situación de edema agudo de pulmón y el shock cardiogénico. $(17,109)$

Además de los hallazgos clínicos, el ecocardiograma es de vital importancia para la evaluación clínica inicial y el seguimiento. Valora la repercusión hemodinámica de la disfunción valvular, la estimación de la presión sistólica de arteria pulmonar, la presencia de derrame pericárdico, la fracción de eyección de ventrículo izquierdo y las presiones telediastólicas de llenado de las cavidades cardiacas. (192)

En general, no existen estudios que evalúen de forma directa el impacto pronóstico de la disfunción valvular en la endocarditis infecciosa, ya que el verdadero factor pronóstico parece ser la repercusión clínica de la misma en situación de insuficiencia cardiaca. 


\subsubsection{Fracción de eyección del ventrículo izquierdo reducida}

La disfunción ventricular izquierda es el factor pronóstico más importante de la patología cardiovascular, en la insuficiencia cardiaca, la cardiopatía isquémica, las valvulopatías, las arritmias, etc (3) También ha sido identificada como factor pronóstico en la endocarditis infecciosa. $(51,215,216)$ Los pacientes con endocarditis sometidos a cirugía con una fracción de eyección inferior al 45\% presentan un riesgo 3 veces mayor de mortalidad al año. (215)

Existen 2 razones que justifican la disfunción ventricular en el contexto de la endocarditis infecciosa. En primer lugar la presencia de condicionantes previos: la edad, la diabetes, la hipertensión o la insuficiencia renal crónica pueden predisponer a la cardiopatía isquémica crónica, pero también la propia enfermedad valvular puede condicionar la aparición de disfunción ventricular. En numerosas ocasiones estaríamos ante una descompensación aguda de una disfunción ventricular preexistente que podría ser conocida o no conocida. (215) Por otro lado, también existen condiciones asociadas a la endocarditis que pueden provocar la disfunción sistólica del ventrículo izquierdo, fundamentalmente por la inflamación, el edema y el efecto tóxico de la acidosis sobre el metabolismo celular. (217) Este mecanismo ha sido descrito como el causante de la disfunción ventricular asociada a la sepsis de cualquier origen, y por tanto, sería compartido por la sepsis secundaria a la endocarditis infecciosa. (218) Además, la destrucción valvular por la endocarditis podría conducir a una situación de sobrecarga aguda de volumen, con el consiguiente aumento inicial de cronotropismo e inotropismo, pero que finalmente podría conducir a una situación de shock cardiogénico por fracaso de estos mecanismos compensadores. De hecho, la disfunción valvular severa y aguda con repercusión hemodinámica es una indicación de cirugía cardiaca emergente en la endocarditis infecciosa. $(3,219)$

Independientemente de la causa de la disfunción ventricular, la fracción de eyección reducida en el ventrículo izquierdo es un marcador de mal pronóstico en endocarditis infecciosa tanto izquierda como derecha. $(216,220)$ Aún está por ver la utilidad de las técnicas de imagen que evalúan la contractilidad regional por medio del

\section{INTRODUCCIÓN}


doppler tisular, y que han resultado útiles en la identificación precoz de pacientes con peor pronóstico en la enfermedad valvular y en la insuficiencia cardiaca. (221-224) En el contexto de la endocarditis infecciosa sólo existe un estudio que refleja un posible efecto adicional sobre la fracción de eyección del ventrículo izquierdo, pero en cualquier caso estaríamos ante un valor muy marginal de la técnica. (215)

\subsubsection{Hipertensión pulmonar}

La hipertensión pulmonar es una complicación frecuente de la enfermedad cardiaca izquierda, refleja su presencia y también su severidad. (225-227) Cuando aparece hipertensión pulmonar en el contexto de enfermedad cardiaca izquierda, ésta cursa con síntomas más severos y mala tolerancia a los esfuerzos, con el consiguiente impacto negativo en el pronóstico. (225-228)

La prevalencia real de la hipertensión pulmonar del grupo 2 es difícil de determinar, ya que la mayoría de estudios basan sus resultados en el ecocardiograma, con puntos de corte diferentes entre ellos. $(226,227)$ La hipertensión pulmonar en este contexto se genera en respuesta a una transmisión pasiva retrógrada del aumento de las presiones de llenado en las cavidades cardiacas, que a menudo precisa de un curso crónico de la enfermedad. Sin embargo, como ya hemos señalado previamente, a menudo la disfunción del ventrículo izquierdo y la enfermedad valvular ya están presentes antes de la infección, lo que justificaría la presencia de hipertensión pulmonar en un grupo seleccionado de pacientes.

Si bien no existen estudios que evalúen el impacto pronóstico de la hipertensión pulmonar en la endocarditis infecciosa, sí existe información de su valor pronóstico en la insuficiencia cardiaca, donde la presencia de hipertensión pulmonar condiciona una mayor mortalidad. (225,229-232) 


\subsubsection{Vegetaciones de gran tamaño}

La vegetación es la lesión paradigmática de la endocarditis infecciosa (Figura 8). Se trata de una masa amorfa de tejido infectado, fibrina y plaquetas con abundantes microorganismos entrelazados y una cantidad moderada de células inflamatorias. Presenta un tamaño variable y se encuentra adherida generalmente al endocardio valvular, aunque ocasionalmente puede aparecer en otras estructuras como comunicaciones interauriculares o interventriculares, sobre las cuerdas tendinosas o sobre el endocardio mural. (1)(2)

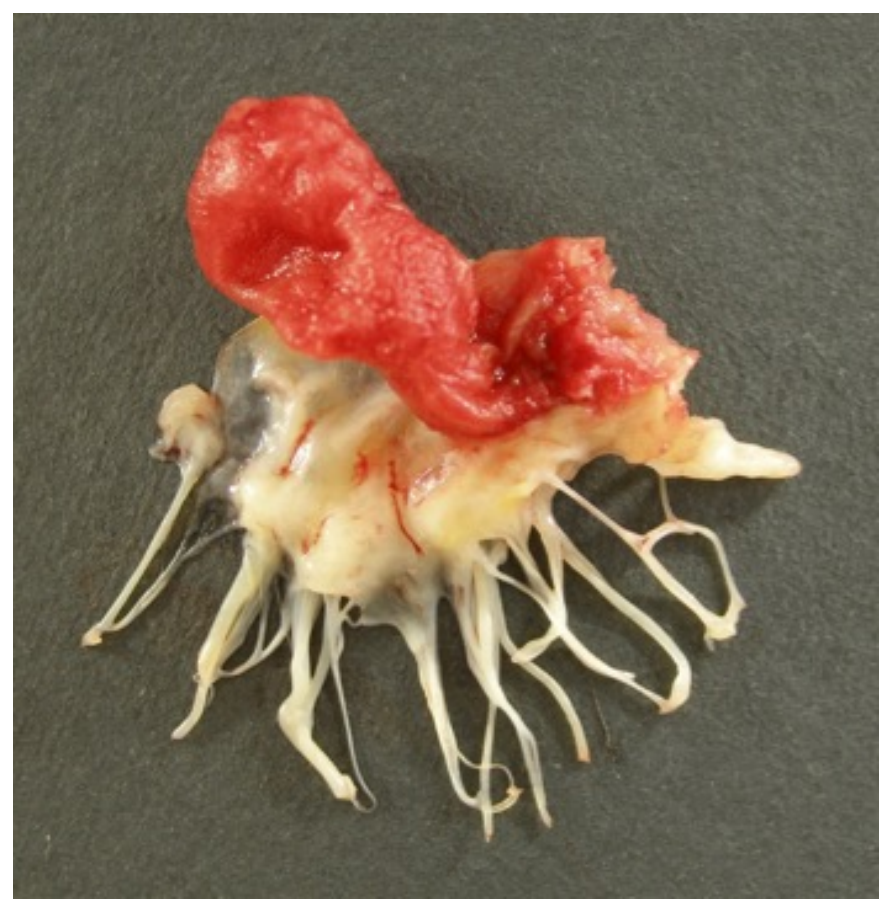

Figura 8. Vegetación endocárdica sobre válvula mitral nativa. 
La presencia de vegetaciones y su tamaño son un factor pronóstico en la endocarditis infecciosa, fundamentalmente por el riesgo de embolia asociado. El cerebro y el bazo son los lugares más frecuentes de embolización en caso de endocarditis izquierda y pueden suponer complicaciones que ponen en riesgo la vida del paciente. (3) Sabemos que los eventos embólicos cursan de forma silente en el 20-50\% de los pacientes con endocarditis infecciosa izquierda. (133-135) El ictus es una complicación grave con importante morbilidad y mortalidad asociadas. (138) El riesgo de eventos embólicos se reduce drásticamente con el inicio de la terapia antibiótica. Se ha demostrado una reducción de la incidencia de ictus en pacientes con tratamiento antibiótico adecuado desde 4.8/1000 pacientes-día durante la primera semana a 1.7/1000 pacientes-día en la segunda. $(21,137,233,234)$

El tamaño y la movilidad de las vegetaciones son los factores predictores de embolismo más potentes, $(135,137,149,191,233,235-239)$ de tal forma que pacientes con vegetaciones más grandes tienen mayor riesgo. $(19,118,239,240)$ No hay que olvidar otros factores de riesgo como la afectación mitral, el Estafilococo aureus o los hongos, la afectación multivalvular o la presencia de embolia previa, $(149,191,233,235,236,241)$ y otros derivados de las características clínicas del paciente: edad, diabetes mellitus, fibrilación auricular o embolismo previo. (242)

La evaluación del riesgo embólico es importante debido a que afecta directamente a la estrategia terapéutica. $(242,243)$ La decisión de cirugía precoz como prevención de embolias es difícil y debe estar marcada por las características particulares de cada paciente. Aunque existe evidencia de que la cirugía es segura en este contexto, $(118,233)$ desde nuestro punto de vista es la indicación clínica de la guía europea con menor grado de evidencia científica que la sustente. (244) 


\subsection{IMPACTO DE LA CIRUGÍA CARDIACA EN LA EVOLUCIÓN DE LA ENDOCARDITIS INFECCIOSA IZQUIERDA}

El tratamiento quirúrgico en la endocarditis infecciosa es necesario en aproximadamente el 50\% de los pacientes debido a complicaciones clínicas severas. (57) Las razones para considerar la cirugía precoz en fase activa de la enfermedad incluyen evitar la progresión a insuficiencia cardiaca y el daño estructural irreversible causado por la infección persistente y prevenir la embolia sistémica. $(21,57,104,245-247)$

Por otro lado, la cirugía cardiaca durante la fase activa de la enfermedad se asocia a un alto riesgo. Por tanto, la cirugía se justifica en pacientes con alto riesgo, poca probabilidad de curación con tratamiento antibiótico y que no presentan comorbilidades o complicaciones asociadas que impidan su recuperación. (3)

Lamentablemente no existen estudios aleatorizados que evalúen el impacto pronóstico de la cirugía cardiaca sistemática en la endocarditis infecciosa, salvo un estudio unicéntrico en una población de muy bajo riesgo (edad media 47 años, endocarditis nativa, microorganismo predominante Estreptococos) que demostró beneficio de la cirugía precoz en un evento combinado de muerte hospitalaria y embolia, fundamentalmente a expensas de reducir el riesgo embólico. (248)

Aunque las indicaciones de cirugía están bien establecidas en las guías de práctica clínica (Tabla 2), los pacientes no siempre encajan dentro de puntos de corte específicos, y existe a menudo debate en formas leves de insuficiencia cardiaca, o respecto al tamaño de la vegetación para considerar el riesgo embólico. El momento óptimo de la cirugía también es motivo de debate. Algunos autores defienden la cirugía precoz, mientras que otros prefieren esperar para conseguir un mejor control de la infección y la estabilización hemodinámica, que sin embargo no siempre ocurren. $(21,193,248-252)$ Entre un 28\% y un $47 \%$ de los pacientes con endocarditis infecciosa sobre válvula nativa que inicialmente son manejados únicamente de forma médica necesitan cirugía cardiaca de remplazo valvular en los 2 años siguientes a la endocarditis infecciosa. (155) 
Por todo ello, la consulta precoz con cirugía cardiaca es crucial, con el fin de determinar la mejor estrategia terapéutica posible. La identificación de pacientes que requieren cirugía cardiaca precoz es difícil y es uno de los objetivos primordiales del "Equipo de Endocarditis". Cada paciente debe ser evaluado de forma individual teniendo en cuenta todos los factores que aumentan el riesgo quirúrgico, de tal forma que la necesidad de cirugía se establece en base a una combinación de varios determinantes de alto riesgo. (253) 
Tabla 2. Indicaciones de cirugía cardiaca en endocarditis infecciosa según la guía europea. (3) (51,105-108)

\begin{tabular}{|c|c|c|c|}
\hline & Tipo cirugía & $\begin{array}{l}\text { Clase } \\
\text { recomendación }\end{array}$ & $\begin{array}{c}\text { Nivel } \\
\text { evidencia }\end{array}$ \\
\hline \multicolumn{4}{|l|}{ INSUFICIENCIA CARDIACA } \\
\hline $\begin{array}{l}\text { Endocarditis aórtica o mitral, nativa o protésica, con insuficiencia valvular severa, obstrucción o } \\
\text { fístula causante de edema pulmonar o shock cardiogénico refractarios. }\end{array}$ & Emergente & I & $\mathrm{B}$ \\
\hline $\begin{array}{l}\text { Endocarditis aórtica o mitral, nativa o protésica, con insuficiencia valvular severa u obstrucción } \\
\text { causante de insuficiencia cardiaca o signos ecocardiográficos de mala tolerancia hemodinámica. }\end{array}$ & Urgente & I & $\mathrm{B}$ \\
\hline \multicolumn{4}{|l|}{ INFECCIÓN NO CONTROLADA } \\
\hline Complicación perianular. & Urgente & I & $\mathrm{B}$ \\
\hline Infección causada por hongos o microorganismos multirresistentes. & Urgente / Electiva & I & $\mathrm{C}$ \\
\hline $\begin{array}{l}\text { Persistencia de hemocultivos positivos a pesar de tratamiento antibiótico apropiado y control de } \\
\text { los focos infecciosos metastásicos. }\end{array}$ & Urgente & IIa & $\mathrm{B}$ \\
\hline Endocarditis protésica por especies de Estafilococos o bacilos gram negativos no HACEK. & Urgente / Electiva & IIa & $\mathrm{C}$ \\
\hline \multicolumn{4}{|l|}{ PREVENCIÓN DE EMBOLIAS } \\
\hline $\begin{array}{l}\text { Endocarditis aórtica o mitral, nativa o protésica con vegetaciones persistentes mayores a } 10 \mathrm{~mm} \\
\text { tras uno o más eventos embólicos a pesar de tratamiento antibiótico adecuado. }\end{array}$ & Urgente & I & $\mathrm{B}$ \\
\hline $\begin{array}{l}\text { Endocarditis aórtica o mitral nativa con vegetaciones }>10 \mathrm{~mm} \text { con estenosis o insuficiencia } \\
\text { valvular severa y bajo riesgo quirúrgico. }\end{array}$ & Urgente & IIa & $\mathrm{B}$ \\
\hline Endocarditis aórtica o mitral, nativa o protésica, con vegetaciones $>30 \mathrm{~mm}$. & Urgente & IIa & $\mathrm{B}$ \\
\hline $\begin{array}{l}\text { Endocarditis aórtica o mitral, nativa o protésica con vegetaciones }>15 \mathrm{~mm} \text { y sin otra indicación } \\
\text { de cirugía. }\end{array}$ & Urgente & $\mathrm{IIb}$ & $\mathrm{C}$ \\
\hline
\end{tabular}

\section{INTRODUCCIÓN}


3. HIPÓTESIS 


\subsection{JUSTIFICACIÓN DEL TRABAJO}

La guía europea de endocarditis infecciosa del año 2015 incide en la estratificación pronóstica precoz para cambiar el curso natural de la enfermedad y mejorar el pronóstico. Propone una serie de variables pronósticas basadas en las características del paciente, el curso clínico de la enfermedad y parámetros microbiológicos y de imagen que pueden evaluarse de forma sencilla. Además, reconoce el papel clave de la cirugía cardiaca para mejorar el pronóstico de la enfermedad y la importancia de la evaluación multidisciplinar para la toma conjunta de decisiones.

Sin embargo, la evaluación de las variables de la guía es subjetiva, difícil de aplicar en la práctica clínica diaria y no se dispone de una herramienta objetiva que permita conocer el impacto pronóstico de cada variable en particular, o incluso poder hacer una estimación de la mortalidad hospitalaria de cada paciente en concreto, que evalúe a la vez el teórico benefício de una cirugía precoz o diferida.

La utilización de aplicaciones móviles es cada vez más frecuente en el ámbito sanitario. En este contexto supondrían una herramienta sencilla, accesible y gratuita que podría ser utilizada a la cabecera del paciente para conocer el pronóstico intrahospitalario de la enfermedad.

\subsection{HIPOTESIS}

Las variables pronósticas propuestas por la guía europea de endocarditis infecciosa permiten estratificar el pronóstico de los pacientes con endocarditis infecciosa izquierda. El desarrollo de un modelo de predicción pronóstica de mortalidad intrahospitalaria en formato aplicación móvil usando estas variables permite una estratificación pronóstica objetiva e individual para cada paciente con endocarditis infecciosa izquierda. 
4. OBJETIVOS 


\subsection{OBJETIVOS PRINCIPALES}

- Desarrollar un modelo predictivo de mortalidad hospitalaria en endocarditis infecciosa izquierda.

- Construir una aplicación informática en base al modelo predictivo para el cálculo individual de la mortalidad hospitalaria de los pacientes con endocarditis infecciosa izquierda.

\subsection{OBJETIVOS SECUNDARIOS}

- Evaluar de forma individual el impacto de cada variable pronóstica propuesta por la guía europea en la mortalidad intrahospitalaria de la endocarditis infecciosa izquierda.

- Validar internamente la capacidad predictiva del modelo de estratificación de mortalidad hospitalaria de la endocarditis infecciosa izquierda.

- Validar externamente la capacidad predictiva del modelo de estratificación de mortalidad hospitalaria de endocarditis infecciosa izquierda.

- Evaluar el impacto de la cirugía cardiaca en el modelo predictivo de mortalidad hospitalaria de la endocarditis infecciosa izquierda. 
5. MATERIAL Y MÉTODOS 


\section{1 ÁMBITO DEL ESTUDIO}

En el presente trabajo han colaborado 4 hospitales terciarios del Sistema Nacional de Salud. Los hospitales Clínico Universitario de Valladolid, el Hospital Clínico San Carlos de Madrid y el Hospital Universitario La Princesa de Madrid forman conjuntamente un grupo multicéntrico para el estudio de la endocarditis infecciosa (grupo ENDOVAL), que comparten protocolos de actuación y proyectos de investigación con una base de datos común a todos ellos. El Hospital Universitario Puerta de Hierro de Madrid ha colaborado con el proyecto para la validación externa del modelo y forma parte de un grupo multicéntrico nacional (GAMES - "Grupo Español de Endocarditis Infecciosa") y de un grupo multicéntrico internacional también para el estudio de la endocarditis infecciosa (grupo ICE - "International Collaboration on Endocarditis").

Los cuatro centros son hospitales terciarios que disponen de cirugía cardiaca y que son referencia para centros satélites colindantes por su experiencia en el manejo de la endocarditis infecciosa.

\subsection{POBLACIONES DEL ESTUDIO}

Hemos utilizado 2 poblaciones de endocarditis infecciosa izquierda. La población empleada para construir y validar internamente el modelo es la población de endocarditis infecciosa del grupo ENDOVAL. Se trata de una cohorte de 1002 pacientes consecutivamente diagnosticados en los 3 centros terciarios entre enero de 2000 y diciembre de 2017. La población utilizada para la validación externa del modelo es la cohorte de 133 pacientes con endocarditis infecciosa izquierda consecutivamente diagnosticados en el Hospital Universitario Puerta de Hierro de Madrid entre 2012 y 2017.

Solamente se han considerado pacientes con diagnóstico definitivo de endocarditis infecciosa con afectación izquierda, ya sea exclusiva o combinada con afectación derecha. Se han seguido los criterios de Duke hasta el año 2002 y los criterios Duke modificados posteriormente. Estos criterios se recogen en los anexos I, II y III. 


\subsection{DISEÑO DEL ESTUDIO}

Se trata de un estudio de cohortes prospectivo con las dos poblaciones de endocarditis infecciosa izquierda presentadas.

La población del grupo ENDOVAL se aleatoriza en una proporción 2:1, de tal forma que se obtienen 2 muestras de pacientes; dos tercios de la población conforman la muestra de derivación o ajuste $(n=688)$, para elaborar el modelo predictivo, y un tercio, la muestra de validación $(\mathrm{n}=314)$, para realizar la validación interna del mismo. La validación externa se realiza en la población del Hospital Universitario Puerta de Hierro. (Figura 9)

La elaboración del modelo predictivo se hace por medio de un análisis multivariado de mortalidad intrahospitalaria en el que se introducen todas las variables pronósticas propuestas por la guía europea de manejo de la endocarditis infecciosa, que se describe en el apartado de análisis estadístico.

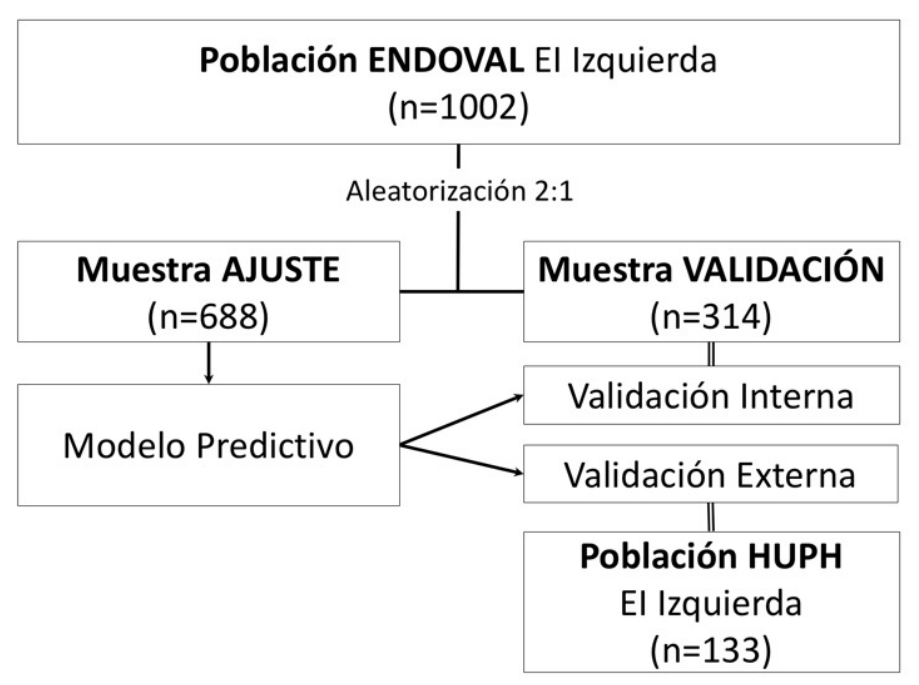

\section{Figura 9. Diseño del estudio.}

Para valorar el impacto de la cirugía cardiaca en la mortalidad hospitalaria de la endocarditis infecciosa izquierda repetimos el análisis multivariado de mortalidad con las variables pronósticas propuestas por la guía europea incluyendo la variable cirugía cardiaca y su momento de realización. 


\subsection{VARIABLES ANALIZADAS}

Para cada paciente con endocarditis infecciosa izquierda incluido en el estudio se ha rellenado una ficha de datos estandarizada según un protocolo predefinido de actuación. El protocolo sigue las directrices éticas de la declaración de Helsinki de 1975 y sus posteriores actualizaciones, y ha sido aprobado por los comités de ética a nivel local.

El protocolo se aplica a todos los pacientes con sospecha de endocarditis infecciosa, pero solamente aquellos con diagnóstico de endocarditis definitiva son incluidos en la base de datos. Para cada paciente evaluado se realiza una historia clínica detallada, una exploración física general y específica para buscar estigmas de la endocarditis, una analítica sanguínea con al menos sistemático y bioquímica, una radiografía de tórax y un electrocardiograma de 12 derivaciones. Además se recogen al menos 3 hemocultivos separados durante media hora en tres sitios de punción diferente, y se realiza al menos un ecocardiograma transtorácico y transesofágico. Otras pruebas realizadas en el proceso diagnóstico también se recogen, así como el tratamiento antibiótico utilizado, la indicación y técnica quirúrgica utilizada, y la evolución clínica hospitalaria de la enfermedad.

Se recogen las siguientes variables:

- Variables demográficas: sexo, edad, origen de la endocarditis (comunitaria, nosocomial, comunitaria asociada a cuidados sanitarios), presencia y tipo de cardiopatía previa, (reumática, prótesis, degenerativa, endocarditis previa), presencia y tipo de enfermedad predisponente (alcoholismo, tratamiento inmunosupresor, anemia crónica, insuficiencia renal crónica, inmunodepresión, diabetes mellitus, cáncer, enfermedad pulmonar obstructiva crónica, colagenopatías, adicción a drogas por vía parenteral, positividad para el virus de la inmunodeficiencia humana - VIH) y presencia y tipo de factor desencadenante (no conocido, manipulación dental, manipulación gastrointestinal, manipulación genitourinaria, catéteres vasculares, infección local, cirugía cardiaca previa).

- Variables clínicas al ingreso y durante la evolución: Inicio agudo de los síntomas, insuficiencia cardiaca, fiebre, insuficiencia renal, shock séptico, manifestaciones cutáneas (pigmentación café con leche, nódulos cutáneos de Osler, lesiones de 
Janeway, lesiones necróticas, lesiones hemorrágicas) accidente cerebrovascular (isquémico, hemorrágico), embolismos sistémicos o pulmonares y muerte hospitalaria ( $\mathrm{si} / \mathrm{no}$, fecha y causa).

- Variables radiológicas: Cardiomegalia, insuficiencia cardiaca izquierda, derrame pleural.

- Variables electrocardiográficas: Bloqueo auriculo-ventricular, bloqueo de rama derecha, bloqueo de rama izquierda, infarto agudo de miocardio, taquicardia supraventricular, fibrilación auricular.

- Variables analíticas: Leucocitos, hemoglobina, hematocrito, plaquetas, velocidad de sedimentación globular, urea, creatinina , GOT, GPT, LDH, sodio, potasio, proteinuria, hematuria.

- Variables ecocardiográficas: localización de la infección (aórtica nativa, mitral nativa, tricúspide nativa, pulmonar nativa, aórtica protésica mecánica, mitral protésica mecánica, tricúspide protésica mecánica, pulmonar protésica mecánica, aórtica protésica biológica, mitral protésica biológica, tricúspide protésica biológica, pulmonar protésica biológica, dispositivo cardiaco implantado), complicación perivalvular (absceso, pseudoaneurisma, fístula), presencia de vegetación, diámetro mayor de la vegetación, diámetro menor de la vegetación, área de la vegetación, perforación, rotura, estenosis, insuficiencia valvular y grado, fracción de eyección del ventrículo izquierdo y datos de hipertensión pulmonar.

- Variables microbiológicas: número y resultado de los hemocultivos, microorganismo causal (Estreptococo bovis, Estreptococo viridans, Enterococo, otros Estreptococos, Estafilococo aureus, Estafilococo coagulasa negativo, bacilos Gram negativos, hongos, otros microorganismos, cultivos negativos), antibiograma, serologías y otros cultivos.

- Variables de tratamiento: antibióticos utilizados, fecha de inicio y fecha de fin de cada antibiótico. Tratamiento antibiótico correcto. Cirugía cardiaca realizada y tipo (urgente/electiva), indicación de cirugía, tipo de intervención realizada, riesgo quirúrgico (Euroscore I y II) y cirugía indicada no realizada. 
Con la ficha estandarizada recogida para cada caso podemos evaluar las variables pronósticas propuestas por la guía europea sobre Endocarditis Infecciosa del año 2015, con algunas adaptaciones que se presentan en la sección de definición de variables.

Las variables propuestas por la guía son las siguientes:

- Características del paciente: edad, diabetes mellitus, endocarditis protésica y comorbilidades.

- Complicaciones clínicas: insuficiencia cardiaca, insuficiencia renal, ictus isquémico, hemorragia cerebral y shock séptico.

- Tipo de microorganismo causal: Estafilococo aureus, hongos y bacilos Gram negativos no-HACEK.

- Hallazgos ecocardiográficos: vegetación de gran tamaño, complicación perianular, fracción de eyección del ventrículo izquierdo deprimida, disfunción valvular o protésica severa, hipertensión pulmonar y el cierre prematuro mitral o signos de elevación de presiones diastólicas. 


\subsection{DEFINICIÓN DE VARIABLES}

La definición de cada factor pronóstico utilizado en la elaboración del modelo predictivo de mortalidad hospitalaria en endocarditis infecciosa izquierda se recoge en la tabla 3. Incluimos las variables pronósticas propuestas por la guía Europea de endocarditis infecciosa.

Tabla 3. Definición de cada factor pronóstico utilizado en el modelo de predicción de muerte hospitalaria en endocarditis infecciosa izquierda.

\begin{tabular}{|c|c|}
\hline Factor pronóstico & Definición \\
\hline \multicolumn{2}{|c|}{ Características del paciente } \\
\hline Edad & Edad al inicio del episodio en años. \\
\hline Endocarditis protésica & $\begin{array}{l}\text { Evidencia por técnicas de imagen de afectación de material } \\
\text { protésico. }\end{array}$ \\
\hline Diabetes mellitus & $\begin{array}{l}\text { Paciente con diagnóstico preestablecido de diabetes mellitus de } \\
\text { acuerdo a los criterios ADA* y que se encuentra bajo control } \\
\text { dietético, tratamiento antidiabético oral o insulinoterapia. }\end{array}$ \\
\hline Comorbilidad & $\begin{array}{l}\text { Al menos una de las siguientes situaciones: insuficiencia renal } \\
\text { crónica (definida por un aclaramiento de creatinina inferior a } \\
60 \mathrm{ml} / \mathrm{min} \text { ), inmunodepresión o enfermedad pulmonar } \\
\text { obstructiva crónica. }\end{array}$ \\
\hline
\end{tabular}

ADA: asociación americana de diabetes 


\begin{tabular}{|l|l|}
\hline Factor pronóstico & Definición \\
\hline Complicaciones clínicas \\
\hline Insuficiencia cardiaca & $\begin{array}{l}\text { Signos y síntomas de acuerdo con los criterios de Framingham para } \\
\text { el diagnóstico de insuficiencia cardiaca. } \\
\text { El hallazgo ecocardiográfico de cierre prematuro mitral o signos de } \\
\text { elevación de presiones diastólicas se ha considerado un subrogante } \\
\text { de insuficiencia cardiaca clínica. }\end{array}$ \\
\hline Insuficiencia renal & $\begin{array}{l}\text { Incremento del nivel sérico de creatinina de al menos 0,3 mg/dL } \\
\text { desde el nivel basal en } 48 \text { horas, o incremento mayor o igual a 1,5 } \\
\text { veces el basal en 7 días con o sin disminución de diuresis asociada. }\end{array}$ \\
\hline Ictus isquémico & $\begin{array}{l}\text { Déficit neurológico con evidencia de un área moderada de necrosis } \\
\text { por técnica de imagen (tomografía axial computerizada multicorte o } \\
\text { resonancia magnética). }\end{array}$ \\
\hline Hemorragia cerebral & $\begin{array}{l}\text { Déficit neurológico con evidencia de hemorragia cerebral en } \\
\text { técnicas de imagen (tomografía axial computerizada multicorte o } \\
\text { resonancia magnética). }\end{array}$ \\
\hline Shock séptico & $\begin{array}{l}\text { Fallo circulatorio agudo en situación de sepsis con hipotensión } \\
\text { arterial persistente (presión arterial sistólica menor a 90 mmHg o } \\
\text { presión arterial media menor a } 65 \text { mmHg) que precisa vasopresores } \\
\text { a pesar de fluidoterapia o en presencia de incremento del lactato } \\
\text { sérico por encima de } 2 \text { mmol/L. }\end{array}$ \\
\hline &
\end{tabular}

\section{Tipo de microorganismo}

\begin{tabular}{|l|l|}
\hline Estafilococo aureus & $\begin{array}{l}\text { Aislamiento de Estafilococo aureus en al menos } 2 \text { muestras } \\
\text { separadas de hemocultivos. }\end{array}$ \\
\hline Hongos & $\begin{array}{l}\text { Aislamiento del mismo hongo en al menos } 3 \text { muestras separadas de } \\
\text { hemocultivos. }\end{array}$ \\
\hline Balcilos Gram & $\begin{array}{l}\text { Aislamiento del mismo bacilo Gram negativo No-HACEK en al } \\
\text { negativos No-HACEK} 3 \text { muestras separadas de hemocultivos. }\end{array}$ \\
\hline
\end{tabular}




\begin{tabular}{|c|c|}
\hline Factor pronóstico & Definición \\
\hline \multicolumn{2}{|c|}{ Hallazgos en pruebas de imagen } \\
\hline $\begin{array}{l}\text { Complicación } \\
\text { perianular }\end{array}$ & $\begin{array}{l}\text { Presencia de absceso, pseudoaneurisma o fístula. } \\
\text { - Absceso: cavidad perivalvular con necrosis y material purulento en } \\
\text { su interior sin comunicación con la luz cardiovascular. } \\
\text { Ecográficamente se observa engrosamiento de la región perianular } \\
\text { con o sin ecolucencias en su interior y ausencia de flujo en su } \\
\text { interior. } \\
\text { - Pseudoaneurisma: cavidad perivalvular comunicando con la luz } \\
\text { cardiovascular. } \\
\text { - Fístula: comunicación entre dos cavidades vecinas a través de una } \\
\text { perforación. }\end{array}$ \\
\hline $\begin{array}{l}\text { Disfunción valvular o } \\
\text { protésica izquierda } \\
\text { severa }\end{array}$ & $\begin{array}{l}\text { Insuficiencia valvular o dehiscencia protésica aórtica y/o mitral } \\
\text { severas de acuerdo con los criterios de la guía europea de } \\
\text { enfermedad valvular cardiaca. }\end{array}$ \\
\hline $\begin{array}{l}\text { Disfunción ventricular } \\
\text { izquierda }\end{array}$ & $\begin{array}{l}\text { Fracción de eyección del ventrículo izquierdo definida por } \\
\text { ecocardiograma transtorácico menor del } 45 \%\end{array}$ \\
\hline $\begin{array}{l}\text { Hipertensión } \\
\text { pulmonar }\end{array}$ & $\begin{array}{l}\text { Elevación de la presión pulmonar arterial media por encima de } 25 \\
\mathrm{mmHg} \text { en un cateterismo cardiaco derecho o el cálculo } \\
\text { ecocardiográfico de una presión sistólica de arteria pulmonar mayor } \\
\text { a } 60 \mathrm{mmHg} \text {, o un valor menor en presencia de signos indirectos de } \\
\text { sobrecarga de ventrículo derecho. }\end{array}$ \\
\hline Vegetación & $\begin{array}{l}\text { Masa intracardiaca móvil o fija sobre el endocardio valvular o sobre } \\
\text { otra estructura cardiaca o material intracardiaco protésico, con } \\
\text { ecogenicidad diferente a la de las estructuras adyacentes y con un } \\
\text { movimiento errático e independiente de la válvula. }\end{array}$ \\
\hline
\end{tabular}


Además, en los anexos I-III definimos los criterios diagnósticos de endocarditis infecciosa y en el anexo IV recogemos las definiciones de cada variable recogida por el grupo ENDOVAL durante el diagnóstico, tratamiento y seguimiento de cada paciente con endocarditis infecciosa incluido en la base de datos multipropósito y que han sido utilizadas en la elaboración de la presente tesis doctoral.

\subsection{ANALISIS ESTADISTICO}

Se trata de un estudio de cohortes prospectivo. Utilizamos dos poblaciones de pacientes con endocarditis infecciosa izquierda reclutados de forma prospectiva con análisis retrospectivo de los datos.

Realizamos un análisis descriptivo y comparativo de las principales características de las poblaciones con endocarditis infecciosa izquierda. Las variables categóricas se han expresado como valor absoluto y porcentaje, y las variables continuas como media $[ \pm]$ desviación estándar, y/o mediana y rango intercuartílico en caso de no normalidad. La asunción de normalidad en las variables cuantitativas se ha comprobado mediante el test de Kolmogorov-Smirnov y visualmente mediante gráficos Q-Q plot. La comparación de variables cualitativas se ha realizado mediante el test de chi cuadrado y el test exacto de Fisher (cuando la frecuencia esperada fuera menor de 5) y la comparación de variables continuas con el test $\mathrm{T}$ de Student o su equivalente no paramétrico para variables con distribución no normal, el test U de Mann-Whitney.

Posteriormente construimos y validamos un modelo predictivo de mortalidad hospitalaria utilizando las variables pronósticas propuestas por la guía europea de manejo de la endocarditis infecciosa. Para ello seguimos los siguientes pasos:

1. Aleatorización de una población de endocarditis infecciosa izquierda en proporción 2:1. Se obtienen dos muestras: dos tercios de la población conforman la muestra de derivación o ajuste, para elaborar el modelo predictivo, y un tercio, la muestra de validación, para realizar la validación interna del mismo. 
2. Derivación del modelo en la muestra de ajuste. Realizamos un análisis multivariado de mortalidad intrahospitalaria en la muestra de ajuste incluyendo las variables pronósticas propuestas por la guía de la Sociedad Europea de Cardiología para el manejo de la endocarditis infecciosa.

El análisis multivariado se realiza por medio de una regresión logística con el método de máxima verosimilitud, calculando las odds ratio (OR) ajustadas para cada variable incluida y sus intervalos de confianza. No se ha tenido en cuenta el principio de parsimonia, que opta por el modelo más sencillo, puesto que el modelo incluye todas las variables de las guías, pero si se ha controlado que por cada variable hubiera 10 eventos, evitando así la sobresaturación del modelo. La capacidad discriminativa se evalúa mediante el área bajo la curva ROC ("Receiver Operating Charactristic") y la calibración con el test de Hosmer-Lemeshow. Un valor de 0.5 indica ausencia de capacidad discriminativa, mientras que un valor de 1 indica discriminación perfecta.

3. Validación del modelo predictivo. Se aplica el modelo sobre la muestra de validación resservada de la aleatorización de la población inicial, y sobre la segunda población de endocarditis. La capacidad discriminativa se evalúa de nuevo mediante el área bajo la curva ROC y se calcula la mortalidad intrahospitalaria media esperada con un intervalo de confianza al 95\%.

Finalmente, para valorar el impacto de la cirugía cardiaca en la mortalidad hospitalaria de la endocarditis infecciosa izquierda se repite la construcción del modelo predictivo incluyendo la variable cirugía cardiaca junto con las variables pronósticas propuestas por la guía europea de manejo de la enfermedad.

Todos los datos han sido analizados en el paquete estadístico IBM SPSS Statistics versión 24 (Armonk, NY: IBM Corp.). Los p valores son bilaterales y se ha considerado estadísticamente significativo un valor de $\mathrm{p}<0.05$. 


\subsection{DISEÑO DE LA APLICACIÓN INFORMÁTICA}

Para diseñar la aplicación móvil (APP) hemos optado por desarrollar una APP híbrida, con lenguajes propios de la web, HTML, Javascript y CSS, lo que nos permite su uso en diferentes plataformas y además, la posibilidad de acceder a las funcionalidades del teléfono gracias a la instalación de plugins; aprovechando así mucho mejor el potencial que ofrecen los dispositivos móviles actualmente.

Como entorno de desarrollo para la programación de la aplicación hemos utilizado Phonegap. El núcleo de este "framework" es un código totalmente abierto, bajo el proyecto Apache Cordova, y la interface de usuario para las aplicaciones se crea mediante HTML, CSS y JavaScript.

Primero construimos la aplicación usando estándares Web como HTML, HTML 5, CSS, CSS3 o JavaScript, y posteriormente combinamos la aplicación Web con PhoneGap para acceder a las características nativas de los dispositivos móviles. Adjuntando un archivo. Zip con nuestro proyecto, PhoneGap compila la app y la devuelve en un fichero ejecutable diferente para cada sistema operativo. En nuestro caso, para Android, el fichero ejecutable tendrá una extensión .APK.

Como la aplicación se ha programado usando estándares web, esto nos permite adaptarla fácilmente a una página web, pudiendo usar esta calculadora desde cualquier sistema que disponga de internet, como son ordenadores, tabletas, móviles, Smart-tv, etc.. Actualmente la dirección web es la siguiente: https://endovalscore.000webhostapp.com/ 


\subsection{CARACTERÍSTICAS PRINCIPALES DE LA POBLACIÓN DE ENDOCARDITIS INFECCIOSA IZQUIERDA DEL GRUPO ENDOVAL}

En el anexo IV se resumen las principales características de la población de 1002 episodios de endocarditis infecciosa izquierda del grupo ENDOVAL.

Destaca una edad media de $65.1 \pm 14.3$ años, con un $67 \%$ de hombres. El origen más frecuente es comunitario (68\%) con un $25 \%$ de endocarditis de origen nosocomial y un 7\% de endocarditis asociada a cuidados sanitarios. Un $49 \%$ de los episodios de endocarditis infecciosa son referidos desde otros centros. Un $83 \%$ de los pacientes presentan cardiopatía de base en la válvula afectada por la endocarditis infecciosa. La condición más frecuente es la presencia de prótesis valvular (40\%), seguida de la valvulopatía degenerativa (19\%) y la reumática (9\%). En un 50\% de los pacientes se identifica un teórico factor desencadenante con capacidad de producir bacteriemia. La presencia de catéteres intravasculares (13\%) y la infección local (11\%) son las situaciones más frecuentes.

El perfil de paciente con endocarditis infecciosa presenta enfermedad subyacente en un 59\% de los casos, con un índice de Charlson medio de $4.2 \pm 5.9$. Entre las comorbilidades más importantes destacan la diabetes mellitus (26\%), la anemia crónica $(22 \%)$ y la insuficiencia renal crónica (15\%), con una baja tasa de pacientes adictos a drogas por vía parenteral (2\%) o VIH (1\%).

Clínicamente la población de endocarditis infecciosa izquierda del grupo ENDOVAL muestra un perfil de alto riesgo. El 49\% presentan un inicio agudo, con menos de 15 días desde el inicio de la clínica al diagnóstico, y el 81\% fiebre. La tasa de complicaciones clínicas son altas: insuficiencia cardiaca (57\%), insuficiencia renal (41\%), shock séptico (16\%), ictus isquémico (18\%) y hemorragia cerebral (7\%). En la población de endocarditis infecciosa izquierda del grupo ENDOVAL la mortalidad hospitalaria es del $30 \%$. 
El microorganismo más frecuente es el Estafilococo aureus (21\%) seguido de los Estafilococos coagulasa negativos (17\%), los Estreptococos del grupo viridans (16\%) y los Enterococos (13\%). Destacamos un 12\% de episodios de endocarditis con cultivos negativos y un $30 \%$ de los pacientes presentan hemocultivos persistentemente positivos tras 48-72 horas del inicio de tratamiento antibiótico.

En el ecocardiograma un $87 \%$ de los pacientes muestran vegetaciones, mientras que la complicación perianular aparece en un 30\%: absceso (18\%), pseudoaneurisma $(17 \%)$ y fístula (3\%). La disfunción ventricular está presente en un $8 \%$ de pacientes, mientras que la hipertensión pulmonar y la disfunción valvular o protésica severa son más frecuentes (14\% y 62\%, respectivamente). La afectación más frecuente es en las válvulas mitral (38\%) y aórtica (36\%) nativas, seguido de las prótesis mecánicas mitral (19\%) y aórtica (12\%). Es poco frecuente la afectación sobre prótesis mitral biológica (2\%) y la afectación derecha concomitante (2\%). Un 22\% de los episodios muestran afectación multivalvular.

El tratamiento quirúrgico se realiza en un $61 \%$ de los pacientes, con un $60 \%$ de cirugías realizadas bajo tratamiento antibiótico y un 40\% de forma electiva. La indicación quirúrgica más frecuente es la insuficiencia cardiaca (72\%), seguida de la infección no controlada $(56 \%)$ y la prevención de embolias (23\%). El 29\% de pacientes $(n=288)$ presentan más de una indicación quirúrgica. El riesgo quirúrgico definido por Euroscore logístico es de 31\% [rango intercuartílico: 9-50] y por Euroscore II de 12\% [rango intercuartílico: 5-21]. El tratamiento antibiótico presenta una duración media de 5 semanas [rango intercuartílico: 3-7], y la tasa de tratamiento antibiótico correcto es del $95 \%$. 


\subsection{CARACTERÍSTICAS PRINCIPALES DE LA POBLACIÓN DE ENDOCARDITIS INFECCIOSA IZQUIERDA DEL HOSPITAL UNIVERSITARIO PUERTA DE HIERRO}

La población de endocarditis infecciosa izquierda del Hospital Universitario Puerta de Hierro se ha utilizado para la validación externa del modelo pronóstico. Presentamos las principales características de esta población, y realizamos una comparación con las características de la población del grupo ENDOVAL (Tablas 4-8).

El perfil epidemiológico se resume en la tabla 4. No existen diferencias significativas en la edad media y el género de ambas poblaciones, así como tampoco en el origen nosocomial de la endocarditis. Sí que existen diferencias significativas en la cardiopatía de base, más frecuente en el grupo ENDOVAL ( $83 \%$ vs 65\%, p <0.001) y con un perfil diferente, más frecuencia de valvulopatía degenerativa ( $19 \%$ vs $11 \%, \mathrm{p}=0.024)$ y reumática $(9 \%$ vs $4 \%, \mathrm{p}=0.045)$. No hay diferencias significativas en la tasa de endocarditis protésica ( $40 \%$ vs $47 \%, \mathrm{p}=0.165$ ). Los pacientes del Hospital Universitario Puerta de Hierro presentan mayor comorbilidad definida de acuerdo a la variable pronostica de la guía europea ( $44 \%$ vs $26 \%$, p $<0.001$ ), con mayor tasa de enfermedad pulmonar obstructiva crónica $(18 \%$ vs $8 \%, \mathrm{p}<0.001)$, pero sin diferencias en insuficiencia renal crónica ( $20 \%$ vs $15 \%, \mathrm{p}=0.152)$ o en diabetes mellitus ( $26 \%$ vs $26 \%, \mathrm{p}=0.849)$.

Clínicamente el perfil de ambas poblaciones es similar (tabla 5) si bien la población del Hospital Universitario Puerta de Hierro presenta con más frecuencia inicio agudo (71\% vs 49\%, p<0.001) mientras que la población del grupo ENDOVAL presenta más insuficiencia cardiaca ( $57 \%$ vs $45 \%, \mathrm{p}=0.010)$. No hay diferencias en el resto de complicaciones clínicas, ni en la mortalidad hospitalaria.

La microbiología de ambas poblaciones es bastante similar (tabla 6), salvo por la presencia de más frecuencia de endocarditis con hemocultivos negativos (22\% vs $12 \%$, $\mathrm{p}=0.001)$, y menor frecuencia de Estreptococos del grupo viridans ( $7 \%$ vs $16 \%, \mathrm{p}=0.005)$ en la población del Hospital Universitario Puerta de Hierro. No hay diferencias estadísticamente significativas en la frecuencia del resto de microorganismos. 
Tabla 4. Análisis comparativo de los datos epidemiológicos entre las poblaciones de endocarditis infecciosa izquierda del grupo ENDOVAL y del Hospital Universitario Puerta de Hierro.

\begin{tabular}{|c|c|c|c|}
\hline \multicolumn{1}{|c|}{$n(\%)$} & $\begin{array}{c}\text { Población ENDOVAL } \\
(\mathbf{n = 1 0 0 2})\end{array}$ & $\begin{array}{c}\text { Población HUPH } \\
(\mathbf{n = 1 3 3 )}\end{array}$ & P-valor \\
\hline Datos epidemiológicos & & & \\
\hline Edad, media $\pm \mathrm{DE}$ & $65.1 \pm 14.3$ & $65.8 \pm 13.4$ & 0.589 \\
\hline Hombre & $666(67)$ & $82(62)$ & 0.271 \\
\hline Origen nosocomial & $253(25)$ & $38(30)$ & 0.307 \\
\hline Cardiopatía de base & $168(17)$ & $46(35)$ & $<\mathbf{0 . 0 0 1}$ \\
\hline Ninguna & $193(19)$ & $15(11)$ & $\mathbf{0 . 0 2 4}$ \\
\hline Degenerativa & $404(40)$ & $62(47)$ & 0.165 \\
\hline Prótesis & $91(9)$ & $5(4)$ & $\mathbf{0 . 0 4 5}$ \\
\hline Reumática & $259(26)$ & $59(44)$ & $<\mathbf{0 . 0 0 1}$ \\
\hline Comorbilidad* & $148(15)$ & $17(13)$ & 0.538 \\
\hline Insuficiencia renal crónica & $84(8)$ & $24(18)$ & $<\mathbf{0 . 0 0 1}$ \\
\hline EPOC & $61(6)$ & $33(25)$ & $<\mathbf{0 . 0 0 1}$ \\
\hline Inmunodepresión & $256(26)$ & $35(26)$ & 0.849 \\
\hline Diabetes mellitus & & & \\
\hline DE: & & & \\
\hline
\end{tabular}

DE: desviación estándar. EPOC: enfermedad pulmonar obstructiva crónica

*Comorbilidad: definida de acuerdo a la guía europea de manejo de la endocarditis infecciosa y que incluye la presencia de insuficiencia renal crónica, EPOC o inmunodepresión. 
Tabla 5. Análisis comparativo de la evolución clínica entre las poblaciones de endocarditis infecciosa izquierda del grupo ENDOVAL y del Hospital Universitario Puerta de Hierro.

\begin{tabular}{|l|c|c|c|}
\hline \multicolumn{1}{|c|}{ n (\%) } & $\begin{array}{c}\text { Población ENDOVAL } \\
(\mathbf{n = 1 0 0 2})\end{array}$ & $\begin{array}{c}\text { Población HUPH } \\
(\mathbf{n = 1 3 3 )}\end{array}$ & P-valor \\
\hline Evolución clínica & $490(49)$ & $86(71)$ & $<\mathbf{0 . 0 0 1}$ \\
\hline $\begin{array}{l}\text { Inicio agudo } \\
\text { (menos de 15 días) }\end{array}$ & $811(81)$ & $102(77)$ & 0.246 \\
\hline Fiebre & $571(57)$ & $60(45)$ & $\mathbf{0 . 0 1 0}$ \\
\hline Insuficiencia cardiaca & $415(41)$ & $62(47)$ & 0.254 \\
\hline Insuficiencia renal & $158(16)$ & $15(11)$ & 0.176 \\
\hline Shock séptico & $180(18)$ & $32(24)$ & 0.090 \\
\hline Ictus isquémico & $67(7)$ & $4(3)$ & 0.100 \\
\hline Hemorragia cerebral & $301(30)$ & $36(27)$ & 0.481 \\
\hline Muerte hospitalaria & & & \\
\hline
\end{tabular}

En los hallazgos ecocardiográficos también existen algunas diferencias significativas entre grupos (Tabla 7). La población del grupo ENDOVAL presenta con mayor frecuencia vegetaciones $(87 \%$ vs $65 \%, \mathrm{p}<0.001)$, disfunción valvular o protésica severa $(62 \%$ vs $27 \%, \mathrm{p}<0.001)$ e hipertensión pulmonar $(14 \%$ vs $6 \%, \mathrm{p}=0.014)$. No hay diferencias en la tasa de complicación perianular ni en la disfunción ventricular. La localización de la endocarditis infecciosa es similar entre grupos, si bien la población del grupo ENDOVAL presenta con más frecuencia afectación multivalvular (22\% vs $11 \%$, $\mathrm{p}=0.006)$, y mayor afectación sobre válvula aórtica nativa ( $36 \%$ vs $25 \%, \mathrm{p}=0.027$ ).

La tasa de cirugía cardiaca es similar entre ambos grupos, aunque las indicaciones quirúrgica son diferentes (Tabla 8); más frecuentes la indicación por insuficiencia cardiaca $(72 \%$ vs $47 \%, \mathrm{p}<0.001)$ y la prevención de embolias $(23 \%$ vs $10 \%)$ entre los pacientes del grupo ENDOVAL. 
Tabla 6. Análisis comparativo de la microbiología entre las poblaciones de endocarditis infecciosa izquierda del grupo ENDOVAL y del Hospital Universitario Puerta de Hierro.

\begin{tabular}{|c|c|c|c|}
\hline $\mathrm{n}(\%)$ & $\begin{array}{l}\text { Población ENDOVAL } \\
\qquad(\mathrm{n}=\mathbf{1 0 0 2})\end{array}$ & $\begin{array}{c}\text { Población HUPH } \\
\qquad(\mathrm{n}=133)\end{array}$ & P-valor \\
\hline \multicolumn{4}{|l|}{ Microbiología } \\
\hline Hemocultivos positivos & $884(88)$ & $104(78)$ & 0.001 \\
\hline Estreptococos spp & $272(27)$ & $26(20)$ & 0.074 \\
\hline Estreptococo bovis & $55(6)$ & $8(6)$ & 0.803 \\
\hline $\begin{array}{l}\text { Estreptococo grupo } \\
\text { viridans }\end{array}$ & $159(16)$ & $9(7)$ & 0.005 \\
\hline Otros estreptococos & $58(6)$ & $9(7)$ & 0.653 \\
\hline Enterococos spp & $130(13)$ & $16(12)$ & 0.760 \\
\hline Estafilococos spp & $382(38)$ & $49(37)$ & 0.849 \\
\hline Estafilococo aureus & $210(21)$ & $23(17)$ & 0.326 \\
\hline $\begin{array}{l}\text { Estafilococo coagulasa- } \\
\text { negativo }\end{array}$ & $172(17)$ & $26(20)$ & 0.496 \\
\hline $\begin{array}{l}\text { Bacilos Gram negativos } \\
\text { no-HACEK }\end{array}$ & $48(5)$ & $4(3)$ & 0.355 \\
\hline Hongos & $16(2)$ & $2(2)$ & 0.999 \\
\hline Grupo HACEK & $7(1)$ & $0(0)$ & 0.999 \\
\hline Anaerobios & $32(3)$ & $3(2)$ & 0.790 \\
\hline Polimicrobiana & $49(5)$ & $0(0)$ & 0.009 \\
\hline Otros microorganismos & $41(4)$ & $3(2)$ & 0.303 \\
\hline Hemocultivos negativos & $118(12)$ & $29(22)$ & 0.001 \\
\hline
\end{tabular}


Tabla 7. Análisis comparativo de los hallazgos de las pruebas de imagen entre las poblaciones de endocarditis infecciosa izquierda del grupo ENDOVAL y del Hospital Universitario Puerta de Hierro.

\begin{tabular}{|c|c|c|c|}
\hline $\mathrm{n}(\%)$ & $\begin{array}{l}\text { Población ENDOVAL } \\
\qquad(\mathrm{n}=\mathbf{1 0 0 2})\end{array}$ & $\begin{array}{c}\text { Población HUPH } \\
\qquad(n=133)\end{array}$ & P-valor \\
\hline \multicolumn{4}{|c|}{ Hallazgos en pruebas de imagen } \\
\hline Vegetaciones & $870(87)$ & $87(65)$ & $<0.001$ \\
\hline Complicación perianular & $302(30)$ & $47(35)$ & 0.222 \\
\hline Absceso & $184(18)$ & $25(19)$ & 0.905 \\
\hline Pseudoaneurisma & $165(17)$ & $18(14)$ & 0.452 \\
\hline Fístula & $34(3)$ & $2(2)$ & 0.424 \\
\hline Insuficiencia valvular severa & $619(62)$ & $36(27)$ & $<0.001$ \\
\hline FEVI $<45 \%$ & $78(8)$ & $10(7)$ & 0.914 \\
\hline Hipertensión pulmonar & $136(14)$ & $8(6)$ & 0.014 \\
\hline \multicolumn{4}{|l|}{ Localización } \\
\hline Válvula aórtica nativa & $359(36)$ & $26(25)$ & 0.027 \\
\hline Válvula mitral nativa & $381(38)$ & $36(35)$ & 0.495 \\
\hline Prótesis aórtica mecánica & $118(12)$ & $19(18)$ & 0.056 \\
\hline Prótesis mitral mecánica & $192(19)$ & $17(16)$ & 0.485 \\
\hline Prótesis aórtica biológica & $108(11)$ & $13(13)$ & 0.592 \\
\hline Prótesis mitral biológica & $21(2)$ & $0(0)$ & 0.250 \\
\hline Afectación derecha & $23(2)$ & $2(2)$ & 0.759 \\
\hline Multivalvular & $215(22)$ & $15(11)$ & 0.006 \\
\hline
\end{tabular}


Tabla 8. Análisis comparativo del tratamiento entre las poblaciones de endocarditis infecciosa izquierda del grupo ENDOVAL y del Hospital Universitario Puerta de Hierro.

\begin{tabular}{|c|c|c|c|}
\hline $\mathrm{n}(\%)$ & $\begin{array}{c}\text { Población ENDOVAL } \\
(n=1002)\end{array}$ & $\begin{array}{c}\text { Población HUPH } \\
\qquad(n=133)\end{array}$ & P-valor \\
\hline \multicolumn{4}{|l|}{ Tratamiento } \\
\hline Cirugía cardiaca & $614(61)$ & $72(54)$ & 0.113 \\
\hline Urgente & $367(60)$ & $71(99)$ & \multirow{2}{*}{$<0.001$} \\
\hline Electiva & $247(40)$ & $1(1)$ & \\
\hline \multicolumn{4}{|l|}{ Indicaciones } \\
\hline Insuficiencia cardiaca & $428(72)$ & $27(47)$ & $<0.001$ \\
\hline Infección no controlada & $335(56)$ & $38(66)$ & 0.180 \\
\hline Prevención de embolias & $139(23)$ & $6(10)$ & 0.022 \\
\hline \multicolumn{4}{|l|}{ Tratamiento antibiótico } \\
\hline $\begin{array}{l}\text { Tratamiento antibiótico } \\
\text { correcto }\end{array}$ & $879(95)$ & $123(93)$ & 0.220 \\
\hline $\begin{array}{l}\text { Semanas tratamiento } \\
\text { antibiótico, mediana [RIQ] }\end{array}$ & $5[3.3-6.6]$ & $5.4[4-6.1]$ & 0.784 \\
\hline
\end{tabular}

DE: desviación estándar. RIQ: rango intercuartílico. 


\subsection{ALEATORIZACIÓN Y ANÁLISIS COMPARATIVO DE LAS MUESTRAS DE AJUSTE Y DERIVACIÓN DEL MODELO PRONÓSTICO.}

Por medio de una aleatorización 2:1 de la población con endocarditis infecciosa izquierda del grupo ENDOVAL obtenemos dos muestras: una muestra de ajuste para la construcción del modelo pronóstico $(n=688)$, y una muestra de validación para la validación interna del mismo $(\mathrm{n}=314)$.

Las características generales de ambas muestras se comparan en las tablas 9-13, y la comparativa de las variables pronósticas propuestas por la guía Europea de Endocarditis Infecciosa del año 2015 se especifican en la tabla 14.

Epidemiológicamente ambas muestras son prácticamente idénticas (Tabla 9), salvo por una mayor frecuencia de la valvulopatía degenerativa en la muestra de validación interna $(24 \%$ vs $17 \%, \mathrm{p}=0.020)$, y una mayor frecuencia de antecedente de manipulación genito-urinaria en la muestra de ajuste ( $4 \%$ vs $2 \%, \mathrm{p}=0.051)$. Clínicamente no existen diferencias entre ambas muestras (Tabla 10). Desde el punto de vista microbiológico (Tabla 11), destaca una mayor persistencia de hemocultivos positivos a las 48/72 horas en la muestra de ajuste ( $33 \%$ vs $23 \%, \mathrm{p}=0.025)$, y una mayor frecuencia de endocarditis polimicrobiana en la muestra de validación ( $8 \%$ vs $4 \%, \mathrm{p}=0.002)$, sin diferencias en la frecuencia del resto de microorganismos. Tampoco existen diferencias en la mayoría de hallazgos ecocardiográficos (Tabla 12), salvo una mayor afectación concomitante del lado derecho en la muestra de validación (4\% vs 2\%, p=0.021). Finalmente, respecto al tratamiento (Tabla 13), señalar que aunque la tasa de pacientes intervenidos es mayor en la muestra de validación, la diferencia no es estadísticamente significativa $(66 \%$ vs $59 \%, \mathrm{p}=0.057)$. Tampoco existen diferencias en las indicaciones quirúrgicas, el riesgo quirúrgico evaluado por Euroscore, las semanas de tratamiento antibiótico y la tasa de tratamiento antibiótico correcto.

No existe ninguna diferencia estadísticamente significativa entre ambas muestras respecto a las variables específicas que conforman el modelo pronóstico utilizado para elaborar la calculadora de mortalidad (Tabla 14). 
Tabla 9. Análisis comparativo de los datos epidemiológicos entre la muestra de ajuste y la muestra de validación interna.

\begin{tabular}{|c|c|c|c|c|}
\hline $\mathrm{n}(\%)$ & $\begin{array}{c}\text { Población } \\
\text { ENDOVAL } \\
(n=1002)\end{array}$ & $\begin{array}{c}\text { Muestra de } \\
\text { ajuste } \\
(n=688)\end{array}$ & $\begin{array}{c}\text { Muestra de } \\
\text { validación } \\
\text { interna }(n=314)\end{array}$ & P-valor \\
\hline \multicolumn{5}{|l|}{ Datos epidemiológicos } \\
\hline Edad, media \pm DE & $65.1 \pm 14.3$ & $64.7 \pm 14.5$ & $66.1 \pm 14$ & 0.154 \\
\hline Hombre & $666(67)$ & $461(67)$ & $205(65)$ & 0.593 \\
\hline Origen nosocomial & $253(25)$ & $181(26)$ & $72(23)$ & 0.248 \\
\hline \multicolumn{5}{|l|}{ Cardiopatía de base } \\
\hline Ninguna & $168(17)$ & $115(17)$ & $53(17)$ & 0.949 \\
\hline Degenerativa & $193(19)$ & $119(17)$ & $74(24)$ & 0.020 \\
\hline Prótesis & $404(40)$ & $278(40)$ & $126(40)$ & 0.933 \\
\hline Reumática & $91(9)$ & $67(10)$ & $24(8)$ & 0.284 \\
\hline \multicolumn{5}{|l|}{ Factor desencadenante } \\
\hline No conocido & $499(50)$ & $339(49)$ & $160(51)$ & 0.621 \\
\hline Manipulación genitourinaria & $32(3)$ & $27(4)$ & $5(2)$ & 0.051 \\
\hline Cateter intravascular & $131(13)$ & $96(14)$ & $35(11)$ & 0.221 \\
\hline Cirugía previa no cardiaca & $50(5)$ & $38(6)$ & $12(4)$ & 0.251 \\
\hline Infección local & $112(11)$ & $81(12)$ & $31(10)$ & 0.376 \\
\hline ADVP & $18(2)$ & $14(2)$ & $4(1)$ & 0.403 \\
\hline VIH & $13(1)$ & $10(2)$ & $3(1)$ & 0.764 \\
\hline Enfermedad subyacente & $587(59)$ & $406(59)$ & $181(58)$ & 0.683 \\
\hline Comorbilidad* & $259(26)$ & $179(26)$ & $80(26)$ & 0.856 \\
\hline Índice Charlson, media $\pm \mathrm{DE}$ & $4.2 \pm 5.9$ & $4.4 \pm 6.9$ & $3.9 \pm 2.9$ & 0.749 \\
\hline Alcoholismo & $73(7)$ & $51(8)$ & $22(7)$ & 0.810 \\
\hline Anemia crónica & $221(22)$ & $151(22)$ & $70(22)$ & 0.921 \\
\hline Insuficiencia renal crónica & $148(15)$ & $106(15)$ & $42(13)$ & 0.396 \\
\hline
\end{tabular}




\begin{tabular}{|l|c|c|c|c|}
\hline Diabetes mellitus & $256(26)$ & $182(27)$ & $74(24)$ & 0.331 \\
\hline Cáncer & $115(12)$ & $83(12)$ & $32(10)$ & 0.384 \\
\hline Inmunodepresión & $61(6)$ & $42(6)$ & $19(6)$ & 0.969 \\
\hline EPOC & $84(8)$ & $57(8)$ & $27(9)$ & 0.873 \\
\hline Colagenopatía & $39(4)$ & $26(4)$ & $13(4)$ & 0.887 \\
\hline
\end{tabular}

*Comorbilidad: definida de acuerdo a la guía europea de endocarditis infecciosa.

DE: desviación estándar. ADVP: adicto a drogas por vía parenteral. VIH: virus inmunodeficiencia humana. EPOC: enfermedad pulmonar obstructiva crónica.RIQ: rango intercuartílico.

Tabla 10. Análisis comparativo de la evolución clínica entre la muestra de ajuste y la muestra de validación interna.

\begin{tabular}{|l|c|c|c|c|}
\hline \multicolumn{1}{|c|}{ n (\%) } & $\begin{array}{c}\text { Población } \\
\text { ENDOVAL } \\
(\mathbf{n = 1 0 0 2 )}\end{array}$ & $\begin{array}{c}\text { Muestra de } \\
\text { ajuste } \\
(\mathbf{n = 6 8 8})\end{array}$ & $\begin{array}{c}\text { Muestra de } \\
\text { validación } \\
\text { interna (n=314) }\end{array}$ & P-valor \\
\hline Evolución clínica \\
\hline Inicio agudo & $490(49)$ & $342(50)$ & $148(47)$ & 0.505 \\
\hline Fiebre & $811(81)$ & $564(82)$ & $247(79)$ & 0.215 \\
\hline Insuficiencia cardiaca & $571(57)$ & $380(55)$ & $191(61)$ & 0.097 \\
\hline Insuficiencia renal & $415(41)$ & $286(42)$ & $129(41)$ & 0.885 \\
\hline Shock séptico & $158(16)$ & $110(16)$ & $48(15)$ & 0.777 \\
\hline Ictus isquémico & $180(18)$ & $123(18)$ & $57(18)$ & 0.916 \\
\hline Hemorragia cerebral & $67(7)$ & $43(6)$ & $24(8)$ & 0.413 \\
\hline Muerte hospitalaria & $301(30)$ & $207(30)$ & $94(30)$ & 0.961 \\
\hline
\end{tabular}


Tabla 11. Análisis comparativo de la microbiología entre la muestra de ajuste y la muestra de validación interna.

\begin{tabular}{|c|c|c|c|c|}
\hline $\mathrm{n}(\%)$ & $\begin{array}{c}\text { Población } \\
\text { ENDOVAL } \\
(n=1002)\end{array}$ & $\begin{array}{l}\text { Muestra de } \\
\text { ajuste } \\
(n=688)\end{array}$ & $\begin{array}{c}\text { Muestra de } \\
\text { validación } \\
\text { interna }(n=314)\end{array}$ & P-valor \\
\hline \multicolumn{5}{|l|}{ Microbiología } \\
\hline $\begin{array}{l}\text { Hemocultivos positivos al } \\
\text { ingreso }\end{array}$ & $733(80)$ & $495(78)$ & $238(82)$ & 0.172 \\
\hline $\begin{array}{l}\text { Hemocultivos positivos a las } \\
48 / 72 \text { horas }\end{array}$ & $167 / 562(30)$ & $\begin{array}{c}126 / 386 \\
(33)\end{array}$ & $41 / 176(23)$ & 0.025 \\
\hline Estreptococos spp & $271(27)$ & $181(26)$ & $90(29)$ & 0.436 \\
\hline Estreptococo bovis & $55(6)$ & $32(5)$ & $23(7)$ & 0.085 \\
\hline $\begin{array}{l}\text { Estreptococo grupo } \\
\text { viridans }\end{array}$ & $159(16)$ & $105(15)$ & $54(17)$ & 0.437 \\
\hline Otros estreptococos & $58(6)$ & $44(6)$ & $14(5)$ & 0.223 \\
\hline Enterococos spp & $130(13)$ & $87(13)$ & $43(14)$ & 0.647 \\
\hline Estafilococos & $381(38)$ & $268(39)$ & $113(36)$ & 0.370 \\
\hline Meticilin sensibles & $219 / 355(62)$ & $161(64)$ & $58(57)$ & 0.235 \\
\hline Estafilococo aurues & $210(21)$ & $148(22)$ & $62(20)$ & 0.524 \\
\hline $\begin{array}{l}\text { Estafilococo coagulasa- } \\
\text { negativo }\end{array}$ & $172(17)$ & $121(18)$ & $51(16)$ & 0.600 \\
\hline $\begin{array}{l}\text { Bacilos gram negativos no- } \\
\text { HACEK }\end{array}$ & $48(5)$ & $30(4)$ & $18(6)$ & 0.346 \\
\hline Hongos & $16(2)$ & $11(2)$ & $5(2)$ & 0.994 \\
\hline Grupo HACEK & $7(1)$ & $4(1)$ & $3(1)$ & 0.684 \\
\hline Anaerobios & $32(3)$ & $20(3)$ & $12(4)$ & 0.445 \\
\hline Polimicrobiana & $49(5)$ & $24(4)$ & $25(8)$ & 0.002 \\
\hline Otros microorganismos & $41(4)$ & $26(4)$ & $15(5)$ & 0.459 \\
\hline Hemocultivos negativos & $118(12)$ & $79(12)$ & $39(12)$ & 0.669 \\
\hline
\end{tabular}

\section{RESULTADOS}

P. E. García Granja 
Tabla 12. Análisis comparativo de los hallazgos en pruebas de imagen entre la muestra de ajuste y la muestra de validación interna.

\begin{tabular}{|c|c|c|c|c|}
\hline $\mathrm{n}(\%)$ & $\begin{array}{c}\text { Población } \\
\text { ENDOVAL } \\
(n=1002)\end{array}$ & $\begin{array}{c}\text { Muestra de } \\
\text { ajuste } \\
(n=688)\end{array}$ & $\begin{array}{c}\text { Muestra de } \\
\text { validación } \\
\text { interna }(n=314)\end{array}$ & P-valor \\
\hline \multicolumn{5}{|c|}{ Hallazgos en pruebas de imagen } \\
\hline Vegetaciones & $870(87)$ & $598(87)$ & $272(87)$ & 0.898 \\
\hline Complicación perianular & $302(30)$ & $208(30)$ & $94(30)$ & 0.924 \\
\hline Absceso & $184(18)$ & $126(18)$ & $58(19)$ & 0.952 \\
\hline Pseudoaneurisma & $165(17)$ & $111(16)$ & $54(17)$ & 0.674 \\
\hline Fístula & $34(3)$ & $24(4)$ & $10(3)$ & 0.805 \\
\hline FEVI $<45 \%$ & $78(8)$ & $56(8)$ & $22(7)$ & 0.535 \\
\hline Hipertensión pulmonar & $136(14)$ & $90(13)$ & $46(15)$ & 0.501 \\
\hline $\begin{array}{l}\text { Disfunción valvular o } \\
\text { protésica severa }\end{array}$ & $619(62)$ & $412(60)$ & $207(66)$ & 0.068 \\
\hline \multicolumn{5}{|l|}{ Localización } \\
\hline Válvula aórtica nativa & $359(36)$ & $234(34)$ & $125(40)$ & 0.076 \\
\hline Válvula mitral nativa & $381(38)$ & $269(39)$ & $112(36)$ & 0.300 \\
\hline Prótesis aórtica mecánica & $118(12)$ & $83(12)$ & $35(11)$ & 0.676 \\
\hline Prótesis mitral mecánica & $192(19)$ & $129(19)$ & $63(20)$ & 0.624 \\
\hline Prótesis aórtica biológica & $108(11)$ & $71(10)$ & $37(12)$ & 0.488 \\
\hline Prótesis mitral biológica & $21(2)$ & $16(2)$ & $5(2)$ & 0.452 \\
\hline Afectación derecha & $23(2)$ & $10(2)$ & $13(4)$ & 0.021 \\
\hline Multivalvular & $215(22)$ & $140(20)$ & $75(24)$ & 0.206 \\
\hline
\end{tabular}

FEVI: fracción de eyección del ventrículo izquierdo. 
Tabla 13. Análisis comparativo del tratamiento entre la muestra de ajuste y la muestra de validación interna.

\begin{tabular}{|c|c|c|c|c|}
\hline n $(\%)$ & $\begin{array}{l}\text { Población } \\
\text { ENDOVAL } \\
(n=1002)\end{array}$ & $\begin{array}{c}\text { Muestra de } \\
\text { ajuste } \\
(n=688)\end{array}$ & $\begin{array}{c}\text { Muestra de } \\
\text { validación } \\
\text { interna }(n=314)\end{array}$ & P-valor \\
\hline \multicolumn{5}{|l|}{ Tratamiento quirúrgico } \\
\hline Cirugía cardiaca & $614(61)$ & $408(59)$ & $206(66)$ & 0.057 \\
\hline Urgente & $367(60)$ & $239(59)$ & $128(62)$ & \multirow{2}{*}{0.433} \\
\hline Electiva & $247(40)$ & $169(41)$ & $78(38)$ & \\
\hline \multicolumn{5}{|l|}{ Indicaciones } \\
\hline Insuficiencia cardiaca & $428(72)$ & $274(69)$ & $154(79)$ & 0.130 \\
\hline Infección no controlada & $335(56)$ & $228(57)$ & $107(55)$ & 0.533 \\
\hline Prevención de embolias & $139(23)$ & $97(24)$ & $42(21)$ & 0.426 \\
\hline \multicolumn{5}{|l|}{ Riesgo quirúrgico } \\
\hline $\begin{array}{l}\text { Euroscore logístico, } \\
\text { mediana [RIQ] }\end{array}$ & 31 [19-50] & $30[19-50]$ & $32[23-52]$ & 0.864 \\
\hline $\begin{array}{l}\text { Euroscore 2, mediana } \\
\text { [RIQ] }\end{array}$ & $12[5-21]$ & $13[5-27]$ & $11[5-20]$ & 0.383 \\
\hline \multicolumn{5}{|l|}{ Tratamiento antibiótico } \\
\hline $\begin{array}{l}\text { Semanas tratamiento, } \\
\text { mediana [RIQ] }\end{array}$ & $5[3-7]$ & $5[3-7]$ & $5[4-7]$ & 0.805 \\
\hline $\begin{array}{l}\text { Tratamiento antibiótico } \\
\text { correcto }\end{array}$ & $879(95)$ & $597(94)$ & $282(97)$ & 0.036 \\
\hline
\end{tabular}

RIQ: rango intercuartílico 
Tabla 14. Análisis comparativo de las variables pronósticas propuestas por la guía europea entre la muestra de ajuste y la muestra de validación interna.

\begin{tabular}{|c|c|c|c|c|}
\hline $\mathrm{n}(\%)$ & $\begin{array}{l}\text { Población } \\
\text { ENDOVAL } \\
(n=1002)\end{array}$ & $\begin{array}{l}\text { Muestra } \\
\text { ajuste } \\
(n=688)\end{array}$ & $\begin{array}{c}\text { Muestra } \\
\text { validación } \\
\text { interna }(n=314)\end{array}$ & P-valor \\
\hline \multicolumn{5}{|l|}{ Características del paciente } \\
\hline Edad, media $\pm \mathrm{DE}$ & $65.1 \pm 14.3$ & $64.7 \pm 14.5$ & $66.1 \pm 14$ & 0.154 \\
\hline Endocarditis protésica & $404(40)$ & $278(40)$ & $126(40)$ & 0.933 \\
\hline Diabetes mellitus & $256(26)$ & $182(27)$ & $74(24)$ & 0.331 \\
\hline Comorbilidad & $259(26)$ & $179(26)$ & $80(26)$ & 0.856 \\
\hline \multicolumn{5}{|l|}{ Complicaciones clínicas } \\
\hline Insuficiencia cardiaca & $571(57)$ & $380(55)$ & $191(61)$ & 0.097 \\
\hline Insuficiencia renal & $415(41)$ & $286(42)$ & $129(41)$ & 0.885 \\
\hline Ictus isquémico & $180(18)$ & $123(18)$ & $57(18)$ & 0.777 \\
\hline Hemorragia cerebral & $67(7)$ & $43(6)$ & $24(8)$ & 0.413 \\
\hline Shock séptico & $158(16)$ & $110(16)$ & $48(15)$ & 0.777 \\
\hline \multicolumn{5}{|l|}{ Tipo de microorganismo } \\
\hline Estafilococo aureus & $210(21)$ & $148(22)$ & $62(20)$ & 0.524 \\
\hline $\begin{array}{l}\text { Bacilos Gram negativos no- } \\
\text { HACEK }\end{array}$ & $48(5)$ & $30(4)$ & $18(6)$ & 0.346 \\
\hline Hongos & $16(2)$ & $11(2)$ & $5(2)$ & 0.994 \\
\hline \multicolumn{5}{|l|}{ Hallazgos por técnicas de imagen } \\
\hline Complicación perianular & $302(30)$ & $208(30)$ & $94(30)$ & 0.924 \\
\hline $\begin{array}{l}\text { Disfunción valvular o protésica } \\
\text { severa }\end{array}$ & $619(62)$ & $412(60)$ & $207(66)$ & 0.068 \\
\hline FEVI $<45 \%$ & $78(8)$ & $56(8)$ & $22(7)$ & 0.535 \\
\hline Hipertensión pulmonar & $136(14)$ & $90(13)$ & $46(15)$ & 0.501 \\
\hline Vegetaciones & $870(87)$ & $598(87)$ & $272(87)$ & 0.898 \\
\hline Mortalidad hospitalaria & $301(30)$ & $207(30)$ & $94(30)$ & 0.961 \\
\hline
\end{tabular}

DE: desviación estándar. FEVI: fracción de eyección de ventrículo izquierdo. 


\subsection{DERIVACIÓN DEL MODELO PREDICTIVO DE MORTALIDAD HOSPITALARIA EN ENDOCARDITIS INFECCIOSA IZQUIERDA.}

Utilizando la muestra de ajuste obtenida por aleatorización 2:1 de la población con endocarditis infecciosa izquierda ENDOVAL construimos un modelo predictivo de mortalidad hospitalaria.

6.4.1 Asociación de las variables pronósticas propuestas por la guía Europea para el manejo de la Endocarditis Infecciosa con la mortalidad hospitalaria.

Inicialmente realizamos un análisis univariado de mortalidad intra-hospitalaria para valorar la asociación lineal de cada variable pronóstica propuesta por la guía Europea para el manejo de la Endocarditis Infecciosa y la mortalidad hospitalaria. Los resultados se presentan en la tabla 15.

Destacamos que prácticamente todas las variables se asocian a mortalidad hospitalaria en el análisis univariado salvo el ictus isquémico ( $21 \%$ vs $17 \%$, $\mathrm{p}=0.194)$, la hemorragia cerebral ( $7 \%$ vs $6 \%, \mathrm{p}=0.479)$, los bacilos Gram negativos no-HACEK ( $5 \%$ vs $4 \%, \mathrm{p}=0.692)$, los hongos ( $2 \%$ vs $1 \%, \mathrm{p}=0.321)$, y la disfunción valvular o protésica severa $(57 \%$ vs $61 \%, p=0.312)$.

Además, realizamos un análisis de la mortalidad de cada subpoblación de endocarditis infecciosa de acuerdo a una variable pronóstica en particular. Los resultados se muestran en la figura 10 y destacamos que la subpoblación de endocarditis infecciosa que más mortalidad asocia es la de pacientes con shock séptico (73\%), seguida de la endocarditis por Estafilococo aureus (56\%). 
Tabla 15. Asociación de las variables pronósticas propuestas por la guía europea de manejo de la endocarditis infecciosa con la mortalidad hospitalaria.

\begin{tabular}{|c|c|c|c|}
\hline $\begin{array}{l}\text { Muestra de ajuste } \\
\qquad(\mathrm{n}=688)\end{array}$ & $\begin{array}{l}\text { Muerte SI } \\
(\mathrm{n}=207)\end{array}$ & $\begin{array}{l}\text { Muerte NO } \\
(\mathrm{n}=481)\end{array}$ & P-valor \\
\hline \multicolumn{4}{|c|}{ Características del paciente, n (\%) } \\
\hline Edad, media \pm DE & $69.6 \pm 11.6$ & $62.6 \pm 15.1$ & $<0.001$ \\
\hline Endocarditis protésica & $96(46)$ & $182(38)$ & 0.036 \\
\hline Diabetes mellitus & $72(35)$ & $110(23)$ & 0.001 \\
\hline Comorbilidades & $79(38)$ & $100(21)$ & $<\mathbf{0 . 0 0 1}$ \\
\hline \multicolumn{4}{|l|}{ Complicaciones clínicas, n (\%) } \\
\hline Insuficiencia cardiaca & $155(75)$ & $225(47)$ & $<0.001$ \\
\hline Insuficiencia renal & $141(68)$ & $145(30)$ & $<0.001$ \\
\hline Ictus isquémico & $43(21)$ & $80(17)$ & 0.194 \\
\hline Hemorragia cerebral & $15(7)$ & $28(6)$ & 0.479 \\
\hline Shock séptico & $80(39)$ & $30(6)$ & $<0.001$ \\
\hline \multicolumn{4}{|l|}{ Tipo de microorganismo, n (\%) } \\
\hline Estafilococo aureus & $83(40)$ & $65(14)$ & $<0.001$ \\
\hline $\begin{array}{l}\text { Bacilos gram negativos no- } \\
\text { HACEK }\end{array}$ & $10(5)$ & $20(4)$ & 0.692 \\
\hline Hongos & $5(2)$ & $6(1)$ & 0.321 \\
\hline \multicolumn{4}{|c|}{ Hallazgos por técnicas de imagen, n (\%) } \\
\hline Complicación perianular & $77(37)$ & $131(27)$ & 0.009 \\
\hline $\begin{array}{l}\text { Disfunción valvular o protésica } \\
\text { severa }\end{array}$ & $118(57)$ & $294(61)$ & 0.312 \\
\hline FEVI $<45 \%$ & $28(14)$ & $28(6)$ & 0.001 \\
\hline Hipertensión pulmonar & $38(18)$ & $52(11)$ & 0.007 \\
\hline Vegetaciones & $190(92)$ & $408(85)$ & 0.013 \\
\hline
\end{tabular}

DE: desviación estándar. FEVI: fracción de eyección de ventrículo izquierdo. 


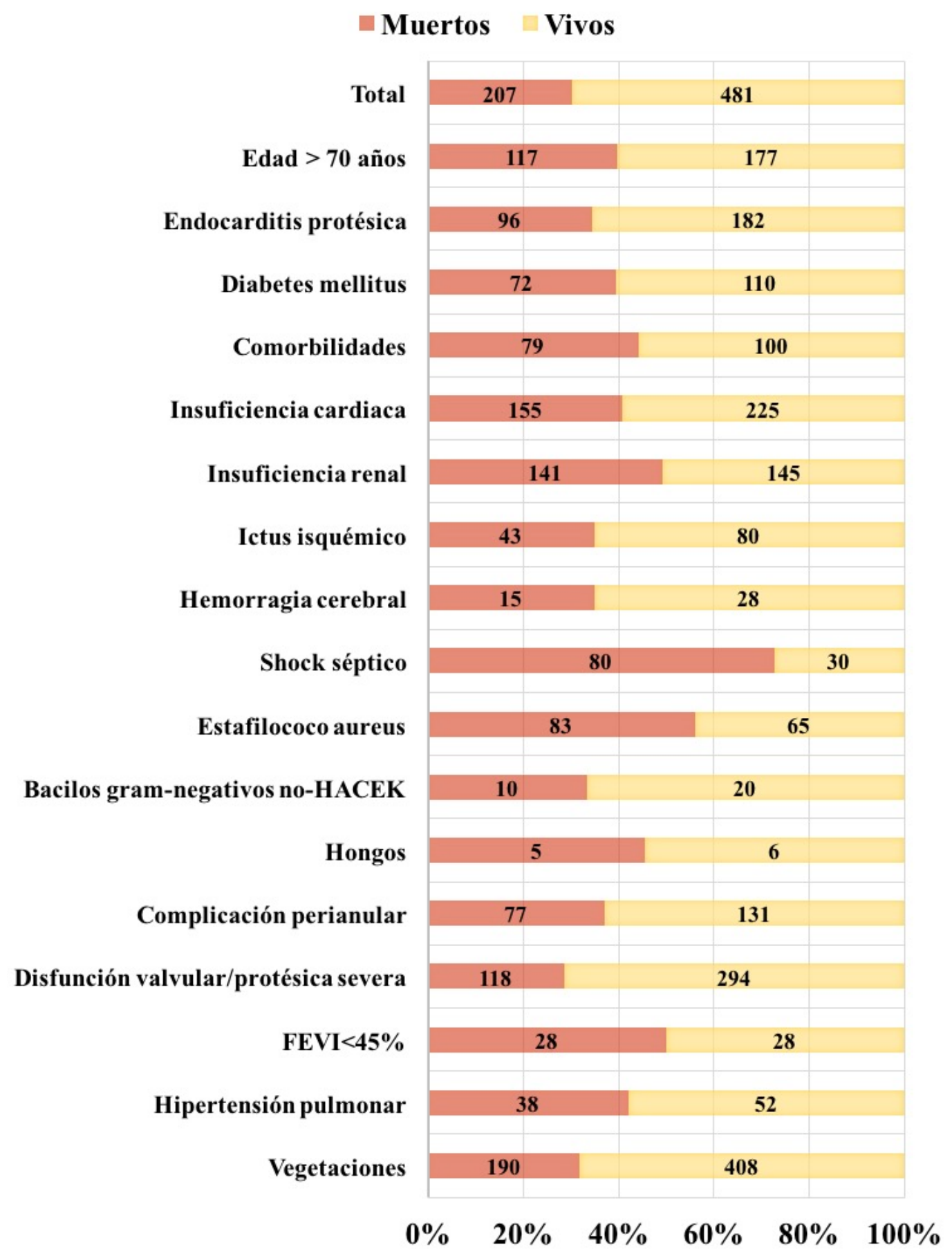

Figura 10. Mortalidad de cada subpoblación de endocarditis infecciosa atendiendo a las variables pronósticas de la guía europea de endocarditis infecciosa. 


\subsubsection{Análisis multivariado de mortalidad ho spitalaria.}

El análisis multivariado se ha realizado por medio de una regresión logística con el método de máxima probabilidad, calculando los odds ratio ajustados para cada variable pronóstica propuesta por la guía Europea de manejo de la Endocarditis Infecciosa. Los resultados se presentan en la tabla 16.

Las variables que muestran una asociación independiente con la mortalidad hospitalaria son la edad (odds ratio 1.033, intervalo de confianza al 95\%: 1.016 - 1.051), la endocarditis protésica (odds ratio 1.841, intervalo de confianza al 95\%: 95\% 1.187 2.856), la comorbilidad (odds ratio 1.652, intervalo de confianza al 95\%: $1.039-2.626$ ), la insuficiencia cardiaca (odds ratio 3.292, intervalo de confianza al 95\%: 2.063 - 5.255), la insuficiencia renal (odds ratio 2.173, intervalo de confianza al 95\%: 1.407-3.357), el shock séptico (odds ratio 5.367, intervalo de confianza al 95\%: 3.063 - 9.405), el Estafilococo aureus (odds ratio 3.653, intervalo de confianza al 95\% 2.193 - 6.084), los hongos (odds ratio 7.532, intervalo de confianza al 95\%: 1.665 - 34.082), las complicaciones perianulares (odds ratio 2.046, intervalo de confianza al 95\%: 1.307 3.203), la disfunción ventricular (odds ratio 2.179, intervalo de confianza al 95\%: 1.094 - 4.338) y las vegetaciones (odds ratio 2.449, intervalo de confianza al 95\%: 1.221 4.914).

El modelo presenta buena capacidad discriminativa con un área bajo la curva ROC de 0.859 (Intervalo de confianza al 95\%: 0.830 - 0.889), sensibilidad 0.792 y especificidad 0.790 (Figura 11), y un p-valor en el Test de Hosmer-Lemeshow de 0.350 (Tabla 17). 
Tabla 16. Análisis multivariado de mortalidad hospitalaria en endocarditis infecciosa izquierda utilizando las variables pronósticas propuestas por la guía Europea de manejo de la Endocarditis Infecciosa.

\begin{tabular}{|c|c|c|c|c|}
\hline \multirow{2}{*}{ Variables } & \multirow{2}{*}{ P-valor } & \multirow{2}{*}{ OR } & \multicolumn{2}{|c|}{ IC 95\% } \\
\hline & & & Inferior & Superior \\
\hline \multicolumn{5}{|l|}{ Características del paciente } \\
\hline Edad & $<0.001$ & 1.033 & 1.016 & 1.051 \\
\hline Endocarditis protésica & 0.006 & 1.841 & 1.187 & 2.856 \\
\hline Diabetes mellitus & 0.227 & 1.318 & 0.842 & 2.063 \\
\hline Comorbilidad & 0.034 & 1.652 & 1.039 & 2.626 \\
\hline \multicolumn{5}{|l|}{ Complicaciones clínicas } \\
\hline Insuficiencia cardiaca & $<0.001$ & 3.292 & 2.063 & 5.255 \\
\hline Insuficiencia renal & $<0.001$ & 2.173 & 1.407 & 3.357 \\
\hline Ictus isquémico & 0.180 & 1.443 & 0.844 & 2.468 \\
\hline Hemorragia cerebral & 0.930 & 1.040 & 0.430 & 2.516 \\
\hline Shock séptico & $<0.001$ & 5.367 & 3.063 & 9.405 \\
\hline \multicolumn{5}{|l|}{ Tipo de microorganismo } \\
\hline Estafilococo aureus & $<0.001$ & 3.653 & 2.193 & 6.084 \\
\hline $\begin{array}{l}\text { Bacilos Gram-negativos no- } \\
\text { HACEK }\end{array}$ & 0.172 & 1.984 & 0.742 & 5.304 \\
\hline Hongos & 0.009 & 7.532 & 1.665 & 34.082 \\
\hline \multicolumn{5}{|c|}{ Hallazgos por técnicas de imagen } \\
\hline Complicaciones perianulares & 0.002 & 2.046 & 1.307 & 3.203 \\
\hline $\begin{array}{l}\text { Disfunción valvular o } \\
\text { protésica severa }\end{array}$ & 0.499 & 1.170 & 0.743 & 1.842 \\
\hline FEVI $<45 \%$ & 0.027 & 2.179 & 1.094 & 4.338 \\
\hline Hipertensión pulmonar & 0.429 & 1.263 & 0.708 & 2.252 \\
\hline Vegetaciones & 0.012 & 2.449 & 1.221 & 4.914 \\
\hline Constante & $<0.001$ & 0.001 & & \\
\hline
\end{tabular}

OR: odds ratio. IC: intervalo de confianza. FEVI: fracción de eyección del ventrículo izquierdo. 


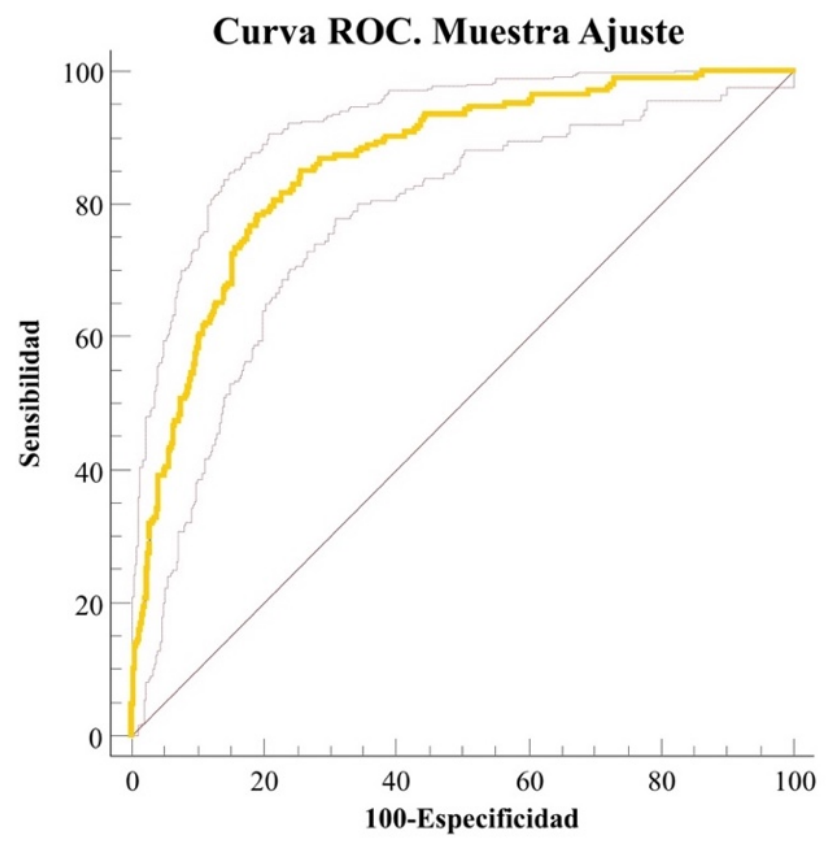

Figura 11. Curva ROC del modelo pronóstico en la muestra de ajuste.

Tabla 17. Tabla de contingencia para la prueba de Hosmer y Lemeshow.

\begin{tabular}{|c|c|c|c|c|c|c|}
\hline & & \multicolumn{2}{|c|}{ Muerte hospitalaria $=$ no } & \multicolumn{2}{|c|}{ Muerte hospitalaria $=$ sí } & \multirow{2}{*}{ Total } \\
\hline & & Observado & Esperado & Observado & Esperado & \\
\hline \multirow[t]{10}{*}{ Paso 1} & 1 & 68 & 67.579 & 1 & 1.421 & 69 \\
\hline & 2 & 65 & 65.570 & 4 & 3.430 & 69 \\
\hline & 3 & 64 & 63.588 & 5 & 5.412 & 69 \\
\hline & 4 & 66 & 61.281 & 3 & 7.719 & 69 \\
\hline & 5 & 56 & 57.776 & 13 & 11.224 & 69 \\
\hline & 6 & 55 & 52.516 & 14 & 16.484 & 69 \\
\hline & 7 & 40 & 45.197 & 29 & 23.803 & 69 \\
\hline & 8 & 32 & 36.268 & 37 & 32.732 & 69 \\
\hline & 9 & 23 & 22.839 & 46 & 46.161 & 69 \\
\hline & 10 & 12 & 8.386 & 55 & 58.614 & 67 \\
\hline
\end{tabular}




\subsubsection{Fórmula para el cálculo de la mortalidad hospitalaria en endocarditis infecciosa izquierda.}

Para la elaborar la fórmula de predicción de mortalidad hospitalaria en endocarditis infecciosa izquierda utilizamos los logaritmos de las odds ratio ajustadas de todas las variables introducidas en el modelo, tengan o no asociación independiente con el evento primario. De tal forma que la probabilidad de muerte hospitalaria predicha por el modelo se ajusta a la siguiente fórmula:

$$
p=\frac{e^{z}}{1+e^{z}}
$$

donde $\mathrm{z}=-6.638+0.033 \mathrm{x}$ Edad $+0.610 \mathrm{x}$ Endocarditis protésica $+0.276 \mathrm{x}$ Diabetes mellitus $+0.502 \times$ Comorbilidad $+1.192 \times$ Insuficiencia cardiaca $+0.776 \times$ Insuficiencia renal $+0.367 \mathrm{x}$ Ictus isquémico $+0.039 \mathrm{x}$ Hemorragia cerebral $+1.680 \mathrm{x}$ Shock séptico + 1.296 x Estafilococo Aureus + 0.685 x Bacilos gram negativos no-HACEK + 2.019 x Hongos +0.716 x Complicación perianular +0.157 x Disfunción valvular o protésica severa $+0.779 \mathrm{x}$ Disfunción ventricular $+0.233 \mathrm{x}$ Hipertensión pulmonar $+0.896 \mathrm{x}$ Vegetación 


\subsection{VALIDACIÓN DEL MODELO PRONÓSTICO DE MORTALIDAD HOSPITALARIA EN ENDOCARDITIS INFECCIOSA IZQUIERDA}

\subsubsection{Validación interna}

Para la validación interna del modelo, aplicamos la fórmula para el cálculo de la mortalidad hospitalaria en endocarditis infecciosa izquierda en la muestra de validación $(n=334)$ obtenida por aleatorización 2:1 de la población del grupo ENDOVAL.

El modelo presenta una buena capacidad discriminativa, con un área bajo la curva ROC de 0.834 (Intervalo de confianza al 95\% 0.786 - 0.881), sensibilidad 0.766 y especificidad 0.768 (Figura 12). Predice una mortalidad hospitalaria para esta muestra de 30.8\% (Intervalo de confianza al 95\%: 27.8 - 33.9\%), mientras que la mortalidad observada en la muestra fue de $29.9 \%$.
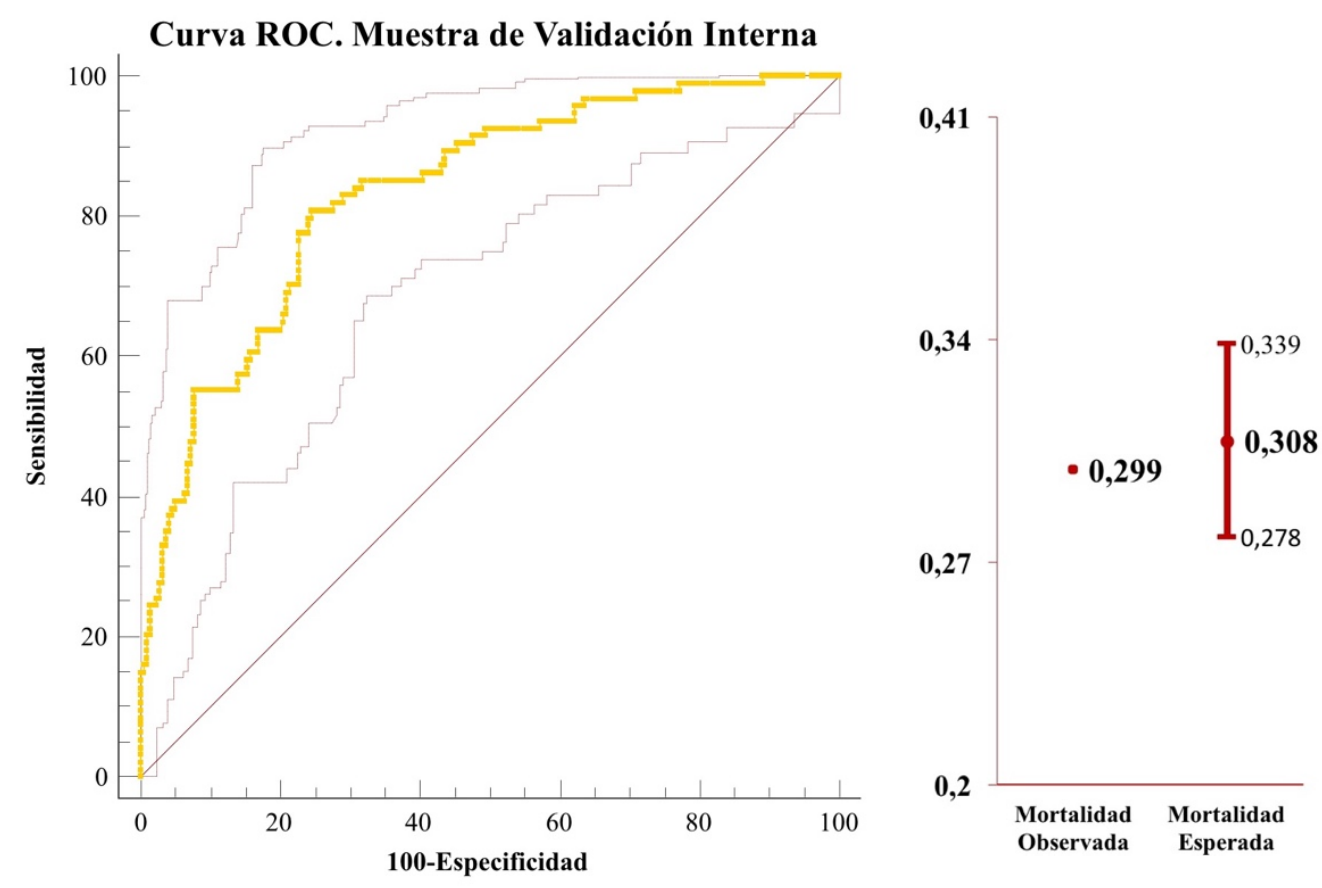

Figura 12. Validación interna del modelo de predicción pronóstica. Izquierda: curva ROC de validación interna del modelo pronóstico de mortalidad hospitalaria en endocarditis infecciosa izquierda. Derecha: representación gráfica de la mortalidad esperada según el modelo y la mortalidad observada en la muestra de validación interna. 


\subsubsection{Validación externa}

Para la validación externa del modelo, aplicamos la fórmula para el cálculo de la mortalidad hospitalaria en endocarditis infecciosa izquierda en la población de endocarditis infecciosa izquierda del Hospital Universitario Puerta de Hierro ( $n=133)$.

El modelo presenta una buena capacidad discriminativa, con un área bajo la curva ROC de 0.759 (Intervalo de confianza al 95\%: 0.665 - 0.853), sensibilidad 0.639 y especificiad 0.825 (Figura 13). Predice una mortalidad hospitalaria para esta muestra de 25.4\% (Intervalo de confianza al 95\%: 21.2 - 29.5\%), mientras que la mortalidad observada en la muestra fue de $27.1 \%$.
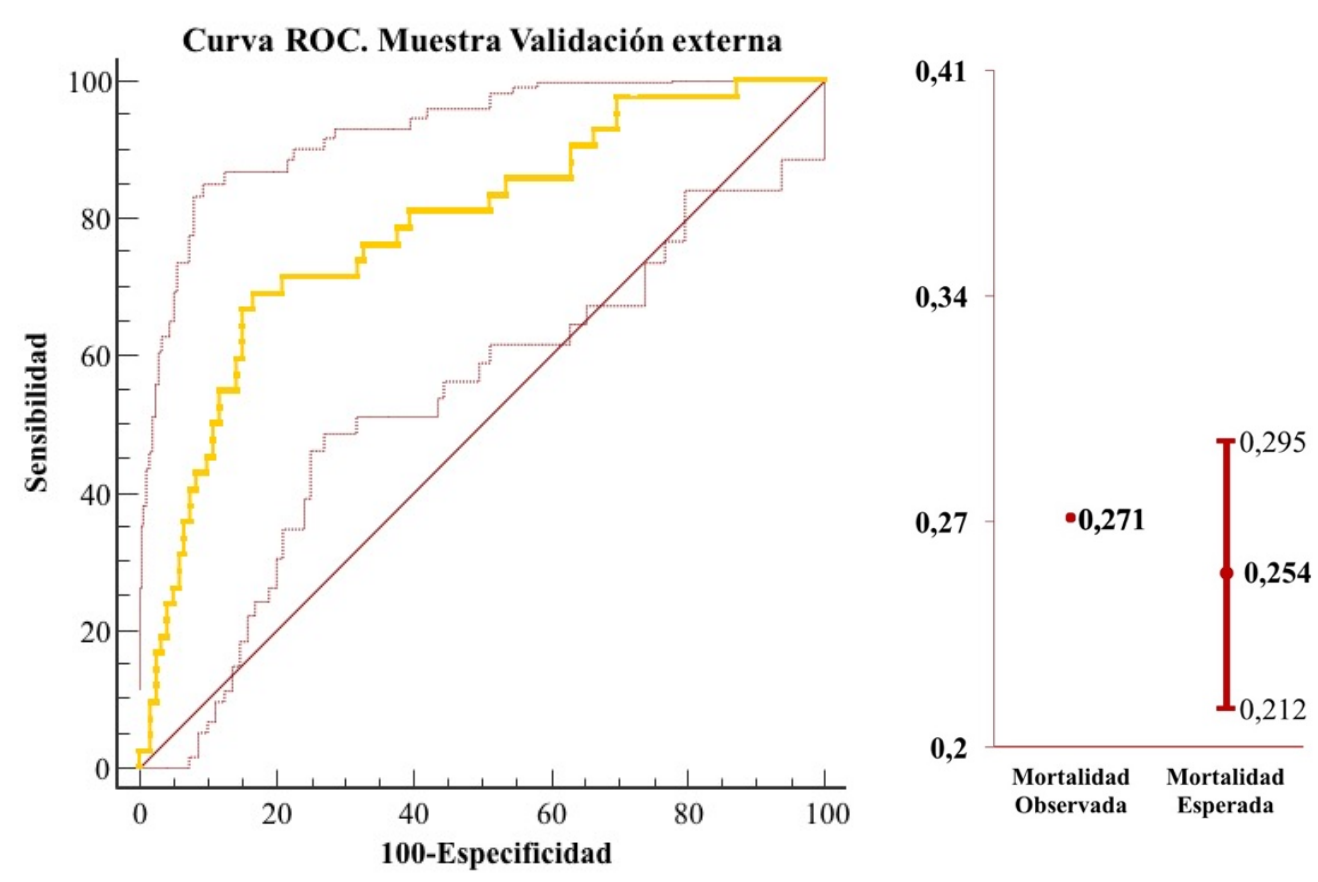

Figura 13. Validación externa del modelo de predicción pronóstica. Izquierda: curva ROC de validación externa del modelo pronóstico de mortalidad hospitalaria en endocarditis infecciosa izquierda. Derecha: representación gráfica de la mortalidad esperada según el modelo y la mortalidad observada en la muestra de validación interna. 


\subsection{DESARROLLO DE LA APLICACIÓN INFORMÁTICA}

Presentamos dirección web desde la que se puede acceder directamente a la aplicación: https://endovalscore.000webhostapp.com/

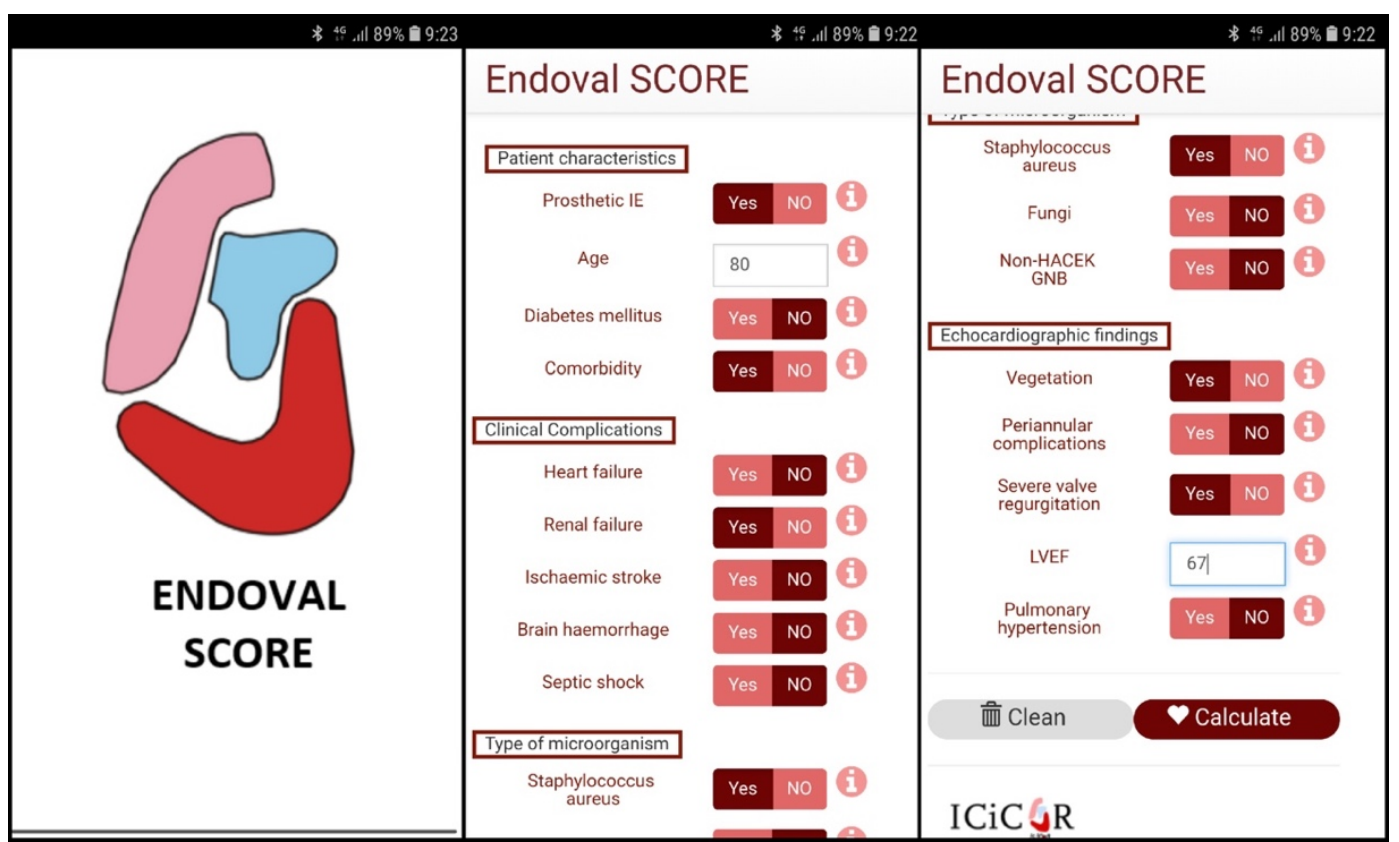

Figura 14. Diseño de la aplicación móvil. Izquierda: portada de la aplicación móvil denominada ENDOVAL score. Medio y derecha: presentación de las variables del modelo predictivo.

La aplicación presenta una portada inicial, y posteriormente se accede a una ventana donde se muestran todas las variables pronósticas propuestas por la guía europea de endocarditis infecciosa e incluidas en el modelo pronóstico agrupadas por características. Por defecto están señalados los valores negativos y las celdas vacías. El facultativo puede acceder a la definición concreta de cada variable en el botón de información (i). Al final tenemos la opción de borrar la información para introducir un nuevo paciente, y la opción de calcular la mortalidad hospitalaria de nuestro paciente (Figura 14). 
Cuando solicitamos calcular la mortalidad hospitalaria recibimos el valor absoluto de la mortalidad estimada para nuestro paciente, y existe la posibilidad de observarlo en formato gráfico (Figura 15).

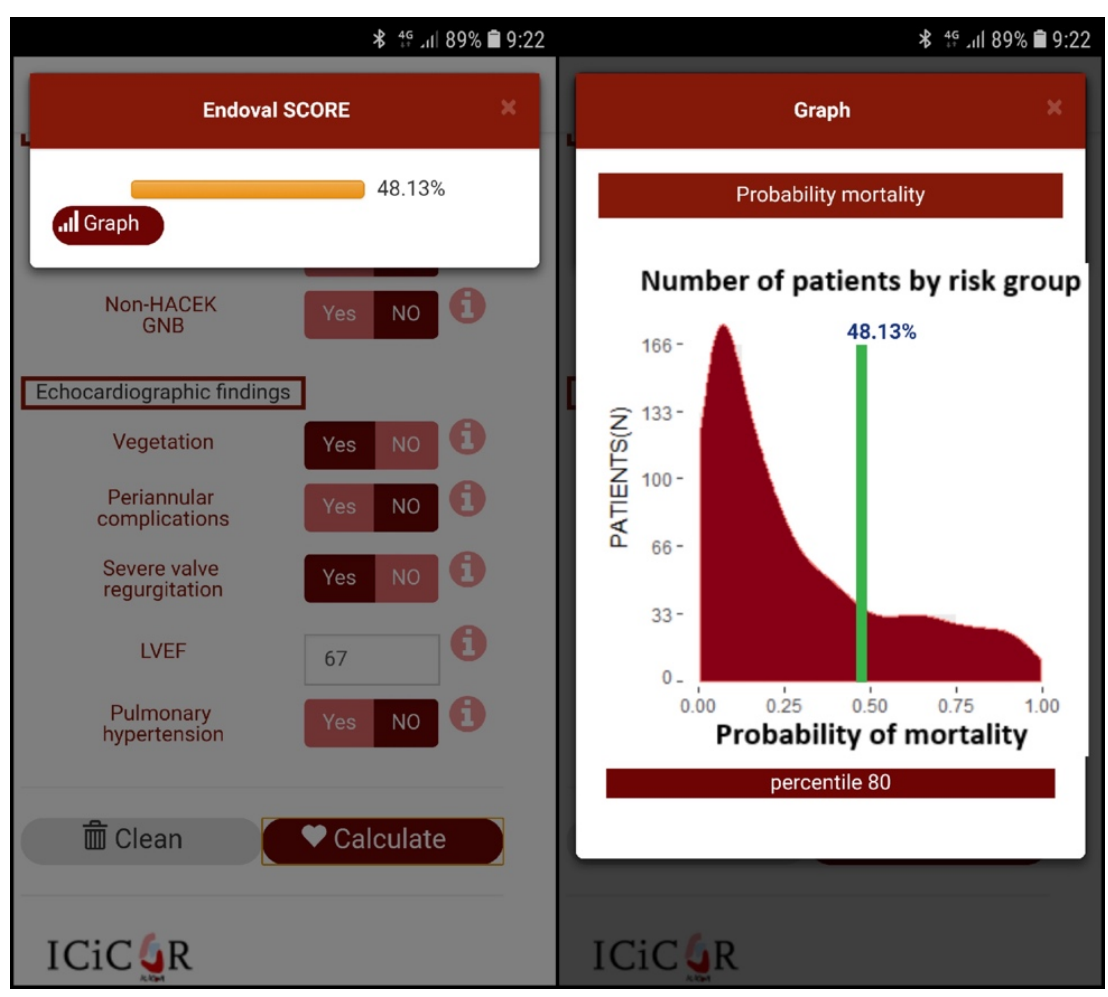

Figura 15. Presentación de la predicción en la aplicación. Izquierda: predicción de mortalidad hospitalaria en valor absoluto. Derecha: representación gráfica de la probabilidad de mortalidad hospitalaria y el percentil en el que se sitúa el paciente con respecto a nuestra población. 


\subsection{VALORACIÓN DEL IMPACTO PRONÓSTICO DE LA CIRUGÍA CARDIACA EN LA MORTALIDAD HOSPITALARIA DE LA ENDOCARDITIS INFECCIOSA IZQUIERDA}

La cirugía cardiaca muestra asociación estadísticamente significativa con la mortalidad hospitalaria de la endocarditis infecciosa izquierda en el análisis univariado en la muestra de ajuste (Tabla 18 y Figura 16).

Tabla 18. Asociación de la cirugía cardiaca y su momento de realización con la mortalidad hospitalaria de la endocarditis infecciosa izquierda

\begin{tabular}{|c|c|c|c|}
\hline $\begin{array}{c}\text { Muestra de ajuste } \\
(\mathbf{n = 6 8 8})\end{array}$ & $\begin{array}{c}\text { Muerte SI } \\
(\mathrm{n}=207)\end{array}$ & $\begin{array}{c}\text { Muerte NO } \\
(\mathrm{n}=481)\end{array}$ & P-valor \\
\hline CIRUGÍA, n (\%) & $95(46)$ & $313(65)$ & $<\mathbf{0 . 0 0 1}$ \\
\hline Cirugía urgente & $66(32)$ & $173(36)$ & 0.337 \\
\hline Cirugía electiva & $29(14)$ & $140(29)$ & $<\mathbf{0 . 0 0 1}$ \\
\hline
\end{tabular}

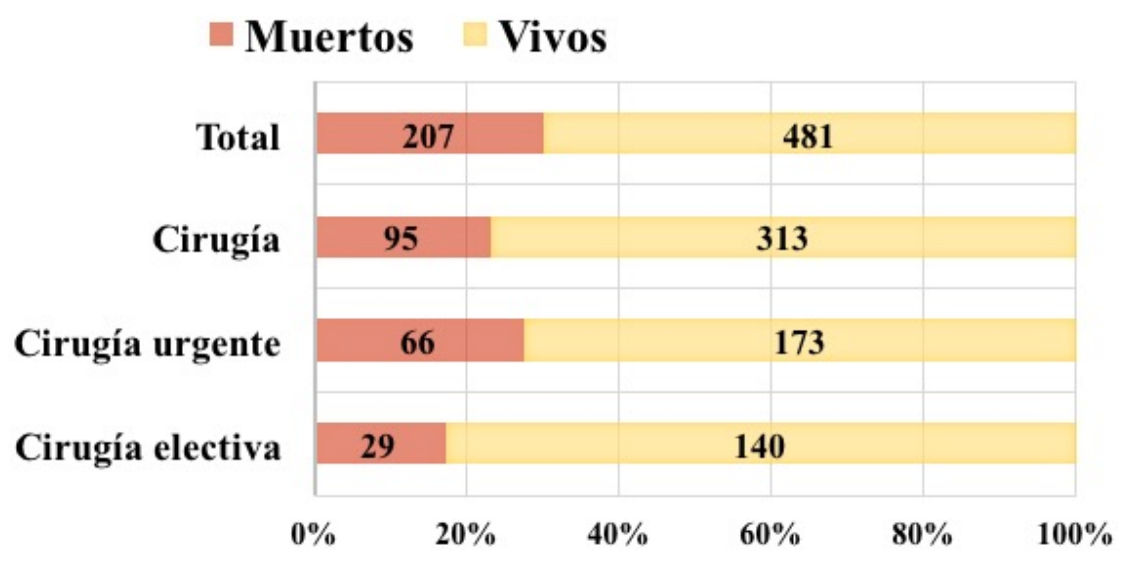

Figura 16. Mortalidad de la endocarditis infecciosa atendiendo a la cirugía cardiaca y su momento de realización. 
Para valorar el impacto de la cirugía cardiaca en la mortalidad hospitalaria de la endocarditis infecciosa izquierda y su valor asociado al modelo pronóstico, realizamos un nuevo análisis multivariado de mortalidad hospitalaria introduciendo las variables pronósticas recomendadas por la guía europea de manejo de la endocarditis infecciosa y la cirugía cardiaca. Los resultados se presentan en la tabla 19.

Las variables de la guía europea mantienen en general su asociación con la mortalidad hospitalaria, salvo la comorbilidad que presenta un odds ratio similar pero con un $\mathrm{p}$ valor $>0.050$, no significativo. La cirugía cardiaca es un factor protector de mortalidad hospitalaria, fundamentalmente si se realiza de forma electiva (odds ratio 0.460, intervalo de confianza al 95\%: $0.258-0.822$ ).

El modelo presenta un p-valor en el test de Hosmer-Lemeshow de 0.353, y un área bajo la curva ROC muy similar al modelo previo, 0.861 (intervalo de confianza al 95\%: $0.830-0.891)$ (Figura 17).

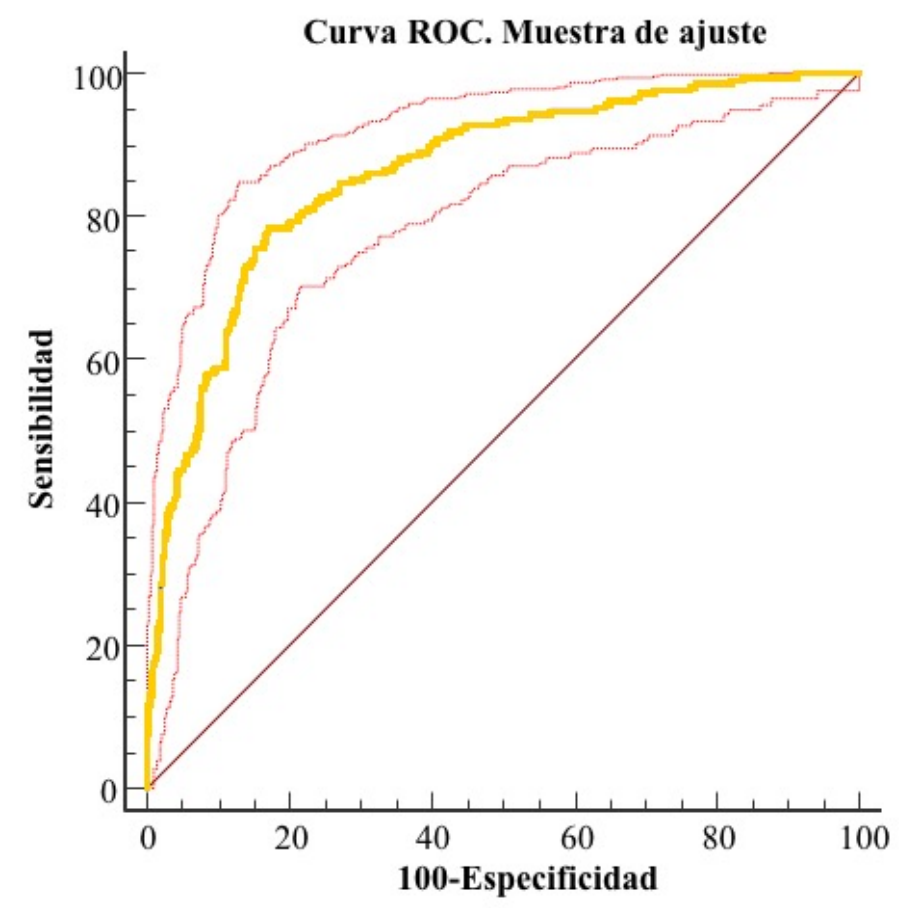

Figura 17. Curva ROC en la muestra de ajuste del modelo de predicción de mortalidad hospitalaria en endocarditis infecciosa izquierda utilizando las variables pronósticas de la guía europea y la cirugía cardiaca. 
Tabla 19. Análisis multivariado de mortalidad hospitalaria en endocarditis infecciosa izquierda incluyendo la variable cirugía cardiaca.

\begin{tabular}{|c|c|c|c|c|}
\hline \multirow{2}{*}{ Variables } & \multirow{2}{*}{ P-valor } & \multirow{2}{*}{ OR } & \multicolumn{2}{|c|}{ IC 95\% } \\
\hline & & & Inferior & Superior \\
\hline \multicolumn{5}{|l|}{ Características del paciente } \\
\hline Edad & $<0.001$ & 1.030 & 1.013 & 1.048 \\
\hline Endocarditis protésica & 0.005 & 1.873 & 1.204 & 2.915 \\
\hline Diabetes mellitus & 0.282 & 1.282 & 0.815 & 2.018 \\
\hline Comorbilidad & 0.060 & 1.569 & 0.981 & 2.512 \\
\hline \multicolumn{5}{|l|}{ Complicaciones clínicas } \\
\hline Insuficiencia cardiaca & $<0.001$ & 3.367 & 2.105 & 5.385 \\
\hline Insuficiencia renal & 0.001 & 2.079 & 1.341 & 3.225 \\
\hline Ictus isquémico & 0.220 & 1.402 & 0.817 & 2.405 \\
\hline Hemorragia cerebral & 0.832 & 1.101 & 0.452 & 2.685 \\
\hline Shock séptico & $<0.001$ & 4.999 & 2.838 & 8.808 \\
\hline \multicolumn{5}{|l|}{ Tipo de microorganismo } \\
\hline Estafilococo aureus & $<0.001$ & 3.763 & 2.245 & 6.306 \\
\hline $\begin{array}{l}\text { Bacilos Gram-negativos no- } \\
\text { HACEK }\end{array}$ & 0.151 & 2.060 & 0.768 & 5.525 \\
\hline Hongos & 0.004 & 9.193 & 2.005 & 42.157 \\
\hline \multicolumn{5}{|c|}{ Hallazgos por técnicas de imagen } \\
\hline Complicaciones perianulares & 0.001 & 2.162 & 1.368 & 3.417 \\
\hline $\begin{array}{l}\text { Disfunción valvular o } \\
\text { protésica severa }\end{array}$ & 0.292 & 1.286 & 0.805 & 2.053 \\
\hline FEVI $<45 \%$ & 0.022 & 2.280 & 1.128 & 4.606 \\
\hline Hipertensión pulmonar & 0.412 & 1.278 & 0.712 & 2.294 \\
\hline Vegetaciones & 0.022 & 2.286 & 1.126 & 4.640 \\
\hline Cirugía cardiaca & 0.025 & & & \\
\hline Cirugía urgente & 0.082 & 0.643 & 0.391 & 1.057 \\
\hline Cirugía electiva & 0.009 & 0.460 & 0.258 & 0.822 \\
\hline Constante & $<0.001$ & 0.002 & & \\
\hline
\end{tabular}

OR: odds ratio. IC: intervalo confianza. FEVI: fracción de eyección del ventrículo izquierdo. 
La cirugía cardiaca es un factor protector de mortalidad en endocarditis infecciosa izquierda. Para ampliar el estudio hemos realizado una evaluación del impacto teórico de la cirugía cardiaca urgente en la mortalidad hospitalaria de la endocarditis infecciosa izquierda calculada por el modelo pronóstico (Figura 18). Según el riesgo calculado de muerte para cada paciente se espera un mayor o menor impacto beneficioso de la cirugía cardiaca urgente. Para los pacientes con un riesgo calculado de muerte entre $0-20 \%$ en ausencia de cirugía, se espera una reducción media del riesgo de muerte de $3.2 \pm 1.6 \%$ para la cirugía realizada en fase activa de la enfermedad $(\mathrm{p}<0.001)$. Para pacientes con un riesgo entre $20-40 \%$ se espera una reducción media del riesgo de $8.1 \pm 1.1 \%(\mathrm{p}<0.001)$. Para pacientes con un riesgo entre 40-60\% se espera una reducción media del riesgo de $10.7 \pm 0.3 \%(\mathrm{p}<0.001)$. Para pacientes con un riesgo entre $60-80 \%$ se espera una reducción media del riesgo de $9.7 \pm 0.9 \%(\mathrm{p}<0.001)$. Y finalmente para pacientes con un riesgo estimado superior al $80 \%$ se espera una reducción media del riesgo de $4.6 \pm 2.1 \%$ $(\mathrm{p}<0.001)$.

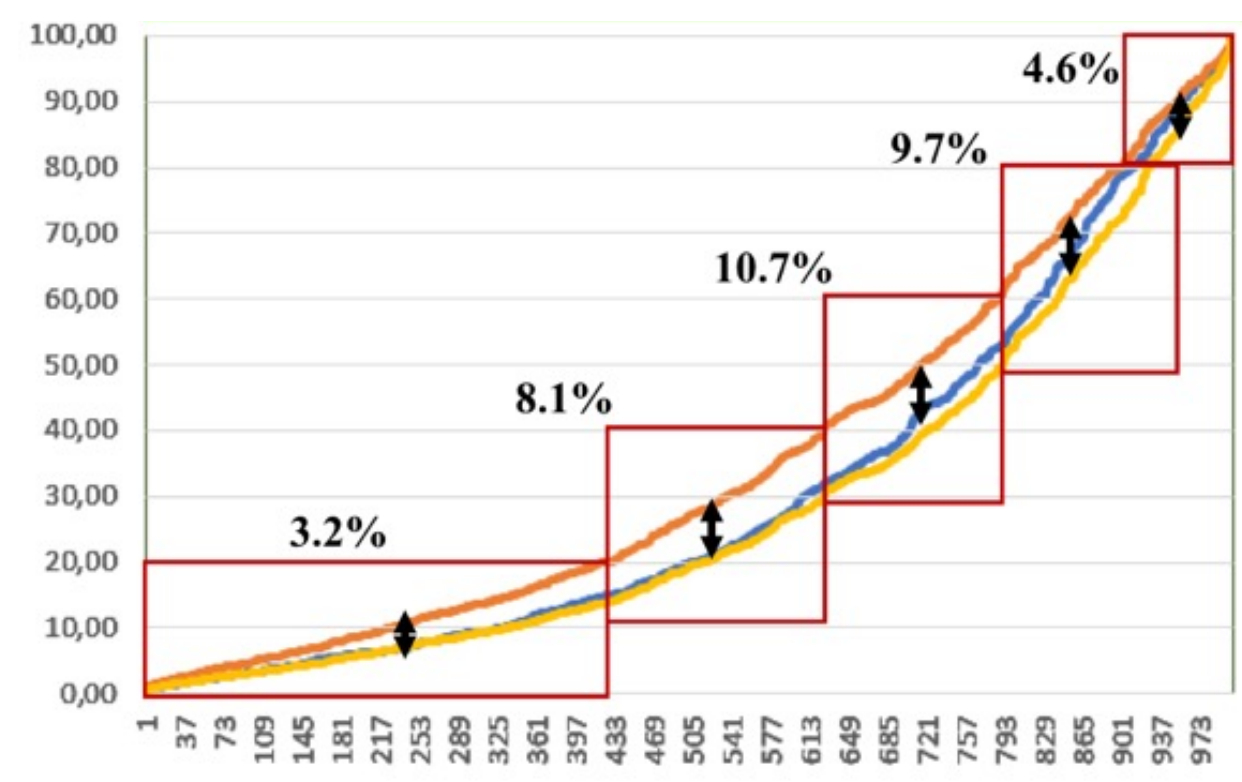

Figura 18. Curva de predicción de mortalidad hospitalaria en endocarditis infecciosa izquierda según el modelo que incluye cirugía cardiaca. Se muestra la predicción del modelo en los pacientes del grupo ENDOVAL de acuerdo a sus características reales (línea azul), suponiendo ausencia de cirugía en todos los pacientes (línea naranja) y suponiendo cirugía urgente en todos los pacientes (línea amarilla). 
7. DISCUSIÓN 


\subsection{PRINCIPALES HALLAZGOS DEL TRABAJO}

Nuestro trabajo es el primer estudio en endocarditis infecciosa que aporta un modelo predictivo capaz de determinar el riesgo de muerte intrahospitalaria individual del paciente con endocarditis infecciosa izquierda con alta precisión. Presentamos un modelo de predicción de mortalidad hospitalaria utilizando las variables pronósticas propuestas por la guía de manejo de la endocarditis infecciosa de la Sociedad Europea de Cardiología. (3)

Existen numerosos estudios que evalúan factores pronósticos concretos en el curso clínico de la endocarditis infecciosa. Muchos de ellos muestran resultados estadísticamente significativos, pero la mayoría tienen un interés práctico marginal, y metodológicamente presentan carencias importantes. La guía europea de práctica clínica en el manejo de la endocarditis infecciosa recoge las variables pronósticas más importantes agrupadas según las características del paciente, las complicaciones clínicas de la enfermedad, el tipo de microorganismo y los hallazgos ecocardiográficos. (3) Es cierto que no todas ellas presentan una extenso soporte científico y bibliográfico para su justificación, pero han sido evaluadas y propuestas por el grupo de autores de la guía, y ratificadas por los revisores, un amplio grupo de expertos en el manejo de la endocarditis infecciosa.

Probablemente habríamos conseguido un modelo predictivo con mayor sensibilidad y especificad interna utilizando únicamente los factores pronósticos relevantes en nuestra población de endocarditis infecciosa. De hecho, no todos los factores pronósticos propuestos por la guía europea mostraron asociación con la mortalidad en los análisis, o al menos, no lo hicieron de forma estadísticamente significativa. Sin embargo, la utilización de una información estándar, avalada por la Sociedad Europea de Cardiología y los máximos expertos en el manejo de la enfermedad, aumenta la utilidad práctica del modelo presentado como se evidencia en los resultados de la validación externa. 
Otro hallazgo relevante del trabajo es la valoración del impacto pronóstico de la cirugía cardiaca en la mortalidad hospitalaria de la endocarditis infecciosa. La cirugía cardiaca es un factor protector para todos los pacientes con endocarditis infecciosa izquierda, pero especialmente en pacientes de riesgo intermedio lo que constituye un hallazgo interesante. Los pacientes de bajo riesgo evolucionan favorablemente en la mayoría de los casos sin necesidad de cirugía. Por otro lado, en los pacientes de alto riesgo, es decir, con indicadores de mal rponóstico, la cirugía llega tarde. Muchos de ellos son pacientes con infección persistente cuyo problema es sitémic, y una solución local como la cirugía apenas influye en el pronóstico. Es en los pacientes de riesgo intermedio en los que la cirugía puede cambiar el curso de la enfermedad.

\subsection{COMPARACIÓN DE LOS RESULTADOS CON LA LITERATURA}

\subsubsection{Trabajos que evalúan el pronóstico de la endocarditis infecciosa}

Revisando la literatura existen 3 trabajos clásicos que evalúan de forma global el pronóstico de la endocarditis infecciosa. $(15,16,20)$.

Un estudio multicéntrico italiano con 1024 episodios de endocarditis infecciosa en 24 centros entre 2004 y 2009 reporta una mortalidad en endocarditis infecciosa del 15\% e identifica la insuficiencia cardiaca, el ictus, la infección protésica, el Estafilococo aureus y la infección asociada a cuidados sanitarios como factores independientes de mortalidad, mientras que la cirugía se muestra como factor protector. (15)

Por otro lado, el grupo multicéntrico internacional ICE ("Interational Collaboration on Endocarditis") presentó en el año 2009 los resultados de un trabajo multicéntrico incluyendo 2781 episodios de endocarditis infecciosa definitiva de 58 hospitales en 25 países entre el año 2000 y 2005. Esta población presenta una mortalidad hospitalaria del $17.7 \%$ y los factores predictores independientes de mortalidad son la endocarditis protésica, la edad, el edema agudo de pulmón, la infección por Estafilococo aureus o Estafilococos coagulasa negativos, la vegetación en válvula mitral y las complicaciones perianulares, mientras que la infección por Estreptococo del grupo viridans y la cirugía se asociaron a una menor mortalidad. (16)

\section{DISCUSIÓN}

\section{P. E. García Granja}


Finalmente, el grupo AEPEI del Hospital de Lyon presentó en 2007559 casos de endocarditis infecciosa definitiva con una mortalidad del 17\%. Los predictores de mortalidad eran el antecedente de insuficiencia cardiaca, la inmunosupresión, la diabetes mellitus insulino-dependiente, la afectación izquierda, el desarrollo de insuficiencia cardiaca o shock séptico, el Glasgow coma score bajo, la hemorragia cerebral y la proteína $\mathrm{C}$ reactiva elevada. (20)

La mortalidad de las 2 poblaciones presentadas en nuestro trabajo es significativamente mayor a la reportada en estos trabajos. Se trata de tres trabajos clásicos sobre el pronóstico de endocarditis infecciosa que presentan una visión global de la enfermedad, pero que a nuestro juicio tienen carencias metodológicas importantes. La principal limitación para la aplicación práctica de la información derivada de estos trabajos es la inclusión de pacientes con endocarditis infecciosa izquierda y derecha. Ya hemos señalado que la endocarditis infecciosa izquierda presenta unas particularidades clínicas y epidemiológicas que condicionan un curso clínico y un pronóstico radicalmente diferente al de la endocarditis infecciosa con afectación derecha, por lo que se trata de 2 entidades clínicas diferentes que no pueden ser evaluadas conjuntamente. (10-14) De hecho, el trabajo del grupo AEPEI reconoce la afectación izquierda como un factor pronóstico independiente de mortalidad hospitalaria. (20)

Por tanto, consideramos que la información derivada de estos trabajos debe ser manejada con cautela, y no es posible su aplicación sistemática en la evaluación de pacientes con endocarditis infecciosa izquierda. 


\subsubsection{Trabajos que evalúan factores pronósticos de la endocarditis infecciosa}

Existen otros trabajos que evalúan el pronóstico intrahospitalario de la endocarditis infecciosa identificando variables pronósticas en el curso clínico de la enfermedad. Algunos de ellos evalúan la población de endocarditis de forma general, y otros lo hacen desde el prisma de un aspecto concreto de la misma como la edad, las comorbilidades, las complicaciones clínicas particulares de la enfermedad, el tipo de microorganismo, la persistencia de hemocultivos positivos, el resultado del cultivo valvular, los hallazgos ecocardiográficos, etc. Estos trabajos son muy heterogéneos y presentan carencias metodológicas importantes pero aportan información muy útil para identificar factores pronósticos de la enfermedad que puedan ser evaluados precozmente durante el proceso diagnóstico y terapéutico de los pacientes. Esta información podría ayudar en la toma de decisiones para modificar el curso clínico de la enfermedad. (21)

Existen muchas variables pronósticas identificadas, pero algunas únicamente reflejan las particularidades concretas de cada población estudiada y no pueden generalizarse en la evaluación de los pacientes con endocarditis. El comité de expertos de la Sociedad Europea de Cardiología para la confección de la guía de manejo de la endocarditis infecciosa evalúa toda la información científica disponible y su propia experiencia clínica e investigadora en el campo y propone los factores pronósticos más importantes de la enfermedad agrupados de acuerdo a las características clínicas del paciente, la evolución clínica de la enfermedad, el tipo de microorganismo y los hallazgos de las pruebas de imagen. (3)

\subsubsection{Características del paciente}

La mayoría de estudios en este sentido se centran en evaluar principalmente el impacto pronóstico de la edad, la endocarditis protésica y la diabetes mellitus, y en menor medida la presencia de otras comorbilidades. 
La edad se identifica repetidamente como un factor de mal pronóstico en la endocarditis infecciosa izquierda y nuestro trabajo está en consonancia con esta información. Existen dos motivos fundamentales que explican esta asociación: el aumento asociado de las comorbilidades del paciente y el condicionamiento del tratamiento. El incremento progresivo en la edad de los pacientes asocia cambios en su perfil epidemiológico y en las características clínicas y microbiológicas de la endocarditis infecciosa que parecen justificar la falta de mejoría en el manejo de la enfermedad en los últimos años. $(5,31)$ Por otro lado, la edad condiciona el tratamiento quirúrgico de la enfermedad. El porcentaje de pacientes sometidos a cirugía cardiaca disminuye progresivamente con la edad. $(28-30)$

Numerosos trabajos evalúan la endocarditis protésica como factor pronóstico en endocarditis infecciosa, y demuestran una mortalidad hospitalaria entre el $20 \%$ y el $40 \%$ según la serie, en línea con los datos presentados en nuestro trabajo. $(3,33,55-57)$ Esta entidad asocia con mayor frecuencia otros factores de mal pronóstico como la edad avanzada, la diabetes mellitus, el Estafilococo aureus, la infección persistente o el shock séptico, pero además condiciona también el manejo terapéutico, con una menor tasa de cirugía cardiaca en este contexto. $(55,57,65)$ Existe información contradictoria respecto al tratamiento de esta entidad particular pero la guía europea de práctica clínica recomienda la estrategia quirúrgica en casos de endocarditis protésica y alto riesgo, pudiéndose optar por el tratamiento conservador con una vigilancia activa en casos de endocarditis protésica tardía no complicada sin afectación por Estafilococos u hongos. $(69,70,73)$

El impacto pronóstico de la diabetes mellitus en endocarditis infecciosa genera controversia en la literatura. Nuestro trabajo está en consonancia con la literatura general demostrando que los pacientes con diabetes mellitus presentan mayor mortalidad pero revela que esta comorbilidad no es un factor independiente de mortalidad hospitalaria. $(15,74-76,80,84,85)$ Probablemente la diabetes mellitus predispone a la infección grave y al desarrollo de infección no controlada, y es el shock séptico el verdadero factor pronóstico independiente en este contexto como se sugiere en un estudio de nuestro grupo específicamente dirigido a evaluar a esta población. (74)

\section{DISCUSIÓN}

\section{P. E. García Granja}


Muchos trabajos evalúan el impacto pronóstico de diferentes comorbilidades en el ámbito de la endocarditis infecciosa. El término comorbilidad es muy amplio, y puede ser interpretado de formas muy diversas. De acuerdo a la guía europea de manejo de la endocarditis infecciosa hemos considerado como comorbilidad la presencia de cualquiera de las siguientes condiciones: insuficiencia renal crónica, enfermedad pulmonar obstructiva crónica e inmunodepresión. La presencia de cualquiera de estas condiciones es un factor pronóstico independiente en nuestro estudio, lo que encaja con los estudios que sugieren que el aumento de la edad y las comorbilidades de los pacientes impiden la mejoría en el pronóstico de la enfermedad asociada a los avances en el diagnóstico y tratamiento de la misma. $(5,27,31)$ Es probable que la utilización de un concepto más amplio de comorbilidad, incluyendo por ejemplo la patología oncológica o la propia diabetes mellitus, o la utilización de escalas de comorbilidad validadas como el índice de Charlson, permitirían evaluar de forma más precisa este concepto abstracto y puedan suponer una mejora de nuestro modelo predictivo en el futuro. (22)

\subsubsection{Complicaciones clínicas}

Las complicaciones clínicas son los factores pronósticos con más bibliografía asociada, y por tanto con mayor evidencia científica para su utilización predictiva. Las indicaciones quirúrgicas de la guía europea de endocarditis infecciosa se basan principalmente en la presencia de estas complicaciones, ya que el objetivo del tratamiento es el control de la infección mediante la eliminación del tejido infectado y la restauración de la funcionalidad de las estructuras cardiacas lo que mejora la situación hemodinámica del paciente $(3,57,101,102)$. 
La insuficiencia cardiaca es un factor pronóstico independiente de mortalidad identificado de forma repetitiva en los diferentes estudios sobre el pronóstico de la endocarditis infecciosa, lo que se encuentra en consonancia con los hallazgos de nuestro trabajo. $(15,17,89,103,104)$ Sin embargo, hay que considerar cierta evidencia científica que sugiere que la insuficiencia cardiaca presenta diferente impacto pronóstico de acuerdo a la clase funcional del paciente y a la presencia de datos de repercusión hemodinámica. $(101,111,112)$ De esta forma, habría que considerar la posibilidad de evaluar la clase funcional de la insuficiencia cardiaca como una manera de mejorar la estraficiación pronóstica del modelo predictivo presentado.

No existe ningún estudio que evalúe de forma directa y sistemática la insuficiencia renal aguda como complicación de la endocarditis infecciosa. Sí que existen trabajos en los que se establece su valor pronóstico independiente. La insuficiencia renal aguda asocia incrementos superiores a 2 veces el riesgo de muerte hospitalaria, fundamentalmente cuando aparece como parte de la fisiopatología de la insuficiencia cardiaca o el shock séptico. $(101,102,115-123)$ Estos resultados están en la línea de nuestros hallazgos y justifican su inclusión como una variable pronóstica por la guía europea de manejo de la endocarditis infecciosa.

Las complicaciones neurológicas también son un factor pronóstico propuesto por la guía europea, por su asociación con la mortalidad pero también por las secuelas funcionales que llevan asociadas. La literatura respecto al valor pronóstico de estas complicaciones no es muy amplia, y suele encontrar asociación con la endocarditis infecciosa por Estafilococo aureus y la presencia de vegetaciones de gran tamaño, variables pronósticas con mayor valor científico contrastado. $(135,136)$ Esta podría ser la causa de la ausencia de valor pronóstico de estas variables en nuestro estudio, junto con el bajo número de casos que los porcentajes representan, y la no inclusión de los fenómenos embólicos silentes. Estos últimos son reconocidos por su valor diagnóstico en la enfermedad pero su valor pronóstico no ha sido evaluado de forma apropiada y podrían actuar como un factor de confusión en algunos estudios. (132-134) 
Quizá el shock séptico sea el factor pronóstico más importante en la endocarditis infecciosa, con numerosos trabajos que evalúan su influencia en la mortalidad de la endocarditis infecciosa $y$ que alcanza el $50 \%$ en algunas series. $(16,18,20,76,109,117,118,142-144)$ Los resultados de nuestro estudio son similares a los de la literatura, con un aumento de la mortalidad asociado a esta condición de entre 8 y 10 veces, y refleja una situación de difícil manejo clínico. El shock séptico asocia frecuentemente otros factores de mal pronóstico como la diabetes mellitus, el Estafilococo aureus, la insuficiencia renal aguda, las vegetaciones de gran tamaño o las complicaciones perianulares. $(18,119,123,145-148,152)$ La actitud terapéutica es difícil de establecer. El desbridamiento de los tejidos infectados es un factor clave para el control de la infección pero el shock séptico refleja una situación de inestabilidad sistémica en el que la cirugía cardiaca entraña un riesgo particularmente alto y cuyo beneficio pronóstico es controvertido. $(3,101,154)$

\subsubsection{Tipo de microorganismo}

Los artículos publicados respecto al impacto pronóstico del microorganismo causal son abundantes. De forma reiterada se identifica el Estafilococo aureus como factor predictor de mal pronóstico y los Estreptococos, fundamentalmente el grupo Viridans, como factor protector de muerte hospitalaria en endocarditis infecciosa. (15, 16) Además, se ha investigado sobre el impacto pronóstico de otros aspectos microbiológicos como la persistencia de hemocultivos positivos, el cultivo valvular positivo, la infección polimicrobiana etc. $(114,254,255)$ La guía de manejo de la endocarditis infecciosa de la Sociedad Europea de Cardiología reconoce como factores pronósticos la infección por Estafilococo aureus, la infección por hongos y la infección por bacilos gram negativos no-HACEK, y además reconoce en su texto que la persistencia de hemocultivos positivos a las 48-72 horas del inicio del tratamiento antibiótico es un predictor precoz de mal pronóstico. (3) 
En nuestro trabajo hemos ratificado el impacto pronóstico de la infección por Estafilococo aureus y por hongos, pero no encontramos asociación estadísticamente significativa con los bacilos gram negativos no-HACEK.

De acuerdo a la literatura, el Estafilococo aureus asocia episodios de endocarditis infecciosa aguda y destructiva, con alta mortalidad sobre todo en casos de afectación protésica. (161) La mortalidad asociada varía según las series consultadas en la literatura, así como varían los criterios de inclusión de las mismas, y se sitúa entre el $22 \%$ y el $46 \%$, algo inferior a la reportada en nuestro trabajo (56\%). No debemos olvidar que el Estafilococo aureus lleva asociados otras factores que también asocian una mayor mortalidad hospitalaria como son la diabetes mellitus, un índice de Charlson elevado, la insuficiencia renal, la afectación protésica o la sepsis severa y el shock séptico. $(172,174)$

La inclusión de los bacilos gram negativos no-HACEK como factor pronóstico en la guía europea se basa en una literatura antigua y escasa. Se reportan cifras de mortalidad que varían entre el $30 \%$ y el $85 \%$, y el único trabajo actual al respecto reporta una mortalidad del $24 \%$, que no es estadísticamente superior a la del resto de la población $(17 \%, \mathrm{p}=0.190)$ y tampoco parece desproporcionada. (181-190) En nuestro trabajo su mortalidad asociada es del 33\%, sin existir una relación independiente de este grupo de microorganismos con la mortalidad, pero basándonos en la recomendación de la guía europea hemos incluido esta variable en el modelo pronóstico.

La mortalidad de la endocarditis infecciosa izquierda por hongos se sitúa en el $50 \%$ en la literatura, similar a la mortalidad de esta población en nuestro estudio. (175178) Probablemente los hongos sean el microorganismo más agresivo pero su importancia pronóstica relativa es baja debido a su baja frecuencia. La guía europea recomienda cirugía cardiaca urgente o electiva en casos de endocarditis infecciosa causada por hongos, pero además propone la realización de tratamientos antifúngicos vía oral de larga duración o incluso indefinidos para evitar las recurrencias. El tratamiento exitoso de estos pacientes es a menudo difícil. $(175,178,179)$ 
Finalmente, señalamos que no hemos evaluado la influencia de los hemocultivos persistentemente positivos a las 48-72 horas del inicio del tratamiento antibiótico porque no disponemos de esta información recogida de forma sistemática en nuestra población. La utilidad de esta variable se basa en un trabajo de nuestro grupo que muestra una asociación independiente de la persistencia de los hemocultivos positivos a las 48-72 horas del inicio del tratamiento antibiótico con la mortalidad hospitalaria. (254) De esta forma, esta variable podría aumentar la capacidad pronóstica del modelo, y podría ser una línea de investigación para el futuro.

\subsubsection{Hallazgos de las pruebas de imagen}

Las técnicas de imagen son esenciales en el proceso diagnóstico de la endocarditis infecciosa pero además aportan un importante valor pronóstico. El ecocardiograma aglutina la mayor parte de bibliografía al tratarse de una herramienta sencilla y fácil de usar que se encuentra ampliamente validada. (101, 191-193). Entre los hallazgos con más información pronóstica se encuentran la complicación perianular y las vegetaciones mientras que otros factores pronósticos como la hipertensión pulmonar y la disfunción ventricular se asumen de acuerdo a su evidencia en la patología cardiovascular en general.

De acuerdo con la literatura la extensión perivalvular de la endocarditis infecciosa es la causa más frecuente de infección no controlada, y precisa cirugía hasta en el $90 \%$ de los casos, con una mortalidad en torno al 40\%. $(52,106,210)$ Estas cifras son muy similares a las de nuestro trabajo. De nuevo debemos señalar que la complicación perianular aparece frecuentemente en contexto de otros factores pronósticos asociados, fundamentalmente la endocarditis protésica, la disfunción valvular severa o el shock séptico. $(208,209)$ 
Por su parte, la presencia de vegetaciones y su tamaño es un factor pronóstico en endocarditis infecciosa, fundamentalmente asociado a un mayor riesgo embólico. $(135,137,149,191,233,235-239)$ La guía de la Sociedad Europea de Cardiología para el manejo de la endocarditis infecciosa señala como factor pronóstico el tamaño de la vegetación, pero nosotros consideramos que esta medida presenta una gran variabilidad intra e interobservador y por tanto sólo hemos considerado la presencia de vegetación como variable dicotómica. (313) No podemos olvidar que la presencia de vegetaciones es un criterio mayor de endocarditis infecciosa, de tal forma que su ausencia, si bien no descarta el diagnóstico, lo hace por lo menos más dudoso y su pronóstico más favorable. De hecho, la endocarditis infecciosa posible muestra un pronóstico claramente más favorable que la endocarditis definitiva, con una mortalidad que es menor de la mitad, de acuerdo a la información presente en la literatura. (256)

El impacto pronóstico de la disfunción valvular o protésica severa no ha sido evaluado de forma directa en ningún estudio. Sabemos que puede cursar de forma asintomática pero frecuentemente asocia insuficiencia cardiaca, y es probable que sea la complicación clínica la que marca el pronóstico de la enfermedad y no tanto la afectación estructural. $(17,109)$ Esto concuerda con la falta de valor pronóstico independiente de esta variable en nuestro estudio.

Finalmente la disfunción ventricular y la hipertensión pulmonar son factores pronósticos clásicos de la patología cardiovascular, pero que no han sido específicamente evaluados en el ámbito de la endocarditis infecciosa. (216,220) Existe un trabajo sobre disfunción ventricular en endocarditis infecciosa que relaciona su presencia con un riesgo 3 veces mayor de mortalidad al año en pacientes con endocarditis infecciosa sometidos a cirugía. (215) Nuestro trabajo avala el factor pronóstico de esta variable, pero parecen necesarios nuevos estudios para profundizar en el estudio esta variable y llegar a determiner el punto de corte de fracción de eyección que mejor determina el riesgo, o identificar la presencia de predictores precoces que ayuden en la estratificación pronóstica. 
Ninguna información existe respecto al impacto pronóstico de la hipertensión pulmonar en endocarditis infecciosa izquierda, y la única información disponible deriva de estudios realizados en pacientes con insuficiencia cardiaca de origen izquierdo. $(226,227)$ Nuestro trabajo sugiere un posible valor pronóstico de esta variable, que puede estar englobado dentro de la insuficiencia cardiaca. Como ocurre con la disfunción valvular severa, sería la manifestación clínica la que marcaría el pronóstico y no tanto el daño estructural. No obstante, debemos reconocer la limitación terminológica del concepto hipertensión pulmonar, en el que hemos valorado prácticamente en exclusiva los hallazgos ecocardiográficos para su identficiación.

\subsubsection{Cirugía cardiaca}

Existen numerosos estudios observacionales en la literatura que sugieren un factor protector de la cirugía cardiaca en el pronóstico de la endocarditis infecciosa. En este contexto la técnica quirúrgica permite el desbridamiento de los tejidos infectados, ayuda al control la infección, evita los fenómenos embólicos y restaura la funcionalidad de las estructuras cardiacas. $(21,57,104,245-247)$ La realización de estudios aleatorizados es difícil en este contexto, y únicamente existe un estudio aleatorizado unicéntrico que valora el impacto pronóstico de la cirugía cardiaca precoz en un evento combinado de muerte hospitalaria y embolias en una población particular de bajo resigo con buenos resultados. (248)

Nuestro trabajo está en consonancia con estos trabajos, apoya el valor protector de la cirugía cardiaca para cualquier tipo de paciente, y demuestra una mayor beneficio relativo en pacientes de riesgo intermedio-alto que en pacientes de riesgo bajo o muy alto. Añadir la variable cirugía a nuestro modelo pronóstico desarrollado con las variables de la guía europea podría tener cierto valor pronóstico añadido además de un interés práctico, por lo que puede ser una vía de investigación en la que insistir en el futuro. 


\subsubsection{Características diferenciales de nuestro estudio}

Nuestro trabajo presenta unas particularidades metodológicas con respecto a la mayoría de trabajos presentados que evalúan el pronóstico de la endocarditis infecciosa, $\mathrm{y}$ creemos que estas diferencias aumentan el valor y la utilidad de los resultados presentados.

Estas particularidades son las siguientes:

- Solamente se ha utilizado en el estudio la información derivada de pacientes con endocarditis infecciosa izquierda o mixta, ya que se trata de la entidad clínica más frecuente y presenta, como hemos explicado previamente, unas implicaciones clínicas, microbiológicas, ecocardiográficas y pronósticas diferentes a la endocarditis con afectación exclusiva derecha o con afectación de dispositivos cardiacos implantados.

- El número de pacientes incluidos en el estudio es muy amplio. La endocarditis infecciosa es una entidad poco frecuente, y no es habitual encontrar estudios con este número de pacientes. Hemos utilizado la información de 4 hospitales terciarios del Sistema Nacional de Salud, lo que evita los sesgos asociados a los estudios unicéntricos, respalda estadística y metodológicamente los resultados y permite una mayor generabilidad de los mismos, al menos para hospitales de tercer nivel con un perfil similar.

- La información recogida es homogénea y de alta calidad. El grupo ENDOVAL está formado por tres centros terciarios que son referencia en el diagnóstico, la atención y el manejo de los pacientes con endocarditis infecciosa, y disponen de equipos multidisciplinares involucrados en este proceso, con lo que se asegura la calidad y la homogeneidad de los datos recogidos, y la baja probabilidad de pérdida de casos de endocarditis infecciosa izquierda. Por su parte, el Hospital Universitario Puerta de Hierro forma también parte de grupos multicéntricos de excelencia en el estudio y manejo de la enfermedad, lo que garantiza la calidad clínica, científica e investigadora del mismo en este ámbito. Como hemos presentado en los resultados, la población del Hospital Puerta de Hierro presenta 
algunas particularidades respecto a la población del grupo ENDOVAL que si bien pueden suponer una limitación metodológica, dan más valor si cabe a los resultados de la validación externa.

- El trabajo no se ha limitado a identificar los factores pronósticos de nuestra población con endocarditis infecciosa izquierda. Se ha evaluado de forma sistemática y conjunta el valor pronóstico de una serie de variables previamente identificadas y evaluadas por el comité de expertos de la guía europea de endocarditis infecciosa. Esto respalda la calidad científica de las variables, evita el sesgo que nuestra población pudiera introducir en la identificación de otras variables pronósticas y favorece la aplicación de nuestros resultados a otras poblaciones con sus particularidades concretas.

- La variable principal del estudio (muerte intra-hospitalaria) es una variable dura. Desde el punto de vista clínico, la evolución intra-hospitalaria es el periodo más critico de los pacientes con endocarditis infecciosa, dónde se concentra el mayor porcentaje de mortalidad, dónde se plantean los retos diagnósticos y terapéuticos para el facultativo, y dónde realmente las decisiones clínicas pueden modificar el pronóstico de la enfermedad. La evolución y la mortalidad tras el alta hospitalaria está generalmente marcada por las características clínicas del paciente y por procesos adyuvantes a la endocarditis infecciosa, sin que ésta juegue un papel pronóstico tan marcado. 


\subsection{IMPLICACIONES PRÁCTICAS DEL TRABAJO}

El diagnóstico y el tratamiento de la endocarditis infecciosa son un desafío clínico. En los últimos años se han producido importantes cambios en el perfil epidemiológico de los pacientes que llevan asociado un aumento de su complejidad, así como abundantes innovaciones tecnológicas en las herramientas diagnósticas y terapéuticas. $(5,27,31) \mathrm{La}$ responsabilidad del proceso asistencial no puede recaer en un único facultativo y por eso surgen los Equipos de Endocarditis. Dentro de sus funciones se encuentra la discusión de casos complejos, la toma de decisiones quirúrgicas, la elección del tipo, duración y seguimiento del tratamiento antibiótico, etc. (3) En este sentido, la identificación precoz de pacientes de alto riesgo que se puedan beneficiar de una intervención quirúrgica es muy útil. Aunque las indicaciones de cirugía cardiaca estén bien establecidas en la guía de la Sociedad Europea de Cardiología, cada caso debe ser evaluado de forma individual teniendo en cuenta sus condicionantes particulares, de tal forma que la indicación quirúrgica debe basarse en la combinación de varios determinantes de alto riesgo que están recogidos en la guía europea. (42)

Nuestro modelo predictivo de mortalidad hospitalaria en endocarditis infecciosa surge como una herramienta sencilla que trata de ayudar en la evaluación individualizada y multidisciplinar por los Equipos de Endocarditis de los pacientes con endocarditis infecciosa izquierda. De esta forma, presentamos una aplicación para móviles que permite evaluar el impacto pronóstico de las características del paciente, la evolución clínica de la enfermedad, el tipo de microorganismo involucrado y los hallazgos de las pruebas diagnósticas. Esta calculadora está especialmente diseñada para ser aplicada en centros terciarios, referencia en el manejo de la endocarditis infecciosa y con disponibilidad inmediata de cirugía cardiaca.

La utilización de nuestro modelo predictivo no debe circunscribirse a la evaluación individualizada en los equipos multidisciplinares. Esta herramienta permite evaluar el impacto pronóstico de cada variable durante la evolución de la enfermedad y modificar la toma de decisiones de acuerdo a la influencia pronóstica que estas variables tienen.

\section{DISCUSIÓN}

\section{P. E. García Granja}


Además, aunque los estudios científicos buscan dar soluciones al facultativo clínico en la toma de decisiones respecto a la enfermedad, no debemos olvidar que realmente es el paciente quién debe tomar las decisiones según una información científica rigurosa y de calidad. En este sentido nuestro modelo y su presentación en formato aplicación móvil es una herramienta muy útil en la información del paciente y sus familiares, para ayudarles a comprender las dimensiones de la enfermedad y el impacto pronóstico de cada evento acontecido durante la evolución de la misma.

Finalmente, la evaluación del impacto pronóstico de la cirugía cardiaca en el modelo predictivo nos permite sugerir su teórico valor protector en endocarditis infecciosa izquierda. La cirugía cardiaca puede ser el elemento modificador del curso clínico de la enfermedad, de tal forma que sea la decisión del "Equipo de Endocarditis" tras la evaluación integral del paciente. Los hallazgos de nuestro trabajo abren la puerta a incluir esta variable en el modelo pronóstico, así como la elaboración de estudios específicamente dirigidos a la evaluación de la indicación quirúrgica de acuerdo al riesgo del paciente. No obstante, en la decisión de la intervención quirúrgica deben evaluarse otros condicionantes, y particularmente el riesgo quirúrgico individualizado de cada paciente de acuerdo a sus características. Las escalas de riesgo de mortalidad quirúrgica como el RISK-E han demostrado su utilidad en este sentido. $(29,30,257,258)$ 


\subsection{LÍNEAS FUTURAS DE INVESTIGACIÓN}

La información derivada de nuestro trabajo abre la posibilidad a nuevas líneas de investigación. En este sentido consideramos prioritarios los siguientes puntos:

- Validar prospectivamente la capacidad discriminativa de nuestro modelo predictivo en diferentes cohortes de pacientes con endocarditis infecciosa izquierda.

- Evaluar de forma prospectiva el impacto pronóstico de la cirugía cardiaca en endocarditis infecciosa izquierda de acuerdo al riesgo particular del paciente estimado por el modelo.

- Explorar la utilidad del modelo pronóstico en endocarditis infecciosa izquierda en la toma de decisiones sobre diferentes estrategias terapéuticas.

- Determinar el momento óptimo de la intervención quirúrgica en pacientes con endocarditis infecciosa izquierda de acuerdo a las características del paciente y el curso de la enfermedad.

- Desarrollar un modelo predictivo similar para otras formas de endocarditis infecciosa como la endocarditis derecha o la endocarditis sobre dispositivos intracardiacos.

La generalización en el uso de nuestra aplicación es el paso previo al inicio de estos nuevos proyectos. El apoyo de las sociedades científicas con la inclusión del modelo en la próxima actualización de la guía europea serían claves en este proceso. Es su responsabilidad fomentar y liderar registros internacionales y ensayos clínicos en patologías poco prevalentes o aspectos controvertidos de las mismas, ya que las recomendaciones de actuación están a menudo limitadas por la calidad científica de los estudios que las avalan. 


\subsection{LIMITACIONES}

Todos los centros que han participado en el estudio son hospitales terciarios con cirugía cardiaca, referencia en endocarditis infecciosa para otros centros sanitarios satélites de sus respectivas regiones. Esto supone un sesgo en el tipo de pacientes incluidos en nuestra serie, ya que no todos los pacientes con endocarditis infecciosa ingresados en otros centros son remitidos a los centros de referencia, sino que generalmente se remiten únicamente los que peor evolución clínica presentan. La población analizada no es representativa de la población general con endocarditis, sino de la atendida en centros de estas características. Por tanto, la utilización del modelo predictivo y las conclusiones obtenidas en el presente trabajo sólo pueden ser aplicables a poblaciones de características similares; hospital terciario, referencia en endocarditis y con acceso inmediato a cirugía cardiaca.

El Hospital Universitario Puerta de Hierro es un centro ajeno al grupo ENDOVAL. Se trata de un centro con un perfil similar: centro terciario, referencia en endocarditis, con disponibilidad de cirugía cardiaca inmediata y comprometido con la investigación multicéntrica, pero no comparte de forma íntegra la metodología de trabajo establecida para nuestro grupo. De esta forma, no podemos asegurar al completo la homogeneidad en la recogida de las variables entre ambos grupos. Además, se trata de una cohorte de pacientes temporalmente más reciente y con un intervalo temporal más pequeño que la población del grupo ENDOVAL. Esto podría justificar algunas de las diferencias encontradas entre ambas poblaciones, y además podría limitar la utilidad de nuestro modelo predictivo en esta población. Sin embargo, desde otro punto de vista, el hecho de que la validación del modelo sea buena (área bajo la curva ROC de 0.751 ) refuerza el interés clínico de nuestra calculadora al funcionar con garantías en una población de endocarditis diferente a la nuestra, pero que representa un ámbito de actuación real.

Aunque la recogida de información en todos los centros se realiza de forma precisa y homogénea debido a su experiencia en el ámbito clínico-asistencial y científico de la endocarditis infecciosa, es posible, que algún paciente con endocarditis infecciosa 
ingresado no haya sido identificado y analizado. La existencia de equipos multidisciplinares de atención de la endocarditis infecciosa en cada centro hace muy improbable esta situación.

Solamente hemos considerado pacientes con endocarditis infecciosa y afectación izquierda, ya sea exclusiva o mixta. Este hecho es una fortaleza de nuestro estudio al haber analizado una población más concreta con unas particularidades epidemiológicas, clínicas, microbiológicas y pronósticas bien establecidas, sin embargo nos impide generalizar el uso del modelo predictivo a la población con afectación exclusiva derecha o a la endocarditis sobre dispositivos cardiacos implantados.

La introducción de las variables en el modelo pronóstico no ha sido aleatoria. Hemos utilizado las variables pronósticas propuestas por la guía de manejo de la endocarditis infecciosa de la Sociedad Europea de Cardiología independientemente de su p-valor en el análisis estadístico en nuestra población. Esto puede limitar el valor predictivo del modelo, pero aumenta la calidad científica del mismo y su utilidad práctica al utilizar información validada por el comité de expertos de la guía europea y al evitar los sesgos que nuestra población podría introducir en la elección de variables.

Algunas de las variables presentan una definición laxa, sujeta a la interpretación del facultativo. Hemos tratado de evitar esta limitación mediante la predefinición de las variables de forma objetiva, sencilla y fácilmente reproducible, y para ello hemos tenido que convertir variables clínicamente continuas en variables dicotómicas. Esto puede limitar la evaluación del impacto pronóstico de cada variable pero facilita el acceso y uso de la aplicación y respalda su reproducibilidad. 
8. CONCLUSIONES 
1. Las variables pronósticas propuestas por la guía de manejo de la endocarditis infecciosa de la Sociedad Europea de Cardiología conforman un modelo predictivo de mortalidad hospitalaria en endocarditis infecciosa izquierda con buena capacidad discriminativa.

2. La presentación del modelo predictivo en formato de aplicación móvil constituye una forma sencilla e intuitiva de facilitar el acceso de los profesionales y los pacientes a la información.

3. La cirugía cardiaca se muestra como un factor protector de mortalidad hospitalaria en endocarditis infecciosa izquierda, y aporta su mayor beneficio en los pacientes con riesgo intermedio. 
9. ANEXOS 


\section{CRITERIOS DIAGNÓSTICOS}

\section{Endocarditis infecciosa definitiva:}

- Criterios anatomopatológicos:

- Microorganismos: demostrados por cultivo o por histología en una vegetación, o en una vegetación que ha producido una embolia, o un absceso intracardíaco.

○ Lesiones anatomopatológicas: vegetación o absceso intracardíaco presente confirmado por una histología que muestra una endocarditis activa

- Criterios clínicos:

- 2 criterios mayores

- 1 criterio mayor y 3 menores o 5 criterios menores.

2. Endocarditis infecciosa posible: Hallazgos compatibles/sugestivos con endocarditis infecciosa que no la clasifican en definitiva ni en rechazo

\section{Endocarditis infecciosa rechazada:}

- Diagnóstico distinto, que justifique los hallazgos

- Resolución de las manifestaciones clínicas con 4 días o menos de antibioterapia

- Ausencia de signos anatomopatológicos de endocarditis en la cirugía o en la autopsia tras 4 días o menos de antibioterapia 
9.2 ANEXO II: Criterios de Duke para el diagnóstico de endocarditis infecciosa (48)

\section{Criterios MAYORES}

\section{Hemocultivo positivo para endocarditis infecciosa}

- Microorganismo típico de endocarditis infecciosa en dos hemocultivos separados:

- Estreptococo viridans

- Estreptococo bovis

○ Grupo HACEK.

- Estafilococo aureus o Enterococos adquiridos en la comunidad, en ausencia de un foco primario.

- Hemocultivos persistentemente positivos:

- Hemocultivos extraídos con más de 12 horas de diferencia: 3/3 positivos o la mayoría de 4 o más, con al menos 1 hora de separación entre la extracción de primero y último.

2. Evidencia de afectación endocárdica (ecocardiograma positivo):

- Masa intracardíaca oscilante en la válvula o las estructuras de soporte, o en el trayecto de un chorro de regurgitación, o en un material implantado, en ausencia de otra explicación anatómica.

○ Absceso.

- Nueva dehiscencia parcial de una prótesis valvular.

- Regurgitación valvular nueva (no el incremento / modificación de una previa)

\section{Criterios MENORES}

- Predisposición: cardiopatía predisponente o consumo de drogas por vía intravenosa.

- $\quad$ Fiebre $>38^{\circ} \mathrm{C}$ 
- Fenómenos vasculares: embolia de una arteria importante, infartos pulmonares sépticos, aneurisma micótico, hemorragia intracraneal, hemorragias cojuntivales, lesiones de Janeway.

- Fenómenos inmunitarios: glomerulonefritis, nódulos de Osler, manchas de Roth, factor reumatoide.

- Pruebas microbiológicas: hemocultivos positivos pero que no cumplen los criterios mayores (excluyendo un sólo hemocultivo con Estafilococos coagulasa negativos y microorganismos no asociados con endocarditis infecciosa) o evidencia serológica de infección activa por un microorganismo asociado con endocarditis infecciosa.

- Ecocardiograma: compatible con endocarditis infecciosa pero sin cumplir los criterios mayores anteriormente descritos

9.3 ANEXO III. Criterios de Duke modificados para el diagnóstico de endocarditis infecciosa (4)

\section{Criterios MAYORES}

\section{Hemocultivos positivos para endocarditis infecciosa:}

- Microorganismos típicos de endocarditis infecciosa en dos hemocultivos separados:

- Estreptococos del grupo viridans

- Estreptococo bovis

- Grupo HACEK

- Estafilococo aureus o Enterococos adquiridos en la comunidad en ausencia de foco primario.

- Hemocultivos persistentemente positivos para microorganismos típicos:

- Hemocultivos con más de $12 \mathrm{~h}$ de separación: 3/3 positivos o la mayoría de 4 o más separados entre el primero y el útimo al menos 1 hora. 
- Un único hemocultivo positivo para C. burnetii o título de anticuerpos IgG antifase $\mathrm{I} \geq 1: 800$.

\section{Evidencia de afectación endocárdica (ecocardiografía positiva):}

- Vegetación en la válvula, en las estructuras adyacentes o en el choque del chorro de regurgitación valvular, donde haya material implantado en ausencia de otra explicación anatómica.

○ Absceso

- Nueva dehiscencia parcial de una válvula protésica

- Nueva regurgitación valvular (incremento o cambio en un soplo preexistente no es suficiente)

\section{Criterios MENORES}

- Predisposición: cardiopatía predisponente o ser adicto a drogas por vía parenteral.

- Fiebre $\geq 38^{\circ} \mathrm{C}$

- Fenómenos vasculares: émbolos en arterias mayores, infartos pulmonares sépticos, aneurismas micóticos, hemorragia intracraneal, hemorragia conjuntival y lesiones de Janeway.

- Fenómenos inmunitarios (glomerulonefritis, nódulos de Osler, manchas de Roth y factor reumatoide).

- Evidencia microbiológica (hemocultivos positivos que no cumplen los criterios mayores, excluyendo un solo hemocultivo con estafilococos coagulasa negativos y microorganismos no asociados con endocarditis infecciosa) o evidencia serológica de infección por un microorganismos que produce endocarditis infecciosa 


\subsection{ANEXO IV. Definición de las variables del grupo ENDOVAL}

\section{Variables de identificación}

Tipo de endocarditis: se incluyen todos los pacientes que cumplen los criterios diagnósticos definitivos de Endocarditis Infecciosa de Duke (anexos I, II y III).

Fecha de ingreso: Fecha del ingreso durante el cual se establece el diagnóstico de endocarditis. En caso de pacientes referidos se consignará la fecha de admisión del paciente en el primer centro.

Fecha de diagnóstico: Fecha en la que se establece el diagnóstico de certeza de endocarditis.

Fecha de alta: fecha en la que el paciente abandona el hospital por alta hospitalaria o fallecimiento.

\section{Datos epidemiológicos}

Edad: se considera la edad del paciente en el momento del diagnóstico de endocarditis infecciosa.

Género: hombre o mujer.

Referido: caso de endocarditis infecciosa diagnosticado en otro hospital y trasladado por necesidad de cuidados de hospital terciario o cirugía cardiovascular.

Origen: lugar de adquisición de la infección, probable o demostrado.

- Comunitaria: episodio de endocarditis manifestada previo al ingreso o durante las primeras 48 horas del mismo sin reunir criterios de infección asociada a cuidados sanitarios.

- Nosocomial: episodio de endocarditis que se manifiesta a partir de las 72 horas del ingreso o en las primeras 8 semanas tras el alta hospitalaria, o en relación con un procedimiento invasivo.

- No nosocomial asociada a cuidados sanitarios: episodio de endocarditis diagnosticada en un paciente con un estrecho contacto con los cuidados sanitarios, definida por cualquiera de los siguientes: 
- Que haya recibido terapia intravenosa, cuidado de heridas y/o cuidados especializados de enfermería en los 30 días previos al diagnóstico.

- Que haya recibido quimioterapia intravenosa y/o se le haya practicado hemodiálisis en los 30 días previos al diagnóstico

- Que haya sufrido una hospitalización de al menos 48 horas en los 90 días previos al diagnóstico

- Que resida en un centro sanitario de larga estancia o residencia

Cardiopatía de base: referida como lesión presente en la estructura cardiaca afectada previa al episodio de endocarditis infecciosa. Incluye valvulopatía degenerativa, valvulopatía reumática, material protésico intracardiaco, dispositivo cardiaco implantado, endocarditis previa... En caso de endocarditis protésica se distinguirán 2 situaciones:

- Endocarditis protésica precoz: episodio de endocarditis protésica diagnosticado menos de un año después de la cirugía de sustitución valvular.

- Endocarditis protésica tardía: episodio de endocarditis protésica diagnosticado a partir de un año tras la cirugía de sustitución valvular.

Factores desencadenantes: procedimientos que puedan causar bacteriemia y que han sido realizados en los dos meses previos a la aparición del cuadro clínico diagnóstico de endocarditis. Se incluyen los siguientes:

- Dental: cualquier procedimiento que dé lugar a sangrado de las encías.

- Respiratorios: incluye cirugía y procedimientos endoscópicos con o sin toma de biopsia.

- Digestivos: incluye cirugía y procedimientos endoscópicos con o sin toma de biopsia.

- Genitourinarios: incluye cirugía y procedimientos endoscópicos con o sin toma de biopsia y el sondaje vesical.

- Catéter intravascular: que el paciente haya sido portador de catéteres intravenosos centrales, periféricos o intraarteriales, para procedimientos diagnósticos o terapéuticos. 
- Infección local: existencia de un proceso supurativo localizado previo al desarrollo de los síntomas o al diagnóstico de endocarditis infecciosa.

- Cirugía previa: realización de cirugía que no sea la sustitución de prótesis valvular o la colocación de tubo valvulado en los 2 meses previos al inicio del cuadro clínico.

Enfermedad subyacente: proceso clínico generalmente de curso crónico pero que se encuentra activo en el momento del diagnóstico de la endocarditis infecciosa o durante el mes previo al mismo.

Incluimos todos los siguientes:

- Alcoholismo: consumo habitual de más de 120 gramos/ día de alcohol.

- Anemia crónica: hemoglobina $<12$ gr/dl durante al menos 3 meses, que no sea ocasionada por la endocarditis.

- Inmunodepresión: cualquier enfermedad o tratamiento inmunosupresor que dé lugar a deterioro de la inmunidad celular o humoral.

- Diabetes mellitus: diagnosticada previamente al episodio de endocarditis y con tratamiento para la misma o bien que cumpla cualquiera de los siguientes criterios en el momento del diagnóstico (confirmados en dos ocasiones): (259)

○ Glucemia en ayunas de 8 horas $\geq 126 \mathrm{mg} / \mathrm{dl}$

- Glucemia $\geq 200 \mathrm{mg} / \mathrm{dl}$ a las 2 horas de test de sobrecarga de glucosa $(75 \mathrm{~g}$ de glucosa disuelta en agua)

○ Niveles de $\mathrm{HbAc1} \geq 6.5 \%$

- En paciente con síntomas clásicos de hiperglucemia o crisis hiperglucémicas, glucemia superior a $200 \mathrm{mg} / \mathrm{dl}$ en cualquier momento.

- Cáncer: la existencia de cualquier neoplasia maligna.

- Enfermedad pulmonar obstructiva crónica (EPOC): limitación crónica al flujo aéreo poco reversible y asociada principalmente al humo del tabaco en cualquiera de sus fenotipos de presentación.

- Colagenopatías: enfermedades inflamatorias de curso crónico, etiología desconocida y patogenia autoinmune. Se incluyen lupus, artritis reumatoide, síndrome de Sjögren, esclerodermia y formas mixtas. 
- Insuficiencia renal crónica: presencia durante al menos tres meses de una de las siguientes características: (260)

○ Filtrado glomerular inferior a $60 \mathrm{ml} / \mathrm{min} / 1,73 \mathrm{~m}^{2}$.

○ Lesión renal: presencia de anormalidades estructurales o funcionales del riñón, que puedan provocar potencialmente un descenso del filtrado glomerular. La lesión renal se pone de manifiesto directamente a partir de alteraciones histológicas en la biopsia renal (enfermedades glomerulares, vasculares, túbulo-intersticiales) o indirectamente por la presencia de albuminuria, alteraciones en el sedimento urinario, alteraciones hidroelectrolíticas o de otro tipo secundarias a patología tubular o a través de técnicas de imagen.

- Adicción a drogas por vía parenteral (ADVP): hábito de la drogadicción por vía parenteral presente en el momento del desarrollo de los síntomas de endocarditis.

- Virus de la inmunodeficiencia humana (VIH): positividad de los anticuerpos frente al virus de la inmunodeficiencia humana en el momento de la aparición de los síntomas de endocarditis.

\section{Datos clínicos}

Inicio: tiempo transcurrido desde el comienzo de la sintomatología hasta el momento del diagnóstico de la endocarditis. Se considera inicio agudo a un tiempo inferior a 15 días.

Curso clínico: se ha considerado la aparición de los siguientes eventos en cualquier momento del curso clínico de la enfermedad, tanto al ingreso, como en la evolución hospitalaria.

- Fiebre: temperatura termometrada mayor a $38^{\circ} \mathrm{C}$, acompañada o no de tiritona $y / o$ afectación del estado general.

- Insuficiencia cardiaca: Signos y síntomas de acuerdo con los criterios de Framingham para el diagnóstico de insuficiencia cardiaca. El hallazgo ecocardiográfico de cierre prematuro mitral o signos de elevación de presiones diastólicas se ha considerado un subrogante de insuficiencia cardiaca clínica. 
- Insuficiencia renal: incremento del nivel sérico de creatinina de al menos 0,3 $\mathrm{mg} / \mathrm{dL}$ desde el nivel basal en 48 horas, o incremento mayor o igual a 1,5 veces el basal en 7 días con o sin disminución de diuresis asociada.

- Ictus isquémico: déficit neurológico con evidencia de un área moderada de necrosis por técnica de imagen (tomografía axial computerizada multicorte o resonancia magnética).

- Hemorragia cerebral: déficit neurológico con evidencia de hemorragia cerebral en técnicas de imagen (tomografía axial computerizada multicorte o resonancia magnética).

- Shock séptico: fallo circulatorio agudo en situación de sepsis con hipotensión arterial persistente (presión sistólica menor a $90 \mathrm{mmHg}$ o presión media menor a $65 \mathrm{mmHg}$ ) que precisa vasopresores a pesar de fluidoterapia o en presencia de incremento del lactato sérico por encima de $2 \mathrm{mmol} / \mathrm{L}$.

- Muerte hospitalaria: muerte durante la fase de ingreso hospitalario secundaria al evento agudo de endocarditis infecciosa y secundaria a las complicaciones cardiacas o extracardiacas ocasionadas por el proceso infeccioso o su tratamiento.

\section{Microbiología}

Hemocultivos: cultivos de sangre realizados para el diagnóstico del episodio de endocarditis. En caso de endocarditis nosocomial que se desarrolla durante el ingreso por otra patología, se considerarán los hemocultivos realizados en las 2 semanas previas al diagnóstico. En caso de endocarditis referidas se considerarán también los hemocultivos realizados al ingreso en el otro centro.

Hemocultivos a las 48-72 horas: se considera la repetición de los cultivos de sangre a las 48-72 horas del inicio del tratamiento antibiótico, y tras una primera serie de hemocultivos positivos. La persistencia de hemocultivos positivos se ha considerado un factor pronóstico de mortalidad en endocarditis infecciosa. (254) 
Microorganismo causal se establece a partir de los hemocultivos o de otras muestras con diagnóstico etiológico de la endocarditis de acuerdo a los criterios diagnósticos previamente especificados.

Definición de los criterios de serología diagnóstica: En todos los pacientes con hemocultivos negativos en las primeras 96 horas se realizan las siguientes serologías:

- Chlamydia (psitacci y pneumoniae): fijación de complemento 1/64 o cuadruplicación del título inicial a las 2 semanas (seroconversión).

- Fiebre Q: título de IgG fase I > 1:800

- Legionella: título por inmunofluorescencia indirecta $>1 / 256$ o seroconversión.

- Mycoplasma pneumoniae: título por fijación de complemento > 1/64 o seroconversión.

- Brucella: títulos de aglutinación > 1/160 o seroconversión.

- Bartonella: títulos de aglutinación > 1/800 o seroconversión o PCR en sangre.

\section{Técnicas de imagen}

A todo paciente con sospecha clínica de endocarditis infecciosa se ha realizado un ecocardiograma transtorácico y un ecocardiograma transesofágico de acuerdo con la guía europea de manejo de la endocarditis infecciosa. (3)

Además se considera la repetición de las pruebas en todas las siguientes situaciones:

- Cambio de la situación clínica del paciente: nuevo soplo, insuficiencia cardiaca, reaparición de fiebre, embolismo, trastorno de conducción...

- Signos de infección persistente (3 días) a pesar de tratamiento antibiótico correcto.

- Al alta hospitalaria.

Vegetación: Masa intracardiaca móvil o fija sobre el endocardio valvular o sobre otra estructura cardiaca o material intracardiaco protésico, con ecogenicidad diferente a la de las estructuras adyacentes y con un movimiento errático e independiente de la válvula. 
Complicación perianular: presencia de absceso, pseudoaneurisma o fístula en cualquier momento del episodio.

- Absceso: cavidad perivalvular con necrosis y material purulento en su interior sin comunicación con la luz cardiovascular. Ecográficamente se observa engrosamiento de la región perianular con o sin ecolucencias en su interior y ausencia de flujo en su interior.

- Pseudoaneurisma: cavidad perivalvular que comunica con la luz vascular con flujo en su interior.

- Fístula: comunicación entre dos cavidades vecinas a través de una perforación.

Perforación: solución de continuidad en alguna de las valvas con flujo a su través y fenómeno de aceleración proximal.

Disfunción valvular o protésica: demonstración de regurgitación valvular o perivalvular clasificada según gravedad (leve, moderada, severa) de acuerdo con la guía europea de manejo de enfermedades valvulares.

Hipertensión pulmonar: Elevación de la presión pulmonar arterial media por encima de $25 \mathrm{mmHg}$ en un cateterismo cardiaco derecho o cálculo de presión sistólica de arteria pulmonar por ecocardiograma mayor a $60 \mathrm{mmHg}$, o un valor menor en caso de signos indirectos de sobrecarga de cavidades derechas.

Función ventricular: fracción de eyección del ventrículo izquierdo calculada ecocardiográficamente por método Simpson biplano, Teichloz o visual. Se considera disfunción ventricular en caso de fracción de eyección del ventrículo izquierdo inferior a $45 \%$. 


\section{Tratamiento}

Antibiótico: tipo de antibiótico utilizado durante el tratamiento del episodio de endocarditis infecciosa, incluyendo el tratamiento antibiótico empírico inicial y el tratamiento dirigido tras conocerse el germen causal y su antibiograma.

Tratamiento antimicrobiano correcto: utilización de tratamiento antibiótico bactericida dirigido frente al microogranismo causal de acuerdo con el antibiograma del mismo y las pautas de tratamiento antibiótico de la guía europea de manejo de la endocarditis infecciosa en cada momento.

Duración del tratamiento antibiótico: se recoge la fecha de inicio y la fecha de finalización del tratamiento antibiótico, calculándose la duración del mismo en semanas. Negativización del hemocultivo: cuando el hemocultivo resulta negativo a las 48 horas de tratamiento. Si los hemocultivos nunca fueron positivos, no procede rellenar esta variable.

Cirugía cardiaca: procedimiento intervencionista destinado a la eliminación del tejido infectado y la reparación de las lesiones estructurales ocasionadas en el corazón.

Tipo de cirugía: clasificamos el tipo de cirugía según una relación temporal de acuerdo a la toma de la decisión quirúrgica y al tratamiento antibiótico, de tal forma que consideramos 3 situaciones:

- Cirugía emergente: intervención realizada antes de las 8 de la mañana del día siguiente a la toma de la decisión.

- Cirugía urgente: intervención realizada en cualquier momento durante el tratamiento antibiótico de la endocarditis infecciosa.

- Cirugía electiva: intervención realizada una vez finalizado el tratamiento antibiótico de la endocarditis infecciosa.

Riesgo quirúrgico: riesgo teórico de mortalidad intra-cirugía cardiaca calculado de acuerdo a modelos predictivos validados. Utilizamos el RISK-E score, el Eursocore logístico y el Euroscore II. 
Indicaciones de la cirugía: motivo de la toma de decisión sobre el acto quirúrgico. Se contemplan 3 escenarios de acuerdo con la guía europea de manejo de la endocarditis infecciosa:

- Insuficiencia cardiaca: cualquiera de las siguientes situaciones; clínica de insuficiencia cardiaca refractaria a tratamiento diurético, disfunción valvular o protésica severa con repercusión clínica o deterioro hemodinámico, o endocarditis que afecta a prótesis valvular.

- Infección no controlada: cualquiera de las siguientes situaciones; infección persistente definida por hemocultivos positivos y/o fiebre persistente más de una semana sin otra justificación a pesar de un tratamiento antibiótico óptimo, o recaída de endocarditis protésica, o infección localmente incontrolable por presencia de complicación perianular o crecimiento del tamaño de la vegetación. Gérmen causal potencialmente agresivo como Estafilococo aurues sobre válvula protésica, o microorganismos difíciles de erradicar con tratamiento antibiótico eficaz como hongos, bacilos gram negativos resistentes, Brucella o Coxiella burnetti.

- Prevención de embolias: cualquiera de las siguientes situaciones; presencia de fenómenos embólicos únicos o múltiples previos a la toma de decisión quirúrgica, o tamaño de vegetación superior a $15 \mathrm{~mm}$. 
9.5 ANEXO V. Tabla descriptiva de la población de endocarditis infecciosa izquierda del grupo ENDOVAL.

\begin{tabular}{|c|c|}
\hline n (\%) & $\begin{array}{l}\text { Población ENDOVAL } \\
\qquad(n=1002)\end{array}$ \\
\hline \multicolumn{2}{|l|}{ Datos epidemiológicos } \\
\hline Edad, media \pm DE & $65.1 \pm 14.3$ \\
\hline Hombre & $666(67)$ \\
\hline Referido & $478(49)$ \\
\hline \multicolumn{2}{|l|}{ Origen } \\
\hline Nosocomial & $253(25)$ \\
\hline Comunitario & $682(68)$ \\
\hline Asociada a cuidados sanitarios & $67(7)$ \\
\hline \multicolumn{2}{|l|}{ Cardiopatía de base } \\
\hline Ninguna & $168(17)$ \\
\hline Degenerativa & $193(19)$ \\
\hline Prótesis & $404(40)$ \\
\hline Prótesis Tardía & $277(69)$ \\
\hline Prótesis Precoz & $127(31)$ \\
\hline Reumática & $91(9)$ \\
\hline \multicolumn{2}{|l|}{ Factor desencadenante } \\
\hline No conocido & $499(50)$ \\
\hline Manipulación genitourinaria & $32(3)$ \\
\hline Cateter intravascular & $131(13)$ \\
\hline Cirugía previa no cardiaca & $50(5)$ \\
\hline Cirugía cardiaca previa & $82(8)$ \\
\hline Infección local & $112(11)$ \\
\hline \multicolumn{2}{|l|}{ Enfermedad subyacente } \\
\hline Ninguna & $415(41)$ \\
\hline Índice de Charlson, media $\pm \mathrm{DE}$ & $4.2 \pm 5.9$ \\
\hline Alcoholismo & $73(7)$ \\
\hline Anemia crónica & $221(22)$ \\
\hline Insuficiencia renal crónica & $148(15)$ \\
\hline Diabetes mellitus & $256(26)$ \\
\hline Cáncer & $115(12)$ \\
\hline Inmunodepresión & $61(6)$ \\
\hline EPOC & $84(8)$ \\
\hline
\end{tabular}




\begin{tabular}{|c|c|}
\hline Colagenopatía & $39(4)$ \\
\hline ADVP & $18(2)$ \\
\hline VIH & $13(1)$ \\
\hline \multicolumn{2}{|l|}{ Datos clínicos } \\
\hline Inicio agudo & $490(49)$ \\
\hline Fiebre & $811(81)$ \\
\hline Insuficiencia cardiaca & $571(57)$ \\
\hline Insuficiencia renal & $415(41)$ \\
\hline Shock séptico & $158(16)$ \\
\hline Ictus isquémico & $180(18)$ \\
\hline Hemorragia cerebral & $67(7)$ \\
\hline Muerte hospitalaria & $301(30)$ \\
\hline \multicolumn{2}{|l|}{ Microbiología } \\
\hline Hemocultivos positivos & $884(88)$ \\
\hline Hemocultivos persistentes a las $48 / 72$ horas & $167 / 562(30)$ \\
\hline Estreptococos spp & $271(27)$ \\
\hline Estreptococo bovis & $55(6)$ \\
\hline Estreptococo grupo viridans & $159(16)$ \\
\hline Otros estreptococos & $58(6)$ \\
\hline Enterococos spp & $130(13)$ \\
\hline Estafilococos spp & $381(38)$ \\
\hline Meticilin sensibles & $219 / 355(62)$ \\
\hline Estafilococo aurues & $210(21)$ \\
\hline Estafilococo coagulasa-negativo & $172(17)$ \\
\hline Bacilos gram negativos no-HACEK & $48(5)$ \\
\hline Hongos & $16(2)$ \\
\hline Grupo HACEK & $7(1)$ \\
\hline Anaerobios & $32(3)$ \\
\hline Polimicrobiana & $49(5)$ \\
\hline Otros microorganismos & $41(4)$ \\
\hline Hemocultivos negativos & $118(12)$ \\
\hline \multicolumn{2}{|l|}{ Hallazgos en pruebas de imagen } \\
\hline Vegetaciones & $870(87)$ \\
\hline Complicación perianular & $302(30)$ \\
\hline Absceso & $184(18)$ \\
\hline Pseudoaneurisma & $165(17)$ \\
\hline Fístula & $34(3)$ \\
\hline
\end{tabular}




\begin{tabular}{|c|c|}
\hline $\begin{array}{l}\text { Fracción de eyección del ventrículo } \\
\text { izquierdo }<45 \%\end{array}$ & $78(8)$ \\
\hline Hipertensión pulmonar & $136(14)$ \\
\hline Disfunción valvular o protésica severa & $619(62)$ \\
\hline \multicolumn{2}{|l|}{ Localización } \\
\hline Multivalvular & $215(22)$ \\
\hline Válvula aórtica nativa & $359(36)$ \\
\hline Válvula mitral nativa & $381(38)$ \\
\hline Prótesis aórtica mecánica & $118(12)$ \\
\hline Prótesis mitral mecánica & $192(19)$ \\
\hline Prótesis aórtica biológica & $108(11)$ \\
\hline Prótesis mitral biológica & $21(2)$ \\
\hline Afectación derecha concomitante & $23(2)$ \\
\hline \multicolumn{2}{|l|}{ Tratamiento quirúrgico } \\
\hline Cirugía & $614(61)$ \\
\hline Urgente & $367 / 614(60)$ \\
\hline Electiva & $247 / 614(40)$ \\
\hline \multicolumn{2}{|l|}{ Indicaciones } \\
\hline Insuficiencia cardiaca & $428(72)$ \\
\hline Infección no controlada & $335(56)$ \\
\hline Prevención de embolias & $139(23)$ \\
\hline \multicolumn{2}{|l|}{ Riesgo quirúrgico } \\
\hline Euroscore logístico, mediana [RIQ] & $31[19-50]$ \\
\hline Euroscore 2, mediana [RIQ] & $12[5-21]$ \\
\hline \multicolumn{2}{|l|}{ Tratamiento antibiótico } \\
\hline Tratamiento antibiótico correcto & $879(95)$ \\
\hline Semanas, mediana [RIQ] & $5[3-7]$ \\
\hline \multicolumn{2}{|c|}{$\begin{array}{l}\text { DE: desviación estándar. EPOC: enfermedad pulmonar obstructiva } \\
\text { crónica. ADVP: adicto a drogas por vía parenteral. VIH: virus de la } \\
\text { inmunodeficiencia humana. }\end{array}$} \\
\hline
\end{tabular}


10. BIBLIOGRAFÍA 
1. Eugen Braunwald. Braunwald's Heart Disease: A Textbook of Cardiovascular Medicine. Novena. Vol. 2. Elsevier.

2. Baddour LM. Twelve-year review of recurrent native-valve infective endocarditis: a disease of the modern antibiotic era. Rev Infect Dis. 1988;10(6):1163-70.

3. Habib G, Lancellotti P, Manuel J. Antunes, Bongiorni MG, Casalta J-P, Del Zotti F, et al. 2015 ESC Guidelines for the management of infective endocarditis: The Task Force for the Management of Infective Endocarditis of the European Society of Cardiology (ESC)Endorsed by: European Association for Cardio-Thoracic Surgery (EACTS), the European Association of Nuclear Medicine (EANM). Eur Heart J. 2015;36(44):3075-128.

4. Li JS, Sexton DJ, Mick N, Nettles R, Fowler VG, Ryan T, et al. Proposed modifications to the Duke criteria for the diagnosis of infective endocarditis. Clin Infect Dis Off Publ Infect Dis Soc Am. 2000;30(4):633-8.

5. Sevilla T, López J, Gómez I, Vilacosta I, Sarriá C, García-Granja PE, et al. Evolution of Prognosis in Left-Sided Infective Endocarditis: A Propensity Score Analysis of 2 Decades. J Am Coll Cardiol. 2017;69(1):111-2.

6. Botelho-Nevers E, Thuny F, Casalta JP, Richet H, Gouriet F, Collart F, et al. Dramatic reduction in infective endocarditis-related mortality with a management-based approach. Arch Intern Med. 2009;169(14):1290-8.

7. Chirillo F, Scotton P, Rocco F, Rigoli R, Borsatto F, Pedrocco A, et al. Impact of a multidisciplinary management strategy on the outcome of patients with native valve infective endocarditis. Am J Cardiol. 2013;112(8):1171-6.

8. Frontera JA, Gradon JD. Right-side endocarditis in injection drug users: review of proposed mechanisms of pathogenesis. Clin Infect Dis Off Publ Infect Dis Soc Am. 2000;30(2):374-9. 
9. Wilson LE, Thomas DL, Astemborski J, Freedman TL, Vlahov D. Prospective study of infective endocarditis among injection drug users. J Infect Dis. 2002;185(12):1761-6.

10. Ortiz C, López J, García H, Sevilla T, Revilla A, Vilacosta I, et al. Clinical classification and prognosis of isolated right-sided infective endocarditis. Medicine (Baltimore). 2014;93(27):e137.

11. Hecht SR, Berger M. Right-sided endocarditis in intravenous drug users. Prognostic features in 102 episodes. Ann Intern Med. 1992;117(7):560-6.

12. Moss R, Munt B. Injection drug use and right sided endocarditis. Heart Br Card Soc. $2003 ; 89(5): 577-81$.

13. Gottardi R, Bialy J, Devyatko E, Tschernich H, Czerny M, Wolner E, et al. Midterm follow-up of tricuspid valve reconstruction due to active infective endocarditis. Ann Thorac Surg. 2007;84(6):1943-8.

14. Gaca JG, Sheng S, Daneshmand M, Rankin JS, Williams ML, O'Brien SM, et al. Current outcomes for tricuspid valve infective endocarditis surgery in North America. Ann Thorac Surg. 2013;96(4):1374-81.

15. Leone S, Ravasio V, Durante-Mangoni E, Crapis M, Carosi G, Scotton PG, et al. Epidemiology, characteristics, and outcome of infective endocarditis in Italy: the Italian Study on Endocarditis. Infection. 2012;40(5):527-35.

16. Murdoch DR, Corey GR, Hoen B, Miró JM, Fowler VG, Bayer AS, et al. Clinical presentation, etiology, and outcome of infective endocarditis in the 21 st century: the International Collaboration on Endocarditis-Prospective Cohort Study. Arch Intern Med. 2009;169(5):463-73.

17. Nadji G, Rusinaru D, Rémadi J-P, Jeu A, Sorel C, Tribouilloy C. Heart failure in left-sided native valve infective endocarditis: characteristics, prognosis, and results of surgical treatment. Eur J Heart Fail. 2009;11(7):668-75. 
18. Olmos C, Vilacosta I, Fernández C, López J, Sarriá C, Ferrera C, et al. Contemporary epidemiology and prognosis of septic shock in infective endocarditis. Eur Heart J. 2013;34(26):1999-2006.

19. García-Cabrera E, Fernández-Hidalgo N, Almirante B, Ivanova-Georgieva R, Noureddine M, Plata A, et al. Neurological complications of infective endocarditis: risk factors, outcome, and impact of cardiac surgery: a multicenter observational study. Circulation. 2013;127(23):2272-84.

20. Delahaye F, Alla F, Béguinot I, Bruneval P, Doco-Lecompte T, Lacassin F, et al. In-hospital mortality of infective endocarditis: prognostic factors and evolution over an 8-year period. Scand J Infect Dis. 2007;39(10):849-57.

21. Thuny F, Beurtheret S, Mancini J, Gariboldi V, Casalta J-P, Riberi A, et al. The timing of surgery influences mortality and morbidity in adults with severe complicated infective endocarditis: a propensity analysis. Eur Heart J. 2011;32(16):2027-33.

22. Lu KJ, Kearney LG, Ord M, Jones E, Burrell LM, Srivastava PM. Age adjusted Charlson Co-morbidity Index is an independent predictor of mortality over longterm follow-up in infective endocarditis. Int J Cardiol. 2013;168(6):5243-8.

23. Charlson M, Szatrowski TP, Peterson J, Gold J. Validation of a combined comorbidity index. J Clin Epidemiol. 1994;47(11):1245-51.

24. Sanchis J, Núñez J, Bodí V, Núñez E, García-Alvarez A, Bonanad C, et al. Influence of comorbid conditions on one-year outcomes in non-ST-segment elevation acute coronary syndrome. Mayo Clin Proc. 2011;86(4):291-6.

25. Theuns DAMJ, Schaer BA, Soliman OII, Altmann D, Sticherling C, Geleijnse ML, et al. The prognosis of implantable defibrillator patients treated with cardiac resynchronization therapy: comorbidity burden as predictor of mortality. Eur Eur Pacing Arrhythm Card Electrophysiol J Work Groups Card Pacing Arrhythm Card Cell Electrophysiol Eur Soc Cardiol. 2011;13(1):62-9. 
26. Kearney L, Ord M, Buxton B, Matalanis G, Patel S, Burrell L, et al. Usefulness of the Charlson co-morbidity index to predict outcomes in patients $>60$ years old with aortic stenosis during 18 years of follow-up. Am J Cardiol. 2012;110(5):695701.

27. Noureddine-López M, de la Torre-Lima J, Ruiz-Morales J, Gálvez-Acebal J, Hidalgo-Tenorio C, de Alarcón González CA, et al. Left endocarditis, changes in the new millennium. Med Clin (Barc). 2018

28. López J, Revilla A, Vilacosta I, Sevilla T, Villacorta E, Sarriá C, et al. Agedependent profile of left-sided infective endocarditis: a 3-center experience. Circulation. 2010;121(7):892-7.

29. Geissler HJ, Hölzl P, Marohl S, Kuhn-Régnier F, Mehlhorn U, Südkamp M, et al. Risk stratification in heart surgery: comparison of six score systems. Eur J CardioThorac Surg Off J Eur Assoc Cardio-Thorac Surg. 2000;17(4):400-6.

30. Olmos C, Vilacosta I, Habib G, Maroto L, Fernández C, López J, et al. Risk score for cardiac surgery in active left-sided infective endocarditis. Heart Br Card Soc. 2017;103(18):1435-42.

31. Olmos C, Vilacosta I, Fernández-Pérez C, Bernal JL, Ferrera C, García-Arribas D, et al. The Evolving Nature of Infective Endocarditis in Spain: A PopulationBased Study (2003 to 2014). J Am Coll Cardiol. 2017;70(22):2795-804.

32. Anderson HJ, Staffurth JS. Subacute bacterial endocarditis in the elderly. Lancet Lond Engl. 1955;269(6899):1055-8.

33. Hoen B, Alla F, Selton-Suty C, Béguinot I, Bouvet A, Briançon S, et al. Changing profile of infective endocarditis: results of a 1-year survey in France. JAMA. 2002;288(1):75-81.

34. Delahaye JP, Poncet P, Malquarti V, Beaune J, Garé JP, Mann JM. Cerebrovascular accidents in infective endocarditis: role of anticoagulation. Eur Heart J. 1990;11(12):1074-8. 
35. López J, Revilla A, Vilacosta I, Sevilla T, Villacorta E, Sarriá C, et al. Agedependent profile of left-sided infective endocarditis: a 3-center experience. Circulation. 2010;121(7):892-7.

36. Peled N, Pitlik S, Livni G, Ashkenazi S, Bishara J. Impact of age on clinical features and outcome of infective endocarditis. Eur J Clin Microbiol Infect Dis Off Publ Eur Soc Clin Microbiol. 2006;25(7):473-5.

37. Castillo Domínguez JC, Anguita Sánchez MP, Ramírez Moreno A, Siles Rubio JR, Mesa Rubio D, Muñoz Carvajal I, et al. [Clinical features and prognosis of infective endocarditis in the elderly]. Rev Esp Cardiol. 2000;53(11):1437-42.

38. Selton-Suty C, Hoen B, Grentzinger A, Houplon P, Maignan M, Juillière Y, et al. Clinical and bacteriological characteristics of infective endocarditis in the elderly. Heart Br Card Soc. 1997;77(3):260-3.

39. Applefeld MM, Hornick RB. Infective endocarditis in patients over age 60. Am Heart J. 1974;88(1):90-4.

40. Terpenning MS, Buggy BP, Kauffman CA. Infective endocarditis: clinical features in young and elderly patients. Am J Med. 1987;83(4):626-34.

41. Robbins N, DeMaria A, Miller MH. Infective endocarditis in the elderly. South Med J. 1980;73(10):1335-8.

42. Di Salvo G, Thuny F, Rosenberg V, Pergola V, Belliard O, Derumeaux G, et al. Endocarditis in the elderly: clinical, echocardiographic, and prognostic features. Eur Heart J. 2003;24(17):1576-83.

43. Werner GS, Schulz R, Fuchs JB, Andreas S, Prange H, Ruschewski W, et al. Infective endocarditis in the elderly in the era of transesophageal echocardiography: clinical features and prognosis compared with younger patients. Am J Med. 1996;100(1):90-7. 
44. Gagliardi JP, Nettles RE, McCarty DE, Sanders LL, Corey GR, Sexton DJ. Native valve infective endocarditis in elderly and younger adult patients: comparison of clinical features and outcomes with use of the Duke criteria and the Duke Endocarditis Database. Clin Infect Dis Off Publ Infect Dis Soc Am. 1998;26(5):1165-8.

45. Netzer RO, Zollinger E, Seiler C, Cerny A. Native valve infective endocarditis in elderly and younger adult patients: comparison of clinical features and outcomes with use of the Duke criteria. Clin Infect Dis Off Publ Infect Dis Soc Am. 1999;28(4):933-5.

46. Cruz JM, Martínez R, García M, Zarzalejos JM, de la Peña F. Infective endocarditis in the elderly. An Med Interna Madr Spain 1984. 2003;20(11):56974.

47. Durante-Mangoni E, Bradley S, Selton-Suty C, Tripodi M-F, Barsic B, Bouza E, et al. Current features of infective endocarditis in elderly patients: results of the International Collaboration on Endocarditis Prospective Cohort Study. Arch Intern Med. 2 2008;168(19):2095-103.

48. Durack DT, Lukes AS, Bright DK. New criteria for diagnosis of infective endocarditis: utilization of specific echocardiographic findings. Duke Endocarditis Service. Am J Med. 1994;96(3):200-9.

49. Ballet M, Gevigney G, Garé JP, Delahaye F, Etienne J, Delahaye JP. Infective endocarditis due to Streptococcus bovis. A report of 53 cases. Eur Heart J. 1995;16(12):1975-80.

50. Fernández Guerrero ML, Goyenechea A, Verdejo C, Roblas RF, de Górgolas M. Enterococcal endocarditis on native and prosthetic valves: a review of clinical and prognostic factors with emphasis on hospital-acquired infections as a major determinant of outcome. Medicine (Baltimore). 2007;86(6):363-77. 
51. Kiefer T, Park L, Tribouilloy C, Cortes C, Casillo R, Chu V, et al. Association between valvular surgery and mortality among patients with infective endocarditis complicated by heart failure. JAMA. 2011;306(20):2239-47.

52. Bashore TM, Cabell C, Fowler V. Update on infective endocarditis. Curr Probl Cardiol. 2006;31(4):274-352.

53. Vongpatanasin W, Hillis LD, Lange RA. Prosthetic heart valves. N Engl J Med. 1996;335(6):407-16.

54. Moreillon P, Que Y-A. Infective endocarditis. Lancet Lond Engl. 2004;363(9403):139-49.

55. Wang A, Athan E, Pappas PA, Fowler VG, Olaison L, Paré C, et al. Contemporary clinical profile and outcome of prosthetic valve endocarditis. JAMA. 2007;297(12):1354-61.

56. Habib G, Thuny F, Avierinos J-F. Prosthetic valve endocarditis: current approach and therapeutic options. Prog Cardiovasc Dis. 2008;50(4):274-81.

57. Tornos P, Iung B, Permanyer-Miralda G, Baron G, Delahaye F, Gohlke-Bärwolf $\mathrm{C}$, et al. Infective endocarditis in Europe: lessons from the Euro heart survey. Heart Br Card Soc. 2005;91(5):571-5.

58. Horstkotte D, Follath F, Gutschik E, Lengyel M, Oto A, Pavie A, et al. Guidelines on prevention, diagnosis and treatment of infective endocarditis executive summary; the task force on infective endocarditis of the European society of cardiology. Eur Heart J. 2004;25(3):267-76.

59. López J, Revilla A, Vilacosta I, Villacorta E, González-Juanatey C, Gómez I, et al. Definition, clinical profile, microbiological spectrum, and prognostic factors of early-onset prosthetic valve endocarditis. Eur Heart J. 2007;28(6):760-5.

60. Habib G, Derumeaux G, Avierinos JF, Casalta JP, Jamal F, Volot F, et al. Value and limitations of the Duke criteria for the diagnosis of infective endocarditis. J Am Coll Cardiol. 1999;33(7):2023-9. 
61. Lamas CC, Eykyn SJ. Suggested modifications to the Duke criteria for the clinical diagnosis of native valve and prosthetic valve endocarditis: analysis of 118 pathologically proven cases. Clin Infect Dis Off Publ Infect Dis Soc Am. 1997;25(3):713-9.

62. Pérez-Vázquez A, Fariñas MC, García-Palomo JD, Bernal JM, Revuelta JM, González-Macías J. Evaluation of the Duke criteria in 93 episodes of prosthetic valve endocarditis: could sensitivity be improved? Arch Intern Med. 2000;160(8):1185-91.

63. Habib G. Management of infective endocarditis. Heart $\mathrm{Br}$ Card Soc. 2006;92(1):124-30.

64. Saby L, Laas O, Habib G, Cammilleri S, Mancini J, Tessonnier L, et al. Positron emission tomography/computed tomography for diagnosis of prosthetic valve endocarditis: increased valvular $18 \mathrm{~F}$-fluorodeoxyglucose uptake as a novel major criterion. J Am Coll Cardiol. 2013;61(23):2374-82.

65. Habib G, Tribouilloy C, Thuny F, Giorgi R, Brahim A, Amazouz M, et al. Prosthetic valve endocarditis: who needs surgery? A multicentre study of 104 cases. Heart Br Card Soc. 2005;91(7):954-9.

66. Gordon SM, Serkey JM, Longworth DL, Lytle BW, Cosgrove DM. Early onset prosthetic valve endocarditis: the Cleveland Clinic experience 1992-1997. Ann Thorac Surg. 2000;69(5):1388-92.

67. Sohail MR, Martin KR, Wilson WR, Baddour LM, Harmsen WS, Steckelberg JM. Medical versus surgical management of Staphylococcus aureus prosthetic valve endocarditis. Am J Med. 2006;119(2):147-54.

68. Wang A, Pappas P, Anstrom KJ, Abrutyn E, Fowler VG, Hoen B, et al. The use and effect of surgical therapy for prosthetic valve infective endocarditis: a propensity analysis of a multicenter, international cohort. Am Heart J. 2005;150(5):1086-91. 
69. Truninger K, Attenhofer Jost CH, Seifert B, Vogt PR, Follath F, Schaffner A, et al. Long term follow up of prosthetic valve endocarditis: what characteristics identify patients who were treated successfully with antibiotics alone? Heart $\mathrm{Br}$ Card Soc. 1999;82(6):714-20.

70. Hill EE, Herregods M-C, Vanderschueren S, Claus P, Peetermans WE, Herijgers P. Management of prosthetic valve infective endocarditis. Am J Cardiol. 2008;101(8):1174-8.

71. Bonow RO, Carabello BA, Chatterjee K, de Leon AC, Faxon DP, Freed MD, et al. 2008 Focused update incorporated into the ACC/AHA 2006 guidelines for the management of patients with valvular heart disease: a report of the American College of Cardiology/American Heart Association Task Force on Practice Guidelines (Writing Committee to Revise the 1998 Guidelines for the Management of Patients With Valvular Heart Disease): endorsed by the Society of Cardiovascular Anesthesiologists, Society for Cardiovascular Angiography and Interventions, and Society of Thoracic Surgeons. Circulation. 2008;118(15):e523-661.

72. López J, Sevilla T, Vilacosta I, García H, Sarriá C, Pozo E, et al. Clinical significance of congestive heart failure in prosthetic valve endocarditis. A multicenter study with 257 patients. Rev Espanola Cardiol Engl Ed. 2013;66(5):384-90.

73. Tornos P, Almirante B, Olona M, Permanyer G, González T, Carballo J, et al. Clinical outcome and long-term prognosis of late prosthetic valve endocarditis: a 20-year experience. Clin Infect Dis. 1997;24(3):381-6.

74. Olmos C, Vilacosta I, Pozo E, Fernández C, Sarriá C, López J, et al. Prognostic implications of diabetes in patients with left-sided endocarditis: findings from a large cohort study. Medicine (Baltimore). 2014;93(2):114-9.

75. Duval X, Alla F, Doco-Lecompte T, Le Moing V, Delahaye F, Mainardi J-L, et al. Diabetes mellitus and infective endocarditis: the insulin factor in patient morbidity and mortality. Eur Heart J. 2007;28(1):59-64. 
76. Kourany WM, Miro JM, Moreno A, Corey GR, Pappas PA, Abrutyn E, et al. Influence of diabetes mellitus on the clinical manifestations and prognosis of infective endocarditis: a report from the International Collaboration on Endocarditis-Merged Database. Scand J Infect Dis. 2006;38(8):613-9.

77. Wild S, Roglic G, Green A, Sicree R, King H. Global prevalence of diabetes: estimates for the year 2000 and projections for 2030. Diabetes Care. 2004;27(5):1047-53.

78. Joshi N, Caputo GM, Weitekamp MR, Karchmer AW. Infections in patients with diabetes mellitus. N Engl J Med. 1999;341(25):1906-12.

79. Calvet HM, Yoshikawa TT. Infections in diabetes. Infect Dis Clin North Am. 2001;15(2):407-21.

80. Chirillo F, Bacchion F, Pedrocco A, Scotton P, De Leo A, Rocco F, et al. Infective endocarditis in patients with diabetes mellitus. J Heart Valve Dis. 2010;19(3):31220.

81. Laupland KB, Gregson DB, Zygun DA, Doig CJ, Mortis G, Church DL. Severe bloodstream infections: a population-based assessment. Crit Care Med. 2004;32(4):992-7.

82. Movahed MR, Hashemzadeh M, Jamal MM. Increased prevalence of infectious endocarditis in patients with type II diabetes mellitus. J Diabetes Complications. 2007;21(6):403-6.

83. Strom BL, Abrutyn E, Berlin JA, Kinman JL, Feldman RS, Stolley PD, et al. Risk factors for infective endocarditis: oral hygiene and nondental exposures. Circulation. 2000;102(23):2842-8.

84. Chu VH, Cabell CH, Benjamin DK, Kuniholm EF, Fowler VG, Engemann J, et al. Early predictors of in-hospital death in infective endocarditis. Circulation. 2004;109(14):1745-9. 
85. Bishara J, Peled N, Samra Z, Sagie A, Leibovici L, Pitlik S. Infective endocarditis in diabetic and non-diabetic patients. Scand J Infect Dis. 2004;36(11-12):795-8.

86. Pant S, Patel NJ, Deshmukh A, Golwala H, Patel N, Badheka A, et al. Trends in infective endocarditis incidence, microbiology, and valve replacement in the United States from 2000 to 2011. J Am Coll Cardiol. 2015;65(19):2070-6.

87. Heiro M, Helenius H, Mäkilä S, Hohenthal U, Savunen T, Engblom E, et al. Infective endocarditis in a Finnish teaching hospital: a study on 326 episodes treated during 1980-2004. Heart Br Card Soc. 2006;92(10):1457-62.

88. Fariñas MC, Llinares P, Almirante B, Barberán J, de Dios Colmenero J, Garau J, et al. New trends in infective endocarditis. Enferm Infecc Microbiol Clin. 2011;29 Suppl 4:22-35.

89. Benito N, Miró JM, de Lazzari E, Cabell CH, del Río A, Altclas J, et al. Health care-associated native valve endocarditis: importance of non-nosocomial acquisition. Ann Intern Med. 2009;150(9):586-94.

90. Sun L-M, Wu J-N, Lin C-L, Day J-D, Liang J-A, Liou L-R, et al. Infective Endocarditis and Cancer Risk: A Population-Based Cohort Study. Medicine (Baltimore). 2016;95(12):e3198.

91. McCOY WC, Mason JM. Enterococcal endocarditis associated with carcinoma of the sigmoid; report of a case. J Med Assoc State Ala. 1951;21(6):162-6.

92. Roses DF, Richman H, Localio SA. Bacterial endocarditis associated with colorectal carcinoma. Ann Surg. 1974;179(2):190-1.

93. Klein RS, Recco RA, Catalano MT, Edberg SC, Casey JI, Steigbigel NH. Association of Streptococcus bovis with carcinoma of the colon. N Engl J Med. 1977;297(15):800-2.

94. Waisberg J, Matheus $\mathrm{C}$ de O, Pimenta J. Infectious endocarditis from Streptococcus bovis associated with colonic carcinoma: case report and literature review. Arq Gastroenterol. 2002;39(3):177-80. 
95. Thomsen RW, Farkas DK, Friis S, Sværke C, Ording AG, Nørgaard M, et al. Endocarditis and risk of cancer: a Danish nationwide cohort study. Am J Med. 2013;126(1):58-67.

96. Kuper H, Adami HO, Trichopoulos D. Infections as a major preventable cause of human cancer. J Intern Med. 2000;248(3):171-83.

97. Vogelmann R, Amieva MR. The role of bacterial pathogens in cancer. Curr Opin Microbiol. 2007;10(1):76-81.

98. Vedham V, Divi RL, Starks VL, Verma M. Multiple infections and cancer: implications in epidemiology. Technol Cancer Res Treat. 2014;13(2):177-94.

99. Durack DT. Evaluating and optimizing outcomes of surgery for endocarditis. JAMA. 2003;290(24):3250-1.

100. Oakley CM. The clinical spectrum and prognosis of native valve infective endocarditis in non-addicts. Eur Heart J. 1995;16(11):1454-5.

101.García-Granja PE, López J, Vilacosta I, Sarriá C, Ladrón R, Olmos C, et al. Surgery changes prognosis in infective endocarditis: The importance of postsurgical clinical evolution. Eur J Intern Med. 2018. Ahead of print.

102.Revilla A, López J, Vilacosta I, Villacorta E, Rollán MJ, Echevarría JR, et al. Clinical and prognostic profile of patients with infective endocarditis who need urgent surgery. Eur Heart J. 2007;28(1):65-71.

103.San Román JA, López J, Vilacosta I, Luaces M, Sarriá C, Revilla A, et al. Prognostic stratification of patients with left-sided endocarditis determined at admission. Am J Med. 2007;120(4):369.e1-7.

104.Hasbun R, Vikram HR, Barakat LA, Buenconsejo J, Quagliarello VJ. Complicated left-sided native valve endocarditis in adults: risk classification for mortality. JAMA. 2003;289(15):1933-40. 
105.Olmos C, Vilacosta I, Fernández C, Sarriá C, López J, Del Trigo M, et al. Comparison of clinical features of left-sided infective endocarditis involving previously normal versus previously abnormal valves. Am J Cardiol. 2014;114(2):278-83.

106. Anguera I, Miro JM, Vilacosta I, Almirante B, Anguita M, Muñoz P, et al. Aortocavitary fistulous tract formation in infective endocarditis: clinical and echocardiographic features of 76 cases and risk factors for mortality. Eur Heart J. 2005;26(3):288-97.

107.Piper C, Hetzer R, Körfer R, Bergemann R, Horstkotte D. The importance of secondary mitral valve involvement in primary aortic valve endocarditis; the mitral kissing vegetation. Eur Heart J. 2002;23(1):79-86.

108.Vilacosta I, San Román JA, Sarriá C, Iturralde E, Graupner C, Batlle E, et al. Clinical, anatomic, and echocardiographic characteristics of aneurysms of the mitral valve. Am J Cardiol. 1999;84(1):110-3, A9.

109. Gelsomino S, Maessen JG, van der Veen F, Livi U, Renzulli A, Lucà F, et al. Emergency surgery for native mitral valve endocarditis: the impact of septic and cardiogenic shock. Ann Thorac Surg. 2012;93(5):1469-76.

110.López J, Fernández-Hidalgo N, Revilla A, Vilacosta I, Tornos P, Almirante B, et al. Internal and external validation of a model to predict adverse outcomes in patients with left-sided infective endocarditis. Heart $\mathrm{Br}$ Card Soc. 2011;97(14):1138-42.

111.Moon MR, Stinson EB, Miller DC. Surgical treatment of endocarditis. Prog Cardiovasc Dis. 1997;40(3):239-64.

112.Wilson WR, Danielson GK, Giuliani ER, Washington JA, Jaumin PM, Geraci JE. Cardiac valve replacement in congestive heart failure due to infective endocarditis. Mayo Clin Proc. 1979;54(4):223-6. 
113. Blaustein AS, Lee JR. Indications for and timing of surgical intervention in infective endocarditis. Cardiol Clin. 1996;14(3):393-404.

114.García-Granja PE, López J, Vilacosta I, Sarriá C, Ladrón R, Olmos C, et al. Impact of valve culture in the prognosis of active left-sided infective endocarditis. Clin Infect Dis. 2018. Ahead of print.

115. Tamura K, Arai H, Yoshizaki T. Long-term outcome of active infective endocarditis with renal insufficiency in cardiac surgery. Ann Thorac Cardiovasc Surg Off J Assoc Thorac Cardiovasc Surg Asia. 2012;18(3):216-21.

116. Wallace SM, Walton BI, Kharbanda RK, Hardy R, Wilson AP, Swanton RH. Mortality from infective endocarditis: clinical predictors of outcome. Heart $\mathrm{Br}$ Card Soc. 2002;88(1):53-60.

117. Gálvez-Acebal J, Rodríguez-Baño J, Martínez-Marcos FJ, Reguera JM, Plata A, Ruiz J, et al. Prognostic factors in left-sided endocarditis: results from the Andalusian multicenter cohort. BMC Infect Dis. 2010;10:17.

118. Thuny F, Di Salvo G, Disalvo G, Belliard O, Avierinos J-F, Pergola V, et al. Risk of embolism and death in infective endocarditis: prognostic value of echocardiography: a prospective multicenter study. Circulation. 2005;112(1):6975.

119.Annane D, Aegerter P, Jars-Guincestre MC, Guidet B, CUB-Réa Network. Current epidemiology of septic shock: the CUB-Réa Network. Am J Respir Crit Care Med. 2003;168(2):165-72.

120.Hill EE, Herijgers P, Claus P, Vanderschueren S, Herregods M-C, Peetermans WE. Infective endocarditis: changing epidemiology and predictors of 6-month mortality: a prospective cohort study. Eur Heart J. 2007;28(2):196-203.

121. Conlon PJ, Jefferies F, Krigman HR, Corey GR, Sexton DJ, Abramson MA. Predictors of prognosis and risk of acute renal failure in bacterial endocarditis. Clin Nephrol. 1998;49(2):96-101. 
122.Erbay AR, Erbay A, Canga A, Keskin G, Sen N, Atak R, et al. Risk factors for inhospital mortality in infective endocarditis: five years' experience at a tertiary care hospital in Turkey. J Heart Valve Dis. 2010;19(2):216-24.

123.Karth G, Koreny M, Binder T, Knapp S, Zauner C, Valentin A, et al. Complicated infective endocarditis necessitating ICU admission: clinical course and prognosis. Crit Care Lond Engl. 2002;6(2):149-54.

124. Majumdar A, Chowdhary S, Ferreira MA, Hammond LA, Howie AJ, Lipkin GW, et al. Renal pathological findings in infective endocarditis. Nephrol Dial Transplant Off Publ Eur Dial Transpl Assoc - Eur Ren Assoc. 2000;15(11):17827.

125.Ferraris L, Milazzo L, Ricaboni D, Mazzali C, Orlando G, Rizzardini G, et al. Profile of infective endocarditis observed from 2003 - 2010 in a single center in Italy. BMC Infect Dis. 2013;13:545.

126.Le V, Gill S. Serious complications after infective endocarditis. Dan Med Bull. 2010;57(10):A4192.

127. Ong DSY, Frencken JF, Klein Klouwenberg PMC, Juffermans N, van der Poll T, Bonten MJM, et al. Short-Course Adjunctive Gentamicin as Empirical Therapy in Patients With Severe Sepsis and Septic Shock: A Prospective Observational Cohort Study. Clin Infect Dis Off Publ Infect Dis Soc Am. 2017;64(12):1731-6.

128. Krishnamoorthy A, Greiner MA, Sharma PP, DeVore AD, Johnson KW, Fonarow $\mathrm{GC}$, et al. Transient and persistent worsening renal function during hospitalization for acute heart failure. Am Heart J. 2014;168(6):891-900.

129. Mårtensson J, Bellomo R. Pathophysiology of Septic Acute Kidney Injury. Contrib Nephrol. 2016;187:36-46.

130.Kim IY, Kim JH, Lee DW, Lee SB, Rhee H, Seong EY, et al. Fluid overload and survival in critically ill patients with acute kidney injury receiving continuous renal replacement therapy. PloS One. 2017;12(2):e0172137. 
131.Heiro M, Nikoskelainen J, Engblom E, Kotilainen E, Marttila R, Kotilainen P. Neurologic manifestations of infective endocarditis: a 17-year experience in a teaching hospital in Finland. Arch Intern Med. 2000;160(18):2781-7.

132.Hess A, Klein I, Iung B, Lavallée P, Ilic-Habensus E, Dornic Q, et al. Brain MRI findings in neurologically asymptomatic patients with infective endocarditis. AJNR Am J Neuroradiol. 2013;34(8):1579-84.

133.Duval X, Iung B, Klein I, Brochet E, Thabut G, Arnoult F, et al. Effect of early cerebral magnetic resonance imaging on clinical decisions in infective endocarditis: a prospective study. Ann Intern Med. 2010;152(8):497-504, W175.

134. Snygg-Martin U, Gustafsson L, Rosengren L, Alsiö A, Ackerholm P, Andersson $\mathrm{R}$, et al. Cerebrovascular complications in patients with left-sided infective endocarditis are common: a prospective study using magnetic resonance imaging and neurochemical brain damage markers. Clin Infect Dis Off Publ Infect Dis Soc Am. 2008;47(1):23-30.

135.Di Salvo G, Habib G, Pergola V, Avierinos JF, Philip E, Casalta JP, et al. Echocardiography predicts embolic events in infective endocarditis. J Am Coll Cardiol. 2001;37(4):1069-76.

136.Iung B, Tubiana S, Klein I, Messika-Zeitoun D, Brochet E, Lepage L, et al. Determinants of cerebral lesions in endocarditis on systematic cerebral magnetic resonance imaging: a prospective study. Stroke. 2013;44(11):3056-62.

137.Dickerman SA, Abrutyn E, Barsic B, Bouza E, Cecchi E, Moreno A, et al. The relationship between the initiation of antimicrobial therapy and the incidence of stroke in infective endocarditis: an analysis from the ICE Prospective Cohort Study (ICE-PCS). Am Heart J. 2007;154(6):1086-94.

138.Thuny F, Avierinos J-F, Tribouilloy C, Giorgi R, Casalta J-P, Milandre L, et al. Impact of cerebrovascular complications on mortality and neurologic outcome during infective endocarditis: a prospective multicentre study. Eur Heart J. 2007;28(9):1155-61. 
139.Ruttmann E, Willeit J, Ulmer H, Chevtchik O, Höfer D, Poewe W, et al. Neurological outcome of septic cardioembolic stroke after infective endocarditis. Stroke. 2006;37(8):2094-9.

140.Yoshioka D, Sakaguchi T, Yamauchi T, Okazaki S, Miyagawa S, Nishi H, et al. Impact of early surgical treatment on postoperative neurologic outcome for active infective endocarditis complicated by cerebral infarction. Ann Thorac Surg. 2012;94(2):489-95.

141.Eishi K, Kawazoe K, Kuriyama Y, Kitoh Y, Kawashima Y, Omae T. Surgical management of infective endocarditis associated with cerebral complications. Multi-center retrospective study in Japan. J Thorac Cardiovasc Surg. 1995;110(6):1745-55.

142. Tsalis K. Septic shock; current pathogenetic concepts from a clinical perspective. Adelais G. Tsiotou, George H. Sakorafas, George Anagnostopoulos, John Bramis Med Sci Monit, 2005; 11(3): RA76-85. Med Sci Monit Int Med J Exp Clin Res. 2006;12(8):LE15-16.

143.Kanafani ZA, Kourany WM, Fowler VG, Levine DP, Vigliani GA, Campion M, et al. Clinical characteristics and outcomes of diabetic patients with Staphylococcus aureus bacteremia and endocarditis. Eur J Clin Microbiol Infect. 2009;28(12):1477-82.

144. Mourvillier B, Trouillet J-L, Timsit J-F, Baudot J, Chastre J, Régnier B, et al. Infective endocarditis in the intensive care unit: clinical spectrum and prognostic factors in 228 consecutive patients. Intensive Care Med. 2004;30(11):2046-52.

145.Kang C-I, Song J-H, Chung DR, Peck KR, Ko KS, Yeom J-S, et al. Risk factors and pathogenic significance of severe sepsis and septic shock in 2286 patients with gram-negative bacteremia. J Infect. 2011;62(1):26-33.

146.Pittet D, Thiévent B, Wenzel RP, Li N, Gurman G, Suter PM. Importance of preexisting co-morbidities for prognosis of septicemia in critically ill patients. Intensive Care Med. 1993;19(5):265-72. 
147.Williams MD, Braun LA, Cooper LM, Johnston J, Weiss RV, Qualy RL, et al. Hospitalized cancer patients with severe sepsis: analysis of incidence, mortality, and associated costs of care. Crit Care Lond Engl. 2004;8(5):R291-298.

148.Leibovici L, Drucker M, Konigsberger H, Samra Z, Harrari S, Ashkenazi S, et al. Septic shock in bacteremic patients: risk factors, features and prognosis. Scand J Infect Dis. 1997;29(1):71-5.

149.Erbel R, Liu F, Ge J, Rohmann S, Kupferwasser I. Identification of high-risk subgroups in infective endocarditis and the role of echocardiography. Eur Heart J. 1995;16(5):588-602.

150. Mansur AJ, Grinberg M, Cardoso RH, da Luz PL, Bellotti G, Pileggi F. Determinants of prognosis in 300 episodes of infective endocarditis. Thorac Cardiovasc Surg. 1996;44(1):2-10.

151.Woo KS, Lam YM, Kwok HT, Tse LK, Vallance-Owen J. Prognostic index in prediction of mortality from infective endocarditis. Int J Cardiol. 1989;24(1):4754.

152. Oppert M, Engel C, Brunkhorst F-M, Bogatsch H, Reinhart K, Frei U, et al. Acute renal failure in patients with severe sepsis and septic shock--a significant independent risk factor for mortality: results from the German Prevalence Study. Nephrol Dial Transplant 2008;23(3):904-9.

153.Luaces M, Vilacosta I, Fernández C, Sarriá C, San Román JA, Graupner C, et al. Vegetation size at diagnosis in infective endocarditis: influencing factors and prognostic implications. Int J Cardiol. 2009;137(1):76-8.

154.Jimenez MF, Marshall JC, International Sepsis Forum. Source control in the management of sepsis. Intensive Care Med. 2001;27 Suppl 1:S49-62.

155.Tornos MP, Permanyer-Miralda G, Olona M, Gil M, Galve E, Almirante B, et al. Long-term complications of native valve infective endocarditis in non-addicts. A 15-year follow-up study. Ann Intern Med. 1992;117(7):567-72. 
156. Hogevik H, Olaison L, Andersson R, Lindberg J, Alestig K. Epidemiologic aspects of infective endocarditis in an urban population. A 5-year prospective study. Medicine (Baltimore). 1995;74(6):324-39.

157.Vincent J-L, Sakr Y, Sprung CL, Ranieri VM, Reinhart K, Gerlach H, et al. Sepsis in European intensive care units: results of the SOAP study. Crit Care Med. 2006;34(2):344-53.

158. Graupner C, Vilacosta I, SanRomán J, Ronderos R, Sarriá C, Fernández C, et al. Periannular extension of infective endocarditis. J Am Coll Cardiol. 2002;39(7):1204-11.

159.Durack DT, Pelletier LL, Petersdorf RG. Chemotherapy of experimental streptococcal endocarditis. II. Synergism between penicillin and streptomycin against penicillin-sensitive streptococci. J Clin Invest. 1974;53(3):829-33.

160. Wilson WR, Geraci JE, Wilkowske CJ, Washington JA. Short-term intramuscular therapy with procaine penicillin plus streptomycin for infective endocarditis due to viridans streptococci. Circulation. 1978;57(6):1158-61.

161. Chirouze C, Cabell CH, Fowler VG, Khayat N, Olaison L, Miro JM, et al. Prognostic factors in 61 cases of Staphylococcus aureus prosthetic valve infective endocarditis from the International Collaboration on Endocarditis merged database. Clin Infect Dis Off Publ Infect Dis Soc Am. 2004;38(9):1323-7.

162.Hoen B. Epidemiology and antibiotic treatment of infective endocarditis: an update. Heart Br Card Soc. 2006;92(11):1694-700.

163. Fowler VG, Miro JM, Hoen B, Cabell CH, Abrutyn E, Rubinstein E, et al. Staphylococcus aureus endocarditis: a consequence of medical progress. JAMA. 2005;293(24):3012-21.

164.Prendergast BD. The changing face of infective endocarditis. Heart Br Card Soc. 2006;92(7):879-85. 
165.Delahaye F, Wong J, Mills PG. Infective endocarditis: a comparison of international guidelines. Heart. 2007;93(4):524-7.

166. Bode LGM, Kluytmans JAJW, Wertheim HFL, Bogaers D, VandenbrouckeGrauls CMJE, Roosendaal R, et al. Preventing surgical-site infections in nasal carriers of Staphylococcus aureus. N Engl J Med. 2010;362(1):9-17.

167.van Rijen MML, Bode LGM, Baak DA, Kluytmans JAJW, Vos MC. Reduced costs for Staphylococcus aureus carriers treated prophylactically with mupirocin and chlorhexidine in cardiothoracic and orthopaedic surgery. PloS One. 2012;7(8):e43065.

168. Braun S, Escalona A, Chamorro G, Corbalán R, Pérez C, Labarca J, et al. [Infective endocarditis: short and long-term results in 261 cases managed by a multidisciplinary approach]. Rev Med Chil. 2000;128(7):708-20.

169.Remadi JP, Habib G, Nadji G, Brahim A, Thuny F, Casalta JP, et al. Predictors of death and impact of surgery in Staphylococcus aureus infective endocarditis. Ann Thorac Surg. 2007;83(4):1295-302.

170. Watanakunakorn C. Staphylococcus aureus endocarditis at a community teaching hospital, 1980 to 1991. An analysis of 106 cases. Arch Intern Med. 1994;154(20):2330-5.

171.Espersen F, Frimodt-Møller N. Staphylococcus aureus endocarditis. A review of 119 cases. Arch Intern Med. 1986;146(6):1118-21.

172.Hsu R-B, Lin F-Y. Methicillin resistance and risk factors for embolism in Staphylococcus aureus infective endocarditis. Infect Control Hosp Epidemiol. 2007;28(7):860-6.

173.Røder BL, Wandall DA, Frimodt-Møller N, Espersen F, Skinhøj P, Rosdahl VT. Clinical features of Staphylococcus aureus endocarditis: a 10-year experience in Denmark. Arch Intern Med. 1999;159(5):462-9. 
174.Charlson ME, Pompei P, Ales KL, MacKenzie CR. A new method of classifying prognostic comorbidity in longitudinal studies: development and validation. J Chronic Dis. 1987;40(5):373-83.

175. Tattevin P, Revest M, Lefort A, Michelet C, Lortholary O. Fungal endocarditis: current challenges. Int J Antimicrob Agents. 2014;44(4):290-4.

176. Kalokhe AS, Rouphael N, El Chami MF, Workowski KA, Ganesh G, Jacob JT. Aspergillus endocarditis: a review of the literature. Int J Infect Dis IJID Off Publ Int Soc Infect Dis. 2010;14(12):e1040-1047.

177. Smego RA, Ahmad H. The role of fluconazole in the treatment of Candida endocarditis: a meta-analysis. Medicine (Baltimore). 2011;90(4):237-49.

178.Gould FK, Denning DW, Elliott TSJ, Foweraker J, Perry JD, Prendergast BD, et al. Guidelines for the diagnosis and antibiotic treatment of endocarditis in adults: a report of the Working Party of the British Society for Antimicrobial Chemotherapy. J Antimicrob Chemother. 2012;67(2):269-89.

179.Lye DCB, Hughes A, O’Brien D, Athan E. Candida glabrata prosthetic valve endocarditis treated successfully with fluconazole plus caspofungin without surgery: a case report and literature review. Eur J Clin Microbiol Infect Dis Off Publ Eur Soc Clin Microbiol. 2005;24(11):753-5.

180.Serrador A, San Román JA, Fernández-Avilés F. Images in cardiology: Echohistological correlation in Candida albicans endocarditis. Heart. 2000;84(1):24.

181. Morpeth S, Murdoch D, Cabell CH, Karchmer AW, Pappas P, Levine D, et al. Non-HACEK gram-negative bacillus endocarditis. Ann Intern Med. 2007;147(12):829-35.

182. Cohen PS, Maguire JH, Weinstein L. Infective endocarditis caused by gramnegative bacteria: a review of the literature, 1945-1977. Prog Cardiovasc Dis. 1980;22(4):205-42. 
183. Geraci JE, Wilson WR. Symposium on infective endocarditis. III. Endocarditis due to gram-negative bacteria. Report of 56 cases. Mayo Clin Proc. 1982;57(3):145-8.

184.Pelletier LL, Petersdorf RG. Infective endocarditis: a review of 125 cases from the University of Washington Hospitals, 1963-72. Medicine (Baltimore). 1977;56(4):287-313.

185.Mills J, Drew D. Serratia marcescens endocarditis: a regional illness associated with intravenous drug abuse. Ann Intern Med. 1976;84(1):29-35.

186.Cooper R, Mills J. Serratia endocarditis. A follow-up report. Arch Intern Med. 1980;140(2):199-202.

187.Witchitz S, Regnier B, Witchitz J, Schlemmer B, Bouvet E, Vachon F. Gram negative bacilli endocarditis. Pathol Biol (Paris).1982;30:569-75.

188. Wieland M, Lederman MM, Kline-King C, Keys TF, Lerner PI, Bass SN, et al. Left-sided endocarditis due to Pseudomonas aeruginosa. A report of 10 cases and review of the literature. Medicine (Baltimore). 1986;65(3):180-9.

189.Levine DP, Crane LR, Zervos MJ. Bacteremia in narcotic addicts at the Detroit Medical Center. II. Infectious endocarditis: a prospective comparative study. Rev Infect Dis. 1986;8(3):374-96.

190. Micol R, Lortholary O, Jaureguy F, Bonacorsi S, Bingen E, Lefort A, et al. Escherichia coli native valve endocarditis. Clin Microbiol Infect Dis. 2006;12(5):401-3.

191.Mügge A, Daniel WG, Frank G, Lichtlen PR. Echocardiography in infective endocarditis: reassessment of prognostic implications of vegetation size determined by the transthoracic and the transesophageal approach. J Am Coll Cardiol. 1989;14(3):631-8. 
192.Habib G, Badano L, Tribouilloy C, Vilacosta I, Zamorano JL, Galderisi M, et al. Recommendations for the practice of echocardiography in infective endocarditis. Eur J Echocardiogr. 2010;11(2):202-19.

193.Habib G, Avierinos J-F, Thuny F. Aortic valve endocarditis: is there an optimal surgical timing? Curr Opin Cardiol. 2007;22(2):77-83.

194.Daniel WG, Mügge A, Martin RP, Lindert O, Hausmann D, Nonnast-Daniel B, et al. Improvement in the diagnosis of abscesses associated with endocarditis by transesophageal echocardiography. N Engl J Med. 1991;324(12):795-800.

195. Sochowski RA, Chan KL. Implication of negative results on a monoplane transesophageal echocardiographic study in patients with suspected infective endocarditis. J Am Coll Cardiol. 1993;21(1):216-21.

196.Karalis DG, Chandrasekaran K, Wahl JM, Ross J, Mintz GS. Transesophageal echocardiographic recognition of mitral valve abnormalities associated with aortic valve endocarditis. Am Heart J. 1990;119(5):1209-11.

197.Pedersen WR, Walker M, Olson JD, Gobel F, Lange HW, Daniel JA, et al. Value of transesophageal echocardiography as an adjunct to transthoracic echocardiography in evaluation of native and prosthetic valve endocarditis. Chest. 1991;100(2):351-6.

198. Feuchtner GM, Stolzmann P, Dichtl W, Schertler T, Bonatti J, Scheffel H, et al. Multislice computed tomography in infective endocarditis: comparison with transesophageal echocardiography and intraoperative findings. J Am Coll Cardiol. 2009;53(5):436-44.

199.Fagman E, Perrotta S, Bech-Hanssen O, Flinck A, Lamm C, Olaison L, et al. ECG-gated computed tomography: a new role for patients with suspected aortic prosthetic valve endocarditis. Eur Radiol. 2012;22(11):2407-14. 
200. Cooper HA, Thompson EC, Laureno R, Fuisz A, Mark AS, Lin M, et al. Subclinical brain embolization in left-sided infective endocarditis: results from the evaluation by MRI of the brains of patients with left-sided intracardiac solid masses (EMBOLISM) pilot study. Circulation. 2009;120(7):585-91.

201. Okazaki S, Yoshioka D, Sakaguchi M, Sawa Y, Mochizuki H, Kitagawa K. Acute ischemic brain lesions in infective endocarditis: incidence, related factors, and postoperative outcome. Cerebrovasc Dis Basel Switz. 2013;35(2):155-62.

202. Goulenok T, Klein I, Mazighi M, Messika-Zeitoun D, Alexandra JF, Mourvillier B, et al. Infective endocarditis with symptomatic cerebral complications: contribution of cerebral magnetic resonance imaging. Cerebrovasc Dis Basel Switz. 2013;35(4):327-36.

203.Iung B, Klein I, Mourvillier B, Olivot J-M, Détaint D, Longuet P, et al. Respective effects of early cerebral and abdominal magnetic resonance imaging on clinical decisions in infective endocarditis. Eur Heart $\mathrm{J}$ Cardiovasc Imaging. 2012;13(8):703-10.

204.Erba PA, Conti U, Lazzeri E, Sollini M, Doria R, De Tommasi SM, et al. Added value of 99mTc-HMPAO-labeled leukocyte SPECT/CT in the characterization and management of patients with infectious endocarditis. J Nucl Med. 2012;53(8):1235-43.

205. Rouzet F, Chequer R, Benali K, Lepage L, Ghodbane W, Duval X, et al. Respective performance of 18F-FDG PET and radiolabeled leukocyte scintigraphy for the diagnosis of prosthetic valve endocarditis. J Nucl Med. 2014;55(12):1980-5.

206. Anguera I, Miro JM, San Roman JA, de Alarcon A, Anguita M, Almirante B, et al. Periannular complications in infective endocarditis involving prosthetic aortic valves. Am J Cardiol. 2006;98(9):1261-8. 
207. Anguera I, Miro JM, Evangelista A, Cabell CH, San Roman JA, Vilacosta I, et al. Periannular complications in infective endocarditis involving native aortic valves. Am J Cardiol. 2006;98(9):1254-60.

208. Forteza A, Centeno J, Ospina V, Lunar IG, Sánchez V, Pérez E, et al. Outcomes in aortic and mitral valve replacement with intervalvular fibrous body reconstruction. Ann Thorac Surg. 2015;99(3):838-45.

209. Chan K-L. Early clinical course and long-term outcome of patients with infective endocarditis complicated by perivalvular abscess. CMAJ Can Med Assoc J J Assoc Medicale Can. 2002;167(1):19-24.

210. Manzano MC, Vilacosta I, San Román JA, Aragoncillo P, Sarriá C, López D, et al. Acute coronary syndrome in infective endocarditis. Rev Esp Cardiol. 2007;60(1):24-31.

211.Leung DY, Cranney GB, Hopkins AP, Walsh WF. Role of transoesophageal echocardiography in the diagnosis and management of aortic root abscess. $\mathrm{Br}$ Heart J. 1994;72(2):175-81.

212.Lengyel M. The impact of transesophageal echocardiography on the management of prosthetic valve endocarditis: experience of 31 cases and review of the literature. J Heart Valve Dis. 1997;6(2):204-11.

213. García-Arribas D, Vilacosta I, Ortega Candil A, Rodríguez Rey C, Olmos C, Pérez Castejón MJ, et al. Usefulness of positron emission tomography/computed tomography in patients with valve-tube graft infection. Heart. 2018;104(17):144754.

214.Jiménez-Ballvé A, Pérez-Castejón MJ, Delgado-Bolton RC, Sánchez-Enrique C, Vilacosta I, Vivas D, et al. Assessment of the diagnostic accuracy of 18F-FDG $\mathrm{PET} / \mathrm{CT}$ in prosthetic infective endocarditis and cardiac implantable electronic device infection: comparison of different interpretation criteria. Eur J Nucl Med Mol Imaging. 2016;43(13):2401-12. 
215.Lauridsen TK, Alhede C, Crowley AL, Kisslo J, Sørensen LL, Hansen TF, et al. Two-dimensional global longitudinal strain is superior to left ventricular ejection fraction in prediction of outcome in patients with left-sided infective endocarditis. Int J Cardiol. 2018;260:118-23.

216.Lauridsen TK, Park L, Tong SYC, Selton-Suty C, Peterson G, Cecchi E, et al. Echocardiographic Findings Predict In-Hospital and 1-Year Mortality in LeftSided Native Valve Staphylococcus aureus Endocarditis: Analysis From the International Collaboration on Endocarditis-Prospective Echo Cohort Study. Circ Cardiovasc Imaging. 2015;8(7):e003397.

217.Stout KK, Verrier ED. Acute valvular regurgitation. Circulation. 2009;119(25):3232-41.

218. Walley KR. Deeper understanding of mechanisms contributing to sepsis-induced myocardial dysfunction. Crit Care Lond Engl. 2014;18(3):137.

219. Risum N, Ali S, Olsen NT, Jons C, Khouri MG, Lauridsen TK, et al. Variability of global left ventricular deformation analysis using vendor dependent and independent two-dimensional speckle-tracking software in adults. J Am Soc Echocardiogr Off Publ Am Soc Echocardiogr. 2012;25(11):1195-203.

220.Mi MY, Nelson SB, Weiner RB. Clinical and Echocardiographic Factors Associated With In-Hospital Mortality in Patients With Infective Endocarditis Affecting the Native Tricuspid Valve. Am J Cardiol. 2016;118(5):739-43.

221.Lancellotti P, Cosyns B, Zacharakis D, Attena E, Van Camp G, Gach O, et al. Importance of left ventricular longitudinal function and functional reserve in patients with degenerative mitral regurgitation: assessment by two-dimensional speckle tracking. J Am Soc Echocardiogr Off Publ Am Soc Echocardiogr. 2008;21(12):1331-6.

222.Dahl JS, Videbæk L, Poulsen MK, Rudbæk TR, Pellikka PA, Møller JE. Global strain in severe aortic valve stenosis: relation to clinical outcome after aortic valve replacement. Circ Cardiovasc Imaging. 2012;5(5):613-20. 
223.Ersbøll M, Valeur N, Mogensen UM, Andersen MJ, Møller JE, Velazquez EJ, et al. Prediction of all-cause mortality and heart failure admissions from global left ventricular longitudinal strain in patients with acute myocardial infarction and preserved left ventricular ejection fraction. J Am Coll Cardiol. 2013;61(23):236573.

224.Iacoviello M, Puzzovivo A, Guida P, Forleo C, Monitillo F, Catanzaro R, et al. Independent role of left ventricular global longitudinal strain in predicting prognosis of chronic heart failure patients. Echocardiogr $\mathrm{Mt}$ Kisco N. 2013;30(7):803-11.

225.Galiè N, Humbert M, Vachiery J-L, Gibbs S, Lang I, Torbicki A, et al. 2015 ESC/ERS Guidelines for the diagnosis and treatment of pulmonary hypertension: The Joint Task Force for the Diagnosis and Treatment of Pulmonary Hypertension of the European Society of Cardiology (ESC) and the European Respiratory Society (ERS): Endorsed by: Association for European Paediatric and Congenital Cardiology (AEPC), International Society for Heart and Lung Transplantation (ISHLT). Eur Heart J. 2016;37(1):67-119.

226. Vachiéry J-L, Adir Y, Barberà JA, Champion H, Coghlan JG, Cottin V, et al. Pulmonary hypertension due to left heart diseases. J Am Coll Cardiol. 2013;62:D100-108.

227.Fang JC, DeMarco T, Givertz MM, Borlaug BA, Lewis GD, Rame JE, et al. World Health Organization Pulmonary Hypertension group 2: pulmonary hypertension due to left heart disease in the adult--a summary statement from the Pulmonary Hypertension Council of the International Society for Heart and Lung Transplantation. J Heart Lung Transplant. 2012;31(9):913-33.

228. Ghio S, Gavazzi A, Campana C, Inserra C, Klersy C, Sebastiani R, et al. Independent and additive prognostic value of right ventricular systolic function and pulmonary artery pressure in patients with chronic heart failure. J Am Coll Cardiol. 2001;37(1):183-8. 
229.Tedford RJ, Beaty CA, Mathai SC, Kolb TM, Damico R, Hassoun PM, et al. Prognostic value of the pre-transplant diastolic pulmonary artery pressure-topulmonary capillary wedge pressure gradient in cardiac transplant recipients with pulmonary hypertension. J Heart Lung Transplant. 2014;33(3):289-97.

230.Gerges C, Gerges M, Lang MB, Zhang Y, Jakowitsch J, Probst P, et al. Diastolic pulmonary vascular pressure gradient: a predictor of prognosis in «out-ofproportion» pulmonary hypertension. Chest. 2013;143(3):758-66.

231.Rapp AH, Lange RA, Cigarroa JE, Keeley EC, Hillis LD. Relation of pulmonary arterial diastolic and mean pulmonary arterial wedge pressures in patients with and without pulmonary hypertension. Am J Cardiol. 2001;88(7):823-4.

232.Miller WL, Grill DE, Borlaug BA. Clinical features, hemodynamics, and outcomes of pulmonary hypertension due to chronic heart failure with reduced ejection fraction: pulmonary hypertension and heart failure. JACC Heart Fail. 2013;1(4):290-9.

233. Vilacosta I, Graupner C, San Román JA, Sarriá C, Ronderos R, Fernández C, et al. Risk of embolization after institution of antibiotic therapy for infective endocarditis. J Am Coll Cardiol. 2002;39(9):1489-95.

234.Steckelberg JM, Murphy JG, Ballard D, Bailey K, Tajik AJ, Taliercio CP, et al. Emboli in infective endocarditis: the prognostic value of echocardiography. Ann Intern Med. 1 1991;114(8):635-40.

235.Rohmann S, Erbel R, Görge G, Makowski T, Mohr-Kahaly S, Nixdorff U, et al. Clinical relevance of vegetation localization by transoesophageal echocardiography in infective endocarditis. Eur Heart J. 1992;13(4):446-52.

236. Sanfilippo AJ, Picard MH, Newell JB, Rosas E, Davidoff R, Thomas JD, et al. Echocardiographic assessment of patients with infectious endocarditis: prediction of risk for complications. J Am Coll Cardiol. 1991;18(5):1191-9. 
237. Cabell CH, Pond KK, Peterson GE, Durack DT, Corey GR, Anderson DJ, et al. The risk of stroke and death in patients with aortic and mitral valve endocarditis. Am Heart J. 2001;142(1):75-80.

238. Tischler MD, Vaitkus PT. The ability of vegetation size on echocardiography to predict clinical complications: a meta-analysis. J Am Soc Echocardiogr Off Publ Am Soc Echocardiogr. 1997;10(5):562-8.

239.Rohmann S, Erbel R, Darius H, Görge G, Makowski T, Zotz R, et al. Prediction of rapid versus prolonged healing of infective endocarditis by monitoring vegetation size. J Am Soc Echocardiogr. 1991;4(5):465-74.

240. Shiue AB, Stancoven AB, Purcell JB, Pinkston K, Wang A, Khera A, et al. Relation of level of B-type natriuretic peptide with outcomes in patients with infective endocarditis. Am J Cardiol. 2010;106(7):1011-5.

241.Pergola V, Di Salvo G, Habib G, Avierinos JF, Philip E, Vailloud JM, et al. Comparison of clinical and echocardiographic characteristics of Streptococcus bovis endocarditis with that caused by other pathogens. Am J Cardiol. $2001 ; 88(8): 871-5$.

242.Hubert S, Thuny F, Resseguier N, Giorgi R, Tribouilloy C, Le Dolley Y, et al. Prediction of symptomatic embolism in infective endocarditis: construction and validation of a risk calculator in a multicenter cohort. J Am Coll Cardiol. 2013;62(15):1384-92.

243. Chu VH, Sexton DJ, Cabell CH, Reller LB, Pappas PA, Singh RK, et al. Repeat infective endocarditis: differentiating relapse from reinfection. Clin Infect Dis Off Publ Infect Dis Soc Am. 2005;41(3):406-9.

244.Iung B, Doco-Lecompte T, Chocron S, Strady C, Delahaye F, Le Moing V, et al. Cardiac surgery during the acute phase of infective endocarditis: discrepancies between European Society of Cardiology guidelines and practices. Eur Heart J. 2016;37(10):840-8. 
245. Baddour LM, Wilson WR, Bayer AS, Fowler VG, Bolger AF, Levison ME, et al. Infective endocarditis: diagnosis, antimicrobial therapy, and management of complications: a statement for healthcare professionals from the Committee on Rheumatic Fever, Endocarditis, and Kawasaki Disease, Council on Cardiovascular Disease in the Young, and the Councils on Clinical Cardiology, Stroke, and Cardiovascular Surgery and Anesthesia, American Heart Association: endorsed by the Infectious Diseases Society of America. Circulation. 2005;111(23):e394-434.

246.Aksoy O, Sexton DJ, Wang A, Pappas PA, Kourany W, Chu V, et al. Early surgery in patients with infective endocarditis: a propensity score analysis. Clin Infect Dis Off Publ Infect Dis Soc Am. 2007;44(3):364-72.

247.Vikram HR, Buenconsejo J, Hasbun R, Quagliarello VJ. Impact of valve surgery on 6-month mortality in adults with complicated, left-sided native valve endocarditis: a propensity analysis. JAMA. 2003;290(24):3207-14.

248.Kang D-H, Kim Y-J, Kim S-H, Sun BJ, Kim D-H, Yun S-C, et al. Early surgery versus conventional treatment for infective endocarditis. $\mathrm{N}$ Engl $\mathrm{J}$ Med. 2012;366(26):2466-73.

249.Ferrera C, Vilacosta I, Fernández C, López J, Sarriá C, Olmos C, et al. Early surgery for acute-onset infective endocarditis. Eur J Cardio-Thorac Surg Off J Eur Assoc Cardio-Thorac Surg. 2018; Ahead of print.

250.Lalani T, Chu VH, Park LP, Cecchi E, Corey GR, Durante-Mangoni E, et al. Inhospital and 1-year mortality in patients undergoing early surgery for prosthetic valve endocarditis. JAMA Intern Med. 2013;173(16):1495-504.

251.Lalani T, Cabell CH, Benjamin DK, Lasca O, Naber C, Fowler VG, et al. Analysis of the impact of early surgery on in-hospital mortality of native valve endocarditis: use of propensity score and instrumental variable methods to adjust for treatmentselection bias. Circulation. 2010;121(8):1005-13. 
252. Chirouze C, Alla F, Fowler VG, Sexton DJ, Corey GR, Chu VH, et al. Impact of early valve surgery on outcome of Staphylococcus aureus prosthetic valve infective endocarditis: analysis in the International Collaboration of EndocarditisProspective Cohort Study. Clin Infect Dis. 2015;60(5):741-9.

253.Di Salvo G, Thuny F, Rosenberg V, Pergola V, Belliard O, Derumeaux G, et al. Endocarditis in the elderly: clinical, echocardiographic, and prognostic features. Eur Heart J. 2003;24(17):1576-83.

254.López J, Sevilla T, Vilacosta I, Sarriá C, Revilla A, Ortiz C, et al. Prognostic role of persistent positive blood cultures after initiation of antibiotic therapy in leftsided infective endocarditis. Eur Heart J. 2013;34(23):1749-54.

255.García-Granja PE, López J, Vilacosta I, Ortiz-Bautista C, Sevilla T, Olmos C, et al. Polymicrobial Infective Endocarditis: Clinical Features and Prognosis. Medicine (Baltimore). 2015;94(49):e2000.

256. Olmos C, Vilacosta I, Sarriá C, Fernández C, López J, Ferrera C, et al. Characterization and clinical outcome of patients with possible infective endocarditis. Int J Cardiol. 2015;178:31-3.

257.Holinski S, Jessen S, Neumann K, Konertz W. Predictive Power and Implication of EuroSCORE, EuroSCORE II and STS Score for Isolated Repeated Aortic Valve Replacement. Ann Thorac Cardiovasc Surg. 2015;21(3):242-6.

258. Poullis M, Pullan M, Chalmers J, Mediratta N. The validity of the original EuroSCORE and EuroSCORE II in patients over the age of seventy. Interact Cardiovasc Thorac Surg. 2015;20(2):172-7.

259. Sonne DP, Hemmingsen B. Comment on American Diabetes Association. Standards of Medical Care in Diabetes-2017. Diabetes Care 2017;40(Suppl. 1):S1-S135. Diabetes Care. 2017;40(7):e92-3.

260. National Kidney Foundation. K/DOQI clinical practice guidelines for chronic kidney disease: evaluation, classification, and stratification. Am J Kidney Dis. 2002;39(2 Suppl 1):S1-266. 